\title{
Shift Scheduling and Overtime: A Critical Review of the Literature
}

P. M. Lewis

March 1985

Prepared for

the Nuclear Regulatory Commission under Contract DE-AC06-76RLO 1830

NRC FIN B2360

Pacific Northwest Laboratory

Operated for the U.S. Department of Energy by Battelle Memorial Institute 


\title{
DISCLAIMER
}

This report was prepared as an account of work sponsored by an agency of the United States Government. Neither the United States Government nor any agency thereof, nor any of their employees, makes any warranty, express or implied, or assumes any legal liability or responsibility for the accuracy, completeness, or usefulness of any information, apparatus, product, or process disclosed, or represents that its use would not infringe privately owned rights. Reference herein to any specific commercial product, process, or service by trade name, trademark, manufacturer, or otherwise, does not necessarily constitute or imply its endorsement, recommendation, or favoring by the United States Government or any agency thereof. The views and opinions of authors expressed herein do not necessarily state or reflect those of the United States Government or any agency thereof.

\author{
PACIFIC NORTHWEST LABORATORY \\ operated by \\ BATTELLE \\ for the \\ UNITED STATES DEPARTMENT OF ENERGY \\ under Contract DE-AC06-76RLO 1830
}




\section{0}

TECHNICAL EVALUATION REPORT

SHIFT SCHEDULING AND OVERTIME:

A CRITICAL REVIEW OF THE LITERATURE

P. M. Lewis

March 1985

Prepared for

the Nuclear Regulatory Commission under Contract DE-AC06-76RLO 1830 NRC Fin B2360

Pacific Northwest Laboratory

Richland, Washington 99352 



\section{ABSTRACT}

This report is a review of literature on shift scheduling, overtime, and their effects on human performance in nuclear and non-nuclear industries. Over 300 articles, reports and books were collected and analyzed.

The main points that emerged from the review are as follows. Human performance generally decreases as the number of hours worked increases. This general decline can be altered to a degree by time-of-day effects and by other effects described below. Errors generally increase at night; this nighttime increase is significantly greater if the worker has already been working four or more hours before midnight. Sleep during the day is shorter and less refreshing than sleep at night. A controversy exists in the literature concerning the optimal speed of rotation. Some experts say it is best to rotate only once every four weeks; others say it is best to rotate every day or two. Most of these same experts say that rotating once per week is the worst situation. Also, most experts believe that forward rotation (i.e., rotating from the morning to the afternoon to the night shift) is less fatiguing than backward rotation, although that theory has not yet been adequately demonstrated in a field experiment. 


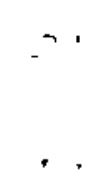




\section{EXECUTIVE SUMMARY}

Pacific Northwest Laboratory (PNL) reviewed literature on shift scheduling, overtime, and their effects on human performance in nuclear and non-nuclear industries. Over 300 articles, reports and books were collected and analyzed. The effects of five shift scheduling factors on a worker's performance were examined. The main points that emerged from the review are as follows:

\section{NUMBER OF HOURS OF WORK AND PERFORMANCE}

- Human performance generally declines as the number of hours of work increases. This conclusion is based on a large volume of research, experience, observation, and evidence. The strength of this conclusion is based on the totality of this evidence; no single report provides a quantitative result that is directly applicable to the nuclear power industry.

- Although performance generally declines as the number of hours of work increases, this general trend $c$ an be altered temporarily by time-of-day effects and other effects that are described below.

- Errors generally increase at night. The increase is significantly greater if the worker has already been working four or more hours before midnight.

- Data exist on error rates for work periods in excess of eight hours in simulated work settings. Few data exist, however, on human error rates for extended hours of work in actual industrial settings with workers performing their normal duties.

- The NRC's policy on overtime is more lenient than the policies of other federal agencies.

\section{TIME OF DAY AND PERFORMANCE}

- Work performance is generally higher during the day, and sleep is more efficient at night. Human error probabilities rise at night, with the highest error rates generally occurring between 3 and 6 AM. These generalizations about night work are probably the best documented observations in the shift scheduling literature.

- Some studies show slightly lower performance in the early hours of the day shift. Many studies show a "post-lunch dip" $\rightarrow$ a performance decrement about 1 PM.

\section{REST PERIODS AND PERFORMANCE}

In this review "rest period" means days off and nonwork periods away from the job site, not on-the-job coffee breaks, etc. 
- According to many European researchers, workers should not work more than one to two nights in a row, and a night shift should be followed by a day off.

- Many researchers state their observations and opinions on the effect of cumulative fatigue, but there are few empirical studies in industrial settings on the amount of rest required to recuperate.

- Workers generally consider long rest periods, especially periods of four or more days, to be one of the most desirable aspects of shift work. Workers of ten prefer long, rigorous work periods interrupted only by short breaks, if they are eventually rewarded with a long rest period.

SPEED OF ROTATION AND PERFORMANCE

A controversy exists in the literature on the optimal speed of rotation.

- Slow rotation (work one shift for 3-4 weeks before rotating to the next shift). The advocates of slow rotation claim that slow rotation gives one's body enough time to adjust to working at night and sleeping during the day; this adjustment makes both work and sleep more efficient.

- Moderate rotation (rotate about once a week). Once-per-week rotation is common in the United States.

- Rapid rotation (rotate every 1-2 days). Many European researchers advocate rapid rotation. They say that even with slow rotation one's circadian rhythms never fully adjust to night work, partly because workers revert to the normal daytime schedule during days of $f$. They say that weekly rotation is worst because just when a worker is almost adjusted to a shift he has to rotate to the next shift, and so he is in a constant state of "circadian desynchrony" or maladjustment. These researchers say that rapid rotation is best because with rapid rotation one's circadian rhythms essentialiy remain fixed on the normal daytime schedule. Therefore, work (and sleep) is efficient for the days (and nights) of morning shift, afternoon shift and days off. The oniy inefficiency occurs during the night shift. These researchers say a worker should not work more than 1-2 consecutive night shifts and that night shifts should always be followed directly by days of $f$ -- rapid rotation allows such a schedule for night shifts.

\section{DIRECTION OF ROTATION AND PERFORMANCE}

- Until recently, direction of rotation (forward vs. backward) has not been a major issue in the literature. However, the potential benefits of forward rotation will probably be small if workers revert to the normal sleep/wake schedule on days off, and if the schedule provides too little time off duty between rotations. 


\section{SHIFT SCHEDULING IN THE AIRLINE INDUSTRY}

- Information on shift scheduling and fatigue in the airline industry is relevant because flight crews and air traffic controllers, like nuclear power plant operators, are highly skilled, work irregular hours, and are responsible for public health and safety.

- Data on shift scheduling fatigue and human performance are difficult to collect in any industry. Most experts agree that the best source of human performance information in the airline industry is obtained from the Aviation Safety Reporting System, which is a voluntary, confidential reporting system that is operated through an independent agency. 
TABLE OF CONTENTS

ABSTRACT ...........................

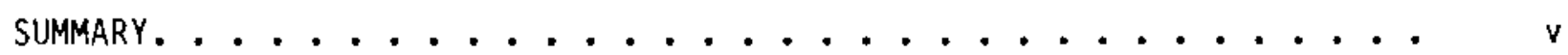

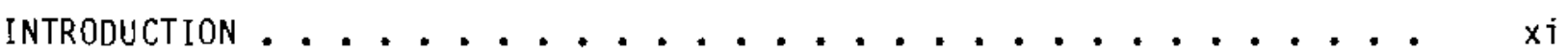

SHIFT SCHEDULING: ESSENTIAL TERMS. ............ xi

CIRCADIAN RHYTHMS: ESSENTIAL CONCEPTS AND TERMS. ....... xiti

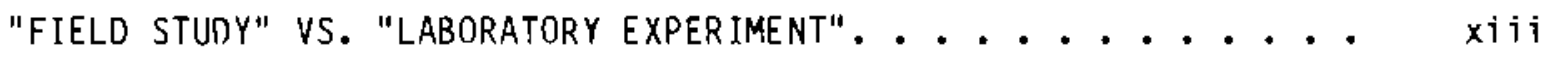

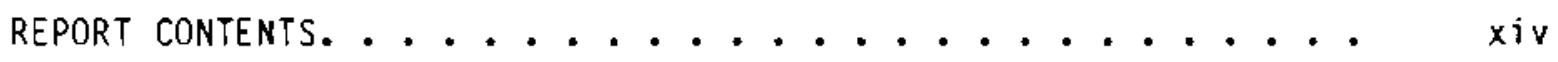

1.0 NUMBER OF HOURS OF WORK AND PERFORMANCE. . . . . . . . . 1.1

1.1 FEDERAL REGULATIONS ON NUMBER OF HOURS WORKED. ........ 1.1

1.2 MAIN POINTS IN THE LITERATURE ON HOURS OF WORK AND PEFORMANCE. • 1.5

1.3 FIELd STUdies ON HOURS OF WORK ANO PERFORMANCE $\ldots \ldots \ldots \ldots$

1.4 LABORATORY EXPERIMENTS ON HOURS OF WORK AND PERFORMANCE. . . . 1.6

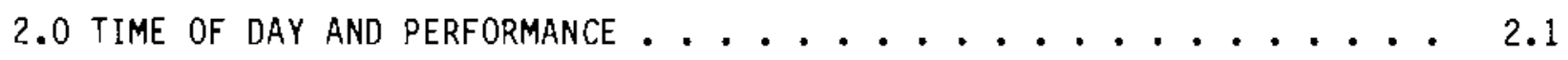

2.1 Field STUDIES ON TIME OF DAY AND PERFORMANCE. . . . . . . 2.1

2.2 LABORATORY EXPERIMENTS ON TIME OF DAY AND PERFORMANCE . . . 2.3

2.3 COMBINED EFFECT OF NIGHTTIME AND LONG HOURS OF WORK ON PERFORMANCE 2.5

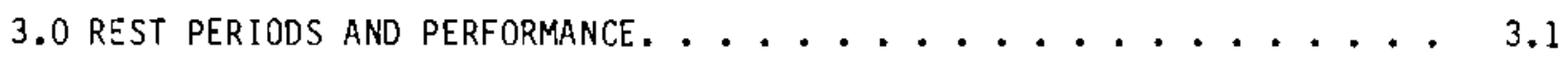

3.1 GOVERNMENT REGULATIONS ON HOURS OF REST ............. 3.1

3.2 Field StUdies ON hOURS OF REST AND PERfORMANCE. . . . . . . 3.2

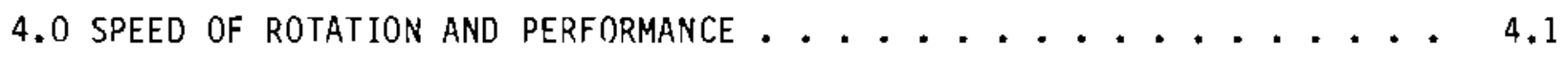

4.1 Field STUdies ON SPEEd OF ROTATION AND PERfORMANCE. ...... 4.1

4.2 Other Studies OF SPEen DF ROtation ANd PERformance. . . . . 4.2

5.0 direction Of Rotation and Performance. . . . . . . . . 5.1

5.1 Field STUDiES ON DIRECTION DF ROTATION AND PERFORMANCE . . . 5.1

5.2 LABORATORY EXPERIMENTS ON DIRECTION OF ROTATION AND PERFORMANCE. • 5.2 
6.0 SHIFT SCHEDULING IN THE AIRLINE INDUSTRY $\ldots . \cdots \cdots .$. 6.1 AIR TRAFF IC CONTROLLERS AND PILOTS . . . . . . . . . . 6.1 6.2 DATA COLLECTION IN THE AIRLINE INDUSTRY. . . . . . . . . 6.2

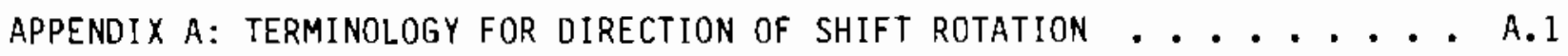
APPENDIX B: NRC POLICY DN WIRKING HOURS. . . . . . . . . . . . . B. APPENDIX C: SUMMARY CHART OF IMPORTANT REPORTS ON SHIFT SCHEDULING . . . . C. 1 APPENDIX D: ANNOTATED BIBLIOGRAPHY . . . . . . . . . . . . D.I B IBLIOGRAPHY AND REFERENCES. . . . . . . . . . . . . . . . . R. 1 


\section{INTRODUCTION}

Pacific Northwest Laboratory (PNL) conducted the Shift Scheduling Project for the U.S. Regulatory, Division of Human Factors Safety, to recommend a policy position concerning the shift scheduling and overtime practices of safety-related personnel in nuclear power plants. The objective of this report for that project was to collect, catalog, review and evaluate available literature pertaining to shift scheduling and overtime practices in nuclear power plants. Because little research has been conducted on shift scheduling in nuclear power plants, most of the literature reviewed here is research on shift scheduling and overtime in non-nuclear industries that have similarities to the nuclear industry. Over 300 relevant articles were collected and reviewed and are listed in the reference and bibliography section of this report.

In this literature review, several shift scheduling characteristics are considered: 1) hours worked by safety-related personnel in any 24-hour period, 48-hour period, 7-day period and 30-day period, 2) fixed vs, rotating shifts, 3) forward vs. backward rotating shifts, 4) rapid vs. slow rotation, 5) length and timing of nonwork periods, and 6) time of day. It further investigates the major means through which these scheduling characteristics affect safety, such as 1) performance on component tasks, 2) vigilance, 3) altertness/fatigue, 4) quantity and quality of sleep, 5) long-and short-term memory, 6) physiological measures, 7) attitude toward one' shift schedule and job, 8) social/family life, 9) absenteesim, and 10) attrition.

The original draft of this report was concluded in June, 1983. Since then, the text has been revised slightly and the bibliography has been updated.

The objective of this report does not include making recomendations concerning guidelines for evaluating shift schedules, although the literature review has been organized so that it can eventually support such recommendations. Conclusions and recommendations are the objective of the project's final report.

Assessing the effect of shift schedules on human performance combines two disparate fields: shift scheduling and the biological study of circadian rhythms. The basic concepts and terminology essential for understanding these two fields and this report are described in this introduction. Additional terms are defined in the glossary in Appendix A.

\section{SHIFT SCHEDULING: ESSENTIAL TERMS}

No single vocabulary, categorization or notation can describe the thousands of shift schedules presently in existence. The following vocabulary, which will be used in this report, attempts to follow common usage as much as possible. 
Industries with continuous operations often divide the 24 hours of the day into 3 shifts of 8 -hour durations:

- morning shift (usually from about 8AM to 4PM)

- afternoon shift (4PM to midnight)

- night shift (midnight to $8 A M$ ).

To continue work over weekends and still provide rest periods for workers, continuous three-shift systems usually have four crews of workers. (If on-thejob training is also required, there might be five crews. Most nuclear power plants want to hire enough operators to staff six crews.) Permanent morning shift means that a crew works the morning shift only. Similarly, permanent afternoon (night) shift means that a crew works the afternoon (night) shift only.

Finding people who are willing to work a permanent night shift is often difficult. Therefore, most firms with continuous work have rotating shifts, so that the relatively desirable day and afternoon shifts and the relatively undesirable night shift are all shared among a larger group of employees.

For example, in a rotating shift schedule a worker works the morning shift for seven days, has two days off, works the afternoon shift for seven days, has two days off, works the night shift for seven days, has three days of $f$, and then starts over again. In this example, the direction of rotation is forward, and the speed of rotation is moderate. These terms are defined further below:

\section{Direction of Rotation}

Forward rotation means that a worker works the morning shift for a certain number of days, then works (rotates to) the afternoon shift, then works the night shift, in that order. (Since it is a cycle, it does not matter where the cycle begins or ends: ... night, morning, afternoon, night, morning, afternoon, night, morning, afternoon ....)

Backward rotation means that a worker works the three shifts in the opposite order: morning shift, night shift, and then afternoon shift.

The direction of rotation is determined solely by the sequence of work periods; it does not matter how rest periods are distributed among the work periods.

\section{Speed of Rotation}

Fast rotation means that a worker works one 8-hour shift for about 1-2 days before rotating (either forward or backward) to the next 8-hour shift. (Rapid rotation is common in Europe.)

Moderate rotation means that a worker works one 8-hour shift for about one week before rotating to the next 8 -hour shift. 
Slow rotation means that a worker works one 8 -hour shift for about 3-4 weeks before rotating to the next 8-hour shift.

\section{CIRCADIAN RHYTHMS: ESSENTIAL CONCEPTS AND TERMS}

For physiological reasons, it is generally easier to work efficiently and safely during the day, and it is generally easier to get refreshing sleep at night. When a person is required to work at night and sleep during the day, both work performance and sleep are degraded. Recent studies of the effect of shift schedules on performance have included attempts to understand and manipulate these physiological daily rhythms to minimize both types of the degradation.

The term "circadian rhythm" is essentially synonymous with "daily rhythm" and refers to anything that varies systematically over time such that one cycie is completed in about 24 hours. The most obvious example is the sleep/wake cycle. Body temperature also usually reaches a nadir at about 6 AM and a peak at about 6PM daily. Hundreds of other bodily functions and abilities have circadian rhythms.

The term "circadian rhythm" was coined in 1959 after an experiment was conducted. It was discovered that if people are placed in isolation chambers without access to the usual cues that tell us whether it is night or day, then most of these rhythms oscillate with a period of not 24 , but rather 25 hours. Hence the term "circadian" was coined, meaning approximately a day (circa = approximately; dies = day).

The fact that our "natural" rhythrs have a cycle of about 25 hours, but usualiy exhibit a rhythm with a cycle of 24 hours, indicates that the period of the cycle is reset daily. One's rhythms can also be reset by flying from New York to Paris; one's circadian rhythms will generally be reset to Paris time within several days. The cycles of light and dark, activity and sleep, meal times and other cues that help to reset one's circadian rhythms are called time cues.

Under normal conditions, the various cycles of one's many circadian rhythms (of body temperature, hormones, adrenaline, blood pressure, grip strength, etc.) exhibit a stable relation to each other. If, however, the normal time cues are altered, the cycles of different physiological functions generally respond somewhat differently. Some can respond quickly, while others respond slowly; some can respond by temporarily speeding up, while others respond by temporarily slowing down; some can respond by changing the range of oscillation, and so forth. Complexities such as these sometimes make assessing the relationships among shift schedules, circadian rhythms, and performance difficult. 
In the body of this report, field studies have been listed separately from laboratory experiments. This allows a quick, general assessment of the type of the evidence on which the conclusions are based.

"Field study" is used to indicate research conducted at the place of work, using the regular workers as subjects, while they are performing their regular duties. By contrast, the typical laboratory experiment is conducted in a research laboratory using students as subjects. The term "laboratory" is added to emphasize that the location, subjects, and/or tasks are controlled artificially.

Because field studies are conducted under real conditions and because they assess performance directly, they are generally considered to be a more reliable source of evidence than laboratory experiments. However, field studies also have disadvantages. For practical reasons, it is usually very difficult to collect enough information to determine with certainty the true cause of a change (e.g., was increased safety the result of a better shift schedule or better training?). Furthermore, some field studies are poorly or erroneously designed.

The advantage of laboratory experiments is that they can more easily control for all potential causes (e.g., shift schedule and training). Thus, both field studies and laboratory experiments are useful, and ideally, conclusions concerning the effect of shift scheduling on safety will be based on concurrence of well-conducted research of both types.

\section{REPORT CONTENTS}

This report is comprised of six chapters, four appendices and an extensive bibliography and reference list. In Chapters 1 through 5 , the effect of various shift scheduling factors on a worker's performance are examined, based on the literature review. Those five factors are number of hours of work, time of day, rest periods, speed of rotation, and direction of rotation. Because of similarities between nuclear plant staff and airline pilots and air traffic controllers, shift scheduling in the airline industry is examined in Chapter 6. A glossary of terminology is provided in Appendix A. Appendix B contains a reprint of NRC's policy on working hours of nuclear power plant staff. Appendix $C$ contains a summary chart of important reports on shift scheduling, and Appendix $D$ is an annotated bibliography of 10 of those reports. 


\subsection{NUMBER OF HOURS OF WORK AND PERFORMANCE}

Long work hours can affect performance and safety by increasing fatigue. Working hours include both regularly scheduled work hours and overtime. Common measures of the number of working hours include number of hours worked per 24-hour period, per 48-hour period, per 7-day period, per 30-day period, and per one-year period.

The following discussion has two parts: (1) federal regulations on number of hours worked, and (2) a summary of the literature on the effect of hours worked on performance/safety.

\subsection{FEDERAL REGULATIONS ON NUMBER OF HOURS WORXED}

The federal government sets guidelines for hours of work for the nuclear industry, the Air Force, and for three transportation industries, which are regulated by the Department of Transportation. The transportation regulations are more detailed than the nuclear regulations and contain a variety of rules and exceptions for special situations (e.g., Alaska bush pilots). All of the regulations allow increased work hours in emergencies or unusual situations. Federal guidelines are sumtirized in Table 1.1.

TABLE 1.1. Summary of Federal Guidelines and Regulations on Working Hours in Four Industries and the U.S. Air Force

\begin{tabular}{|c|c|c|c|c|c|}
\hline & $\begin{array}{l}\text { Nuclear Power } \\
\text { Industry } \\
\end{array}$ & $\begin{array}{l}\text { Air } \\
\text { Force }\end{array}$ & $\begin{array}{l}\text { Airline pilots } \\
\quad \text { and Crew } \\
\end{array}$ & $\begin{array}{l}\text { Railroad } \\
\text { Operators }\end{array}$ & $\begin{array}{l}\text { Truck } \\
\text { Drivers }\end{array}$ \\
\hline $\begin{array}{l}\text { Consecutive } \\
\text { Hours Worked }\end{array}$ & 16 & 12 & 8 & 12 & 10 \\
\hline $\begin{array}{l}\text { Length of } \\
\text { Break }\end{array}$ & $\begin{array}{l}8 \\
\text { (after up to } \\
\text { if hrs worked) }\end{array}$ & $--(a)$ & $\begin{array}{c}8 \\
\text { (after } 8 \text { hrs } \\
\text { dloft })\end{array}$ & $\begin{array}{l}10 \\
\text { (after } 12 \\
\text { consecutive } \\
\text { hrs worked) }\end{array}$ & $\ldots$ \\
\hline $\begin{array}{l}\text { Hrs Worked in } \\
\text { a } 24-\mathrm{Hr} \text { Period }\end{array}$ & 16 & -- & -. & $\ldots$ & - \\
\hline $\begin{array}{l}\text { Hrs Worked in } \\
\text { a } 48-H r \text { Period }\end{array}$ & 24 & - & -- & $\cdots$ & 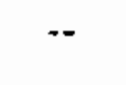 \\
\hline $\begin{array}{l}\text { Hrs Worked in } \\
\text { a } 7 \text {-Day Period }\end{array}$ & 72 & - & 30 & -- & 60 \\
\hline $\begin{array}{l}\text { Hrs Worked in } \\
\text { a 30-Day Period }\end{array}$ & $d$ & 125 & 100 & -- & -- \\
\hline $\begin{array}{l}\text { Hrs Worked in } \\
\text { a Year }\end{array}$ & $\ldots$ & 1320 & 1000 & -- & -. \\
\hline
\end{tabular}

(a) Dashes indicate that no guideline is specified. 
As shown in Table 1.1, the NRC's policy on overtime is more lenient than those of other federal agencies on two important measures:

(1) Nuclear plant staff are permitted 16 consecutive hours of work, whereas Air Force pilots, airline pilots, railroad operators and truck drivers are permitted only $12,8,12$, and 10 , respectively.

(2) Nuclear plant staff are permitted 72 hours of work within a 7-day period, whereas airline pilots and truck drivers are permitted only 30 and 60 , respectively.

\subsubsection{Nuclear Power P lant Staff}

The most recent NRC policy on nuclear power plant staff working hours is contained in Generic Letter 82-12 of June 15, 1982 (reprinted in Appendix B). Reactor owners are directed to adhere to the following guidelines:

a. "An individual should not be permitted to work more than 16 hours straight (excluding shift turnover time).

b. An individual should not be permitted to work more than 16 hours in any 24-hour period, nor more than 24 hours in any 48-hour period, nor more than 72 hours in any seven-day period (all excluding shift turnover time).

c. A break of at least eight hours should be allowed between work periods (including shift turnover time).

d. Except during extended shutdown periods, the use of overtime should be considered on an individual basis and not for the entire staff on a shift."

Under FR 50.54(h), operating license holders are subject to rules, regulations, and orders that are issued by the Commission subsequent to the operating license. The above guidelines are not regulations. They were sent to each operating license holder and published in the Federal Register as an NRC policy statement. These guidelines are also incorporated in the latest revision of Regulatory Guide 1.33, "Quality Assurance Program Requirements (Operation)."

\subsubsection{U.S. Air Force Limits on Flight Time}

Table l.l summarizes basic U.S. Air Force flight-duty time limits. The first row in the table shows the maximum allowable number of hours in a single flight-duty period. A flight-duty period begins when crew members report for a mission or briefing, and ends when engines are stopped at the end of a mission or series of missions. Table 1.1 indicates that the maximum allowable number of hours in a single flight-duty period is 12 for a single control (one pilot) aircraft. 
Air Force regulations provide different maximum flight-duty periods, depending on several considerations. Such considerations include the type of aircraft, whether the aircraft has single control or dual control, whether the aircraft has sleeping provisions, and whether the crew is a basic crew or an augmented crew (facilities for an augmented crew would allow one crew to sleep). For example, if a jet fighter has dual controls and two pilots, the maximum flight-duty time is 16 hours. With a few exceptions, the maximum flight-duty time for aircraft with a single crew and no sleeping provisions is 12 hours, and the maximum for aircraft with a single crew and sleeping provisions is 16 hours.

Table 1.1 also indicates that maximum flying time in 30 consecutive days is 125 hours. The maximum flying time in a calendar quarter is 330 hours of logged flight time; this is interpreted in Table 1.1 as a 1 imit of 1320 hours in one year.

The regulations described above are general Air Force regulations. Each Command within the Air Force also establishes its own specific regulations. Those specific regulations must at least meet the minimum safety standards of the general Air Force standards and may set higher safety standards. The U.S. Air Force Material Air Conmand (MAC), for example, is very explicit and strict in requiring an adequate rest period before flight duty. If a MAC crew is scheduled for a mission that will take them away from their home station for more than one duty day, the crew rest period begins 24 hours before reporting for the mission. As stated in the Material Air Command Regulations, "During the first 12 hours of this period, a crew member may accomplish limited nonflying duties. The second 12-hour period is inviolate; no duties may be performed. Infringement of the inviolate crew rest period will necessitate the start of another 12-hour inviolate crew rest period" (emphasis added).(a)

\subsubsection{Commercial Airline Pilots and Crew Members}

The allowable flight time for pilots and other aircraft crew members is regulated by the Federal Aviation Administration (FAA). Applicable regulations are at 14 CFR Subparts Q, R, and S. The basic limitations are at 14 CFR 121.471 and include the following:

(a) "No domestic air carrier may schedule any flight crewmember for duty aloft in scheduled air transportation or in other comercial flying if the crewmember's total flight time in all conmercial flying will exceed:

(1) 1,000 hours in any calendar year.

(2) 100 hours in any calendar month.

(3) 30 hours in any seven consecutive days.

(a) U.S. Department of Defense, U.S. Air Force. January 15, 1975. Material Air Command Regulations, Vol. 1, p.2-2 (not readily available to the public). 
(b) No donestic air carrier may schedule a flight crewmember for duty aloft for more than eight hours during any 24 consecutive hours without a rest period at or before the end of that eight hours, equal to twice the number of hours of duty al of $t$ since the last rest period, but not less than eight hours."

The regulations include a wide variety of exceptions to this basic rule, including special rules for transcontinental flights, helicopter pilots, etc. The rules also differ depending on how many crewmen are in the aircraft.

In 1982 the FAA issued new proposed rules that were intended to update and simplify the current flight time limitations. The proposed rules received extensive comment and were subsequently withdrawn by the FAA for further study.

\subsubsection{Railroad 0perators}

The working hours of railroad employees are regulated by the Federal Railroad Administration (FRA) under the authority of the Hours of Service Act. A summary of the Act's requirements prepared by FRA is included in the Code of Regulations as Appendix A to 49 CFR 228. The following excerpt on the basic hour Iimitations is taken from this Appendix:

"Limitations on Hours. The Act establishes 2 limitations on hours of service. First, no employee engaged in train or engine service may be required or permitted to work in excess of 12 consecutive hours. After working a full 12 consecutive hours, an employee must be given at least 10 consecutive hours off duty before being permitted to return to work.

Second, no employee engaged in train or engine service may be required or permitted to continue on duty or go on duty unless he has had at least eight consecutive hours off duty within the preceding 24 hours. This latter limitation, when read in conjunction with the requirements on computation of duty time (discussed below), results in several conclusions:

(1) When an employee's work tour is broken or interrupted by a valid period of interim release ( 4 hours or more at a designated terminal), he may return to duty for the balance of the total 12-hour work tour during a 24-hour period.

(2) After completing the 12 hours of broken duty, or at the end of the 24-hour period, whichever occurs first, the employee may not be required or permitted to continue on duty or to go on duty until he has had at least 8 consecutive hours off duty.

(3) The 24-hour period referred to in paragraph 1 and 2 above sha 11 begin upon the commencement of a work tour by the employee immediately after his having received a statutory off-duty period of 8 to 10 hours as appropriate." 


\subsubsection{Truck Drivers}

The Federal Highway Administration (FHA) regulates maximum working hours for commercial truck drivers. Again, various special rules and exemptions exist, and the actual regulations need to be studied for their application to a particular situation. The basic regulations are found at 49 CFR 395.3. These regulations (slightly edited for this report) are as follows:

No motor carrier shall permit or require any driver used by it to drive nor shall any such oriver drive:

(1) more than 10 hours following 8 consecutive hours off duty; or

(2) for any period after having been on duty 15 hours following 8 consecutive hours off duty. (Time "on duty" includes driving driving time and time performing other duties.)

(3) Exemption: Drivers using sleeper berth equipment may cumulate the required 8 consecutive hours off duty resting in a sleeper berth in 2 separate periods totaling 8 hours, neither period to be less than 2 hours.

No motor carrier shall permit or require any driver used by it to be on duty, nor shall any such driver be on duty, more than 60 hours in any 7 consecutive days as defined in 49 CFR 395.2 (c) regardless of the number of motor carriers using the driver's services. However, carriers operating vehicles every day in the week may permit drivers to remain on duty for a total of not more than 70 hours in any period of 8 consecutive days.

The logic and mathematical consistency of FAA and FHA regulations are not always clear. Partly for this reason, FAA regulations in particular have been the subject of much litigation.

\subsection{MAIN POINTS IN THE LITERATURE ON HOURS OF WORK AND PERFORMANCE}

Over 40 reports containing some data and information on the effects of the number of continuous hours of work were identified and obtained. The main points in these reports are as follows:

- Performance generally does decline with an increase in the number of hours of continuous work (although there are exceptions, and although it is not always easy to prove empirically).

- Errors generally increase at night. The increase is significantly greater if the worker has already been working four or more hours before midnight.

- Opinions vary concerning human error rates after 8 hours of continuous work. Many authors say that work should be limited to 8 hours per day. Yet, 12-hour-per-day shifts are common, especially in the petroleum industry. Northrup, Wilson and Rose (1979) asked managers of plants that had changed from 8-hour to 12-hour shifts whether the change had brought increased error rates; most managers said that it had not. 
- Schneider, Brooke and Moray (1982, p. 73) assumed for their analysis that errors would occur between 8 and 12 hours at about the same rate they occur between 4 and 8 hours of work. Compared to the assumption that error rates decline steadily, this assumption understates the error rate. Nonetheless, this assumption still leads logically to the conclusion that the error rate over a 24-hour period is higher with two 12-hour shifts than with three 8-hour shifts (because with two 12-hour shifts there are four 4-hour periods of high error rates, whereas with three 8-hour shifts there are only three 4 -hour periods of high error rates).

\subsection{FIELD STUDIES ON HOURS OF WORK AND PERF ORMANCE}

In this section, field studies that assess the effect of hours of work on performance are sumarized one at a time. In a field study, research conducted at the place of work, using regular workers as subjects, while they are performing their regular duties.

Mackie and Miller (1978) conclude that the probability of a truck accident occurring increases with increased driving time. They based their study on data collected by the Bureau of Motor Carrier Safety. The data were collected using a standard accident report form that truckers are obliged to $f i l l$ out if they have an accident that results in death, injury, or property damage in excess of $\$ 2,000$. The report form requests information on the number of hours the driver had been driving at the time of the accident. Although this is a highly quantitative study, the methodology leaves some questions unanswered (see Mackie and Miller in the annotated bibliography).

Schneider, Brooke and Moray (1982, pp. 36, 38) conducted a literature search on the effect of number of hours worked on performance. The following summary statements of field studies are from their study. Shannon and Lane (1971) reported that aircraft accidents were associated with more than 8 hours of duty and with circadian displacement. Hurst (1976) identified pilot errors with duty beyond 8 hours. Vernon (1945) reported that occupational injuries fell significantly when 12-hour shifts were replaced by 8 -hour shifts. Wilkinson, Tyler and Varley (1975) noted that more than one-third of junior doctors working 13 hours per day claimed that their efficiency was reduced as a result of the long hours.

Schneider, Brooke and Moray (1982, p. 42) summarize field studies on the effect of hours of work on vigilance as follows. Colquhoun et al. (1969) reported an 11\% increase in error rates for radar screen monitoring over 12hours in duration. Platz et al. (1978) reported no change in a vigilance task over 9 hours. Oobbins et al. (1963) also reported no change in a vigilance task for army truckers driving over 9 hours.

\subsection{LABORATORY EXPERIMENTS ON HOURS OF WORK AND PERF ORMANCE}

In this section laboratory experiments that assess the effect of hours of work on performance are summarized individually. The typical laboratory experiment is conducted in a research laboratory using students as subjects. 
Brown, Tickner and Simmonds (1970) conclude that drivers take greater risks after 8 to 12 hours of driving. Unfortunately, this report has methodological problems (see Brown, Tickner and Simmonds in the annotated bibliography).

The following surmary statements of laboratory experiments are from the literature search by Schneider, Brooke and Moray (1982, pp. 36, 38, 42, 43 \& 47). Zagoruiko and Tambovtsev (1982) reported that speed of reading slowed by $22 \%$ to $73 \%$ over 4 hours. Higgins et al. (1975) reported increased errors for a complex test battery that included monitoring for more than 12 hours. Kogi et al. (1975) reported that the performance of nurses on a vigilance task decreased when they changed from 8-hour to 12-hour shifts at night. Mckenzie and Elliot (1965) reported decreased ability to align flight meters in a flight simulator when work extended beyond 8 hours. Mackie and Miller (1978) reported deterioration in a critical tracking task in truck driving after 8 hours. Huxtable (reported in Ray, Martin and Alluisi 1961, p. 8) reported an increased error rate for repeated mental multiplication that would amount to a $17 \%$ increase over a 24-hour period for a 12-hour shift schedule as opposed to an 8-hour shift schedule. For complex decision making Wojtczak-Jaroszowa (1977) reported data that indicate an increased error rate of approximately 70\%. Mckenzie and Elliot (1965) report data on a tracking task in an aircraft simulator that imply a $6 \%$ increase in errors over 24-hours for 12-hour shifts compared to 8-hour shifts. From a car driving test, Herbert and Jaynes (1964) report data that imply a $10 \%$ increase for 12-hour shifts. 


\subsection{TIME OF DAY AND PERFORMANCE}

Over 50 reports dealing directly or indirectly with the effect of time of day on performance were identified and obtained for this task. The main points in these reports are as follows:

- Vigilance drops and human error probabilities rise at night. This generalization is probably the best documented observation in the shift scheduling literature.

- Many studies show a "post-lunch dip" -- a performance decrement at about IPM. Some studies suggest that, despite its name, the post-lunch dip is unrelated to eating lunch.

- Some studies show low performance in the early hours of the morning shift, from about 7AM to 9AM.

- The usual increase in human error probability at night is increased significantly if the worker has already worked an afternoon shift immediately before working the night shift.

\subsection{FIELD STUDIES ON TIME OF DAY AND PERFORMANCE}

A well-accepted generalization in the literature is that performance levels drop at night. However, relatively few field studies prove this point. Rutenfranz and Colquhoun (1979, cited in Reinberg, Vieux and Andlauer 1981, p. 179) state: "Performance studies making measurements at night or from night workers on the job are rare and the results are difficult to interpret." Folkard and Monk ( 1979, p. 483) state: "For a variety of reasons, such as union or management opposition and problems in finding appropriate measures, there appear to be only six published studies that report relatively continuous, 24-hour reallife performance measures. Nevertheless, there is a fair agreement among these studies that a major impaiment of performance occurs during the night shift." These six studies are shown in four graphs in Figure 2.1.

Figure 2.1 shows that in all six cases performance drops at night (the graphs have been redrawn so that "bad" performance is toward the bottom of the graph). Four of the graphs also show a post-lunch dip in perfornance. Graph 1 shows that it takes telephone switchboard operators about $90 \%$ longer than average to respond to calls at night (8rown 1949; quantitative data cited in Mackie 1977, p. 117). Graph 2 shows that meter readers make more errors at night (Swensson 1953, cited in Mackie 1977, p. 117). Graph 3 shows that drivers "nod off" primarily at night and about IPM (sample size, $n=500$ ) (Prokop and Prokop 1955, cited in Mackie 1977, p. 117). Graph 4 shows that the speed of spinners joining threads is slower at night (Wojtczak-Jaroszowa 1977; Pawlowska-Skyba 1967, cited in Mackie 1977, p. 117). Graph 5 shows that train drivers miss more warning signals at night (Hildebrandt, Rohmert and Rutenfranz 1974; see also annotated bibliography). Graph 6 shows that the frequency of minor accidents in a hospital is higher at night (Folkard, Monk and Lobban 1978). 


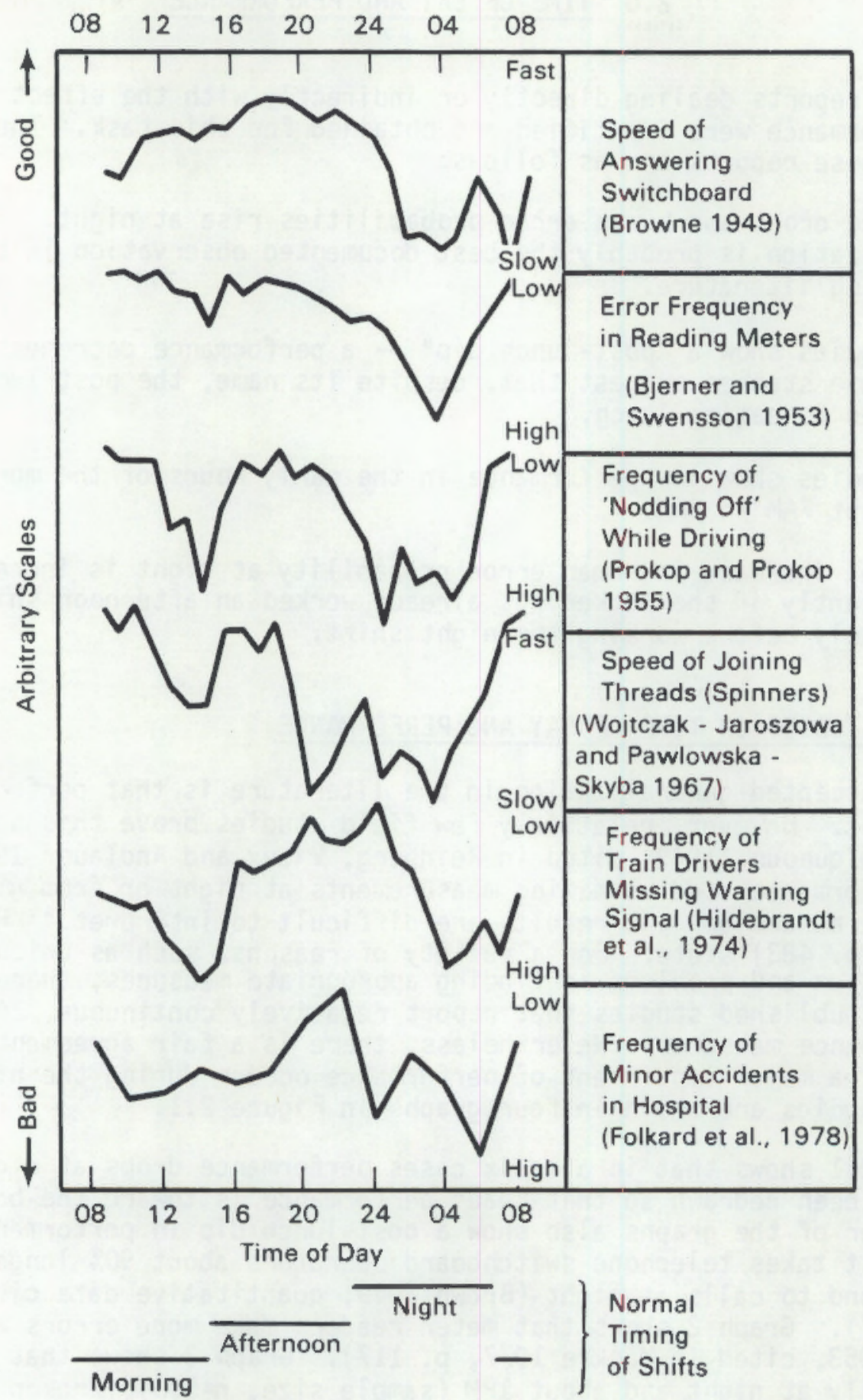

FIGURE 2.1. Variations in Job Performance Over the 24-Hour Period in Six Field Studies (Scheving and Halberg 1980, p. 295; from Folkard and Monk 1979) 
In a highly quantified study of truck accidents, Mackie and Miller (1978) show that most truck accidents in which the driver was dozing occur at night, even though more trucks are on the road during the day. Figure 2.2 shows this result. In Figure 2.2 "exposure" is the number of accidents that would have occurred during each hour of the day if the percentage of trucks on the road that have "dozing-driver" accidents were constant for all hours of the day. Under that assumption, one would expect more "dozing-driver" accidents during the day because there are more trucks on the road during the day. Thus, the larger number of "dozing-driver" accidents at night is not due to a higher volume of truck traffic at night.

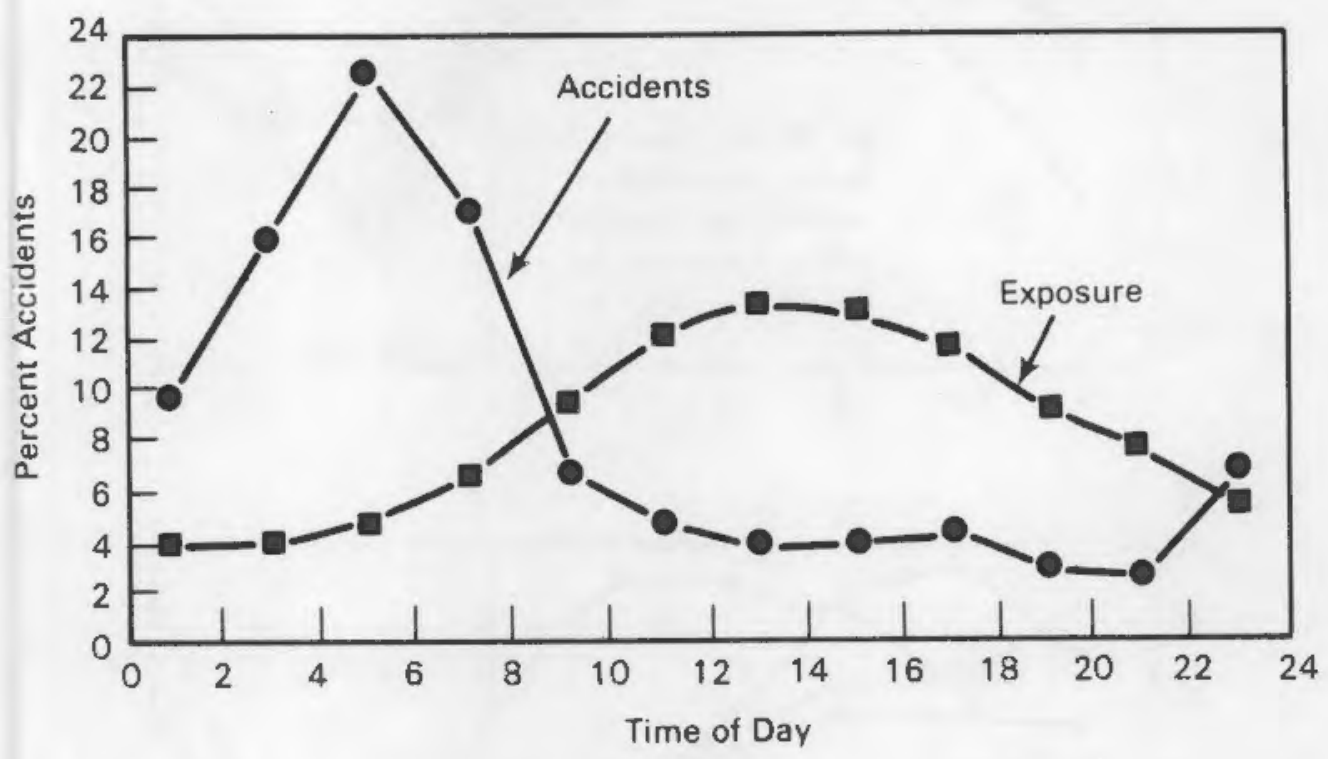

FIGURE 2.2. Percentage of Accidents by Time of Day for "Dozing Drivers" and Normalized Percentage of Trucks on the Highway for a Random Sample of Interstate Drivers (exposure) ( $\mathrm{N}=493$ accidents) (Mackie and Miller 1978 , p. 56)

The studies examined in this section clearly show that performance drops at night. Circadian rhythms undoubtedly account for much of the performance decrement. A study by Meers (1975, cited in Folkard and Monk 1979, p. 484), however, shows that part of the performance decrement in the industrial settings might be due to poorer maintenance of equipment on the night shift.

\subsection{LABORATORY EXPERIMENTS ON TIME OF DAY AND PERFORMANCE}

Early laboratory studies generally corroborate the results of the field studies: performance is lower at night. These early studies also found a high correlation between circadian rhythms in performance and body tempera- 
ture. Figure 2.3 shows circadian rhythms in a psychomotor test, a speed of cancellation test, a test in simple addition, and two aircraft simulator tests. The top graph in Figure 2.3 shows that the normalized curves for the circadian rhythms are almost identical. Comparison with the bottom graph shows that all of these are very similar to the curve for body temperature. (The bottom graph also shows the circadian rhythms for three other physiologic functions.)
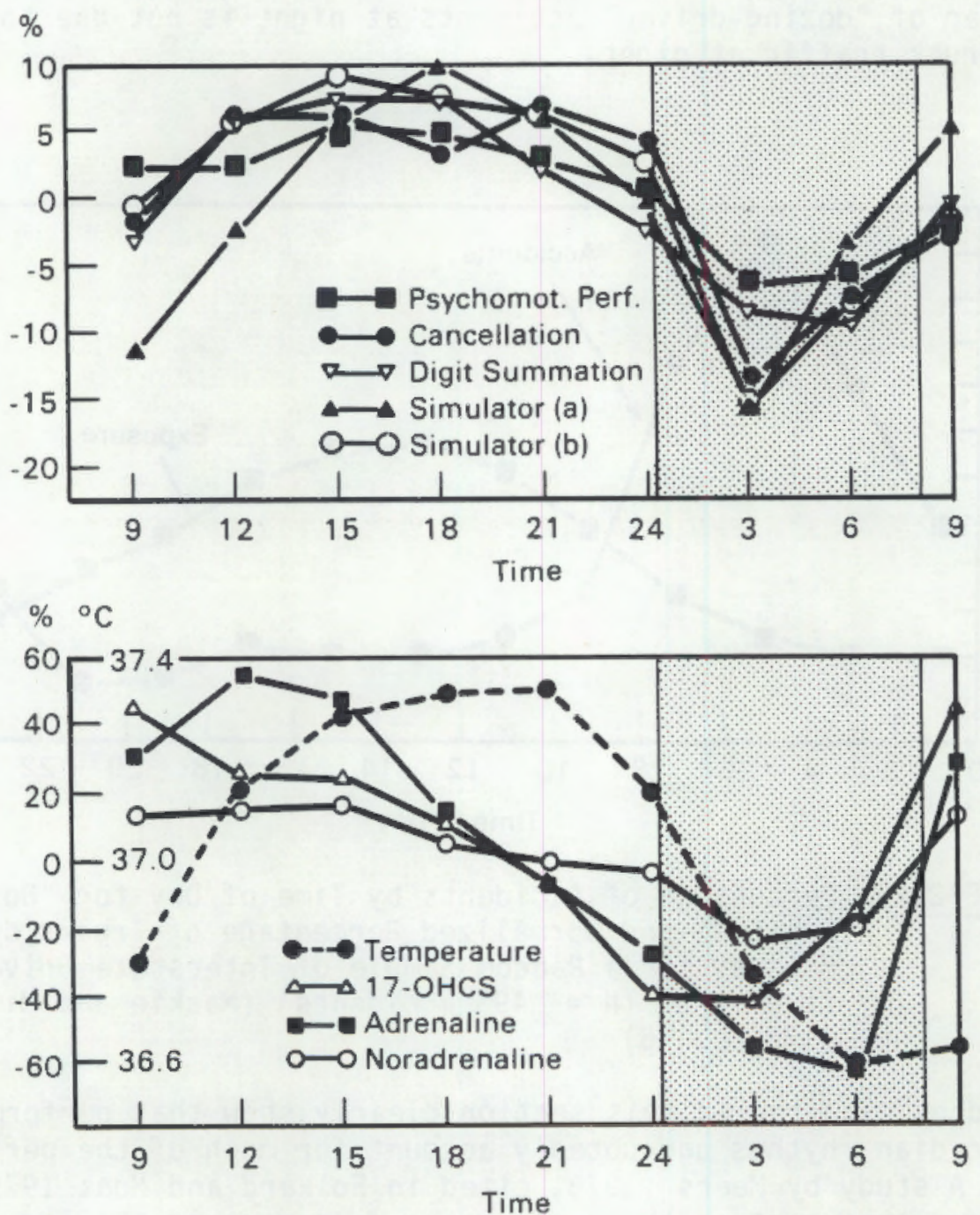

FIGURE 2.3. Circadian Rhythms of Test Abilities and Physiologic Functions in Percent of the 24-Hour Mean (Mackie 1977, p. 113) 
The very clear circadian rhythms shown in Figure 2.3 result in part from the experimental design: the subjects maintained a normal sleep/wake schedule, but they were awakened from sleep twice a night to perform the tests. Under these circumstances, one would expect low performance scores at night because the subjects' circadian rhythms had little time to adjust to wakefulness. Early experiments in which the subjects remained awake and "at work" for 12 consecutive 8-hour night shifts show that although one's circadian rhythms (measured by physiological and performance tests) do substantially adapt to the new sleep/wake schedule, the adaptation is not complete, and performance is still generally lower at night than during the day (Colquhoun and Rutenfranz 1980 , p. 195).

More recent laboratory studies have shown that the circadian rhythms for tasks that require little short-term memorization are positively correlated with body temperature (as are all the tests in Figure 2.3), but the circadian rhythms for tasks that require a great deal of short-term memorization are negatively correlated with body temperature. (See Folkard et al. 1976 in the annotated bibliography.) It has been demonstrated that in a higher memory load task, workers adapted faster to night work conditions simulated in a laboratory and to a time zone change following transmeridian airplane flight (Klein and Wegmann 1980, p. 10).

\subsection{COMBINED EFFECT OF NIGHTTIME AND LONG HOURS OF WORK ON PERFORMANCE}

Night work and long hours have a synergistic effect on performance. Performance is usually low at night. But it is even lower, sometimes much lower, if the worker had already been working a number of hours before midnight.

Hildebrandt, Rohmert and Rutenfranz (1974; see annotated bibliography, Figure 0.2 ) show that the error rate for German locomotive engineers at $3 A M$ is about 5 times higher for engineers in their 4th to 6 th hour of work than for engineers in their 1st to 3rd hour of work. Alluisi (1972) showed that the percentage of correct arithmetic computations generally reaches a nadir around 7AM, but the nadir is much lower if the subject has been deprived of sleep.

Figure 2.4 shows the performance levels of two groups of subjects who worked for 34 hours. The first group (shown by the solid line) began working at noon; the second group (shown by the dotted line) began working at midnight. After working 16 hours, at 4 AM, the performance of the first group began to deteriorate rapidly. By contrast, also after working 16 hours, but at $4 \mathrm{PM}$, the performance of the second group was still quite high. After working 30 hours, at 6PM, the performance of the first group was still relatively high. By contrast, also after working 30 hours, but at $6 \mathrm{AM}$, the performance of the second group had plummeted.

Performance was measured by a multiple task performance battery (MTPB), a combination of the following six separate tests: blinking-lights monitoring, 
warning lights monitoring, probability monitoring, arithemetic computations, code-lock solving, and target identifications (Coates 1974, pp. 24-26).

The evidence in this section indicates that working overtime increases error probabilities during the early morning hours, whether that overtime occurs before working the night shift or after working the afternoon shift.

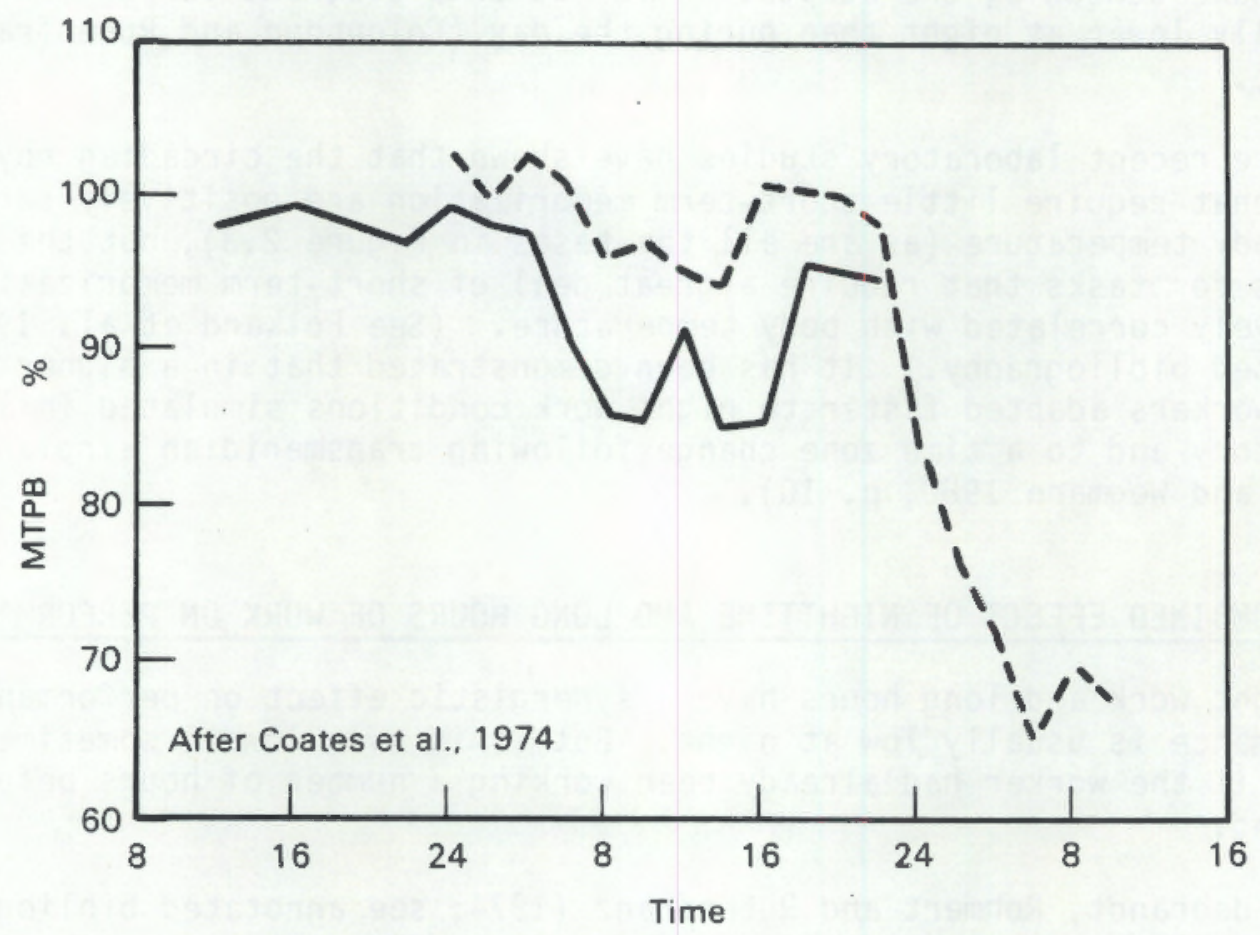

FIGURE 2.4. Combined Effect of Nighttime and Long Hours of Work on Performance ( 2 groups of subjects)

(Mackie 1977, p. 115) 


\subsection{REST PERIODS AND PERFORMANCE}

"Rest period" is used to mean days off and non-work periods away from the job site, not on-the-job coffee breaks, etc. About 15 reports that deal directly or indirectly with the effect of rest periods on performance have been identified and obtained. None of those reports, however, can provide a rigorous base for regulatory guidance.

The following main points have emerged from that literature review:

- Sleep during the day is shorter and less refreshing than sleep at night.

- According to many European researchers, workers should not work more than 1 to 2 nights in a row, and a night shift should be followed by a day off.

- Many authors express opinions on the effect of the cumulative fatigue of continuous work, but there are few empirical studies of the amount of rest needed to overcome that fatigue.

- Workers generally consider long rest periods, especially periods of four or more days, to be one of the most desirable aspects of shift work. Workers of ten prefer long, rigorous work periods interrupted only by short breaks, if they are eventually rewarded with a long rest period.

\subsection{GOVERNMENT REGULATIONS ON HOURS OF REST}

Although there is general agreement in the literature that sleep during the day is shorter and less refreshing than sleep at night, in most government regulations on work hours, that fact has not been considered. FAA regulations, for example, have provisions for rest time, but the formula for computing rest time does not consider one's circadian rhythms. (By contrast, unofficial formulas for computing recommended rest periods and presumed fatigue for air crews do take circadian rhythms into account. These formulas are discussed and evaluated in Klein and Wegmann 1980, Appendices I and II.) In their book The Clocks That Time Us, Moore-Ede, Sulzman and Fuller (1982, p. 330) state: "It is essential ... that FAA's regulations be revised to take into consideration the body times of the air crew."

In contrast to the U.S. regulations, German regulations on the length of rest periods do take into consideration circadian rhythms: the formula for computing the required length of rest is based in the number of time zones crossed. (Crossing time zones is analogous to daytime sleep in that it of ten necessitates attempting to sleep at the improper time in one's circadian cycle.) Concerning the German regulations (as of 1974), Klein and Wegmann (1980, p. 29) state:

"As a general rule for flight crews on transmeridian routes, the regulations imply that resynchronization to a new time zone must not be 
enforced but instead aircrews return as fast as possible to their home base. This applies only on the premises that sufficient rest time is provided within each 24-hour period away from home. To prevent sleep deficits, 14 hours rest time are considered the minimum under these conditions, and the operator is obliged to supply quarters which can be shielded from light and noise during local daylight hours. Upon returning to home base, the minimum rest period will be extended, if one or more flight segments have been spent in time zones differing from home base by 4 or more hours. The additional rest period required by regulation will then be calculated by multiplying the largest time zone difference while on duty with the factor 8 . Thus, if the largest difference has been 6 , for instance, the additional rest period will be $6 \times 8=48$ hours; or with the largest difference being 12 time zones, the rest period requires additional $12 \times 8=96$ hours."

It might be argued that 96 hours of rest required by German regulations is excessive, because the formula is based on the time required to resynchronize one's body temperature after a time zone change. However, as stated above, the crew is encouraged to keep their body rhythms fixed on the time at their home base. If they do so, they would not have to resynchronize to home base time.

\subsection{FIELD STUDIES ON HOURS OF REST AND PERF ORMANCE}

Some European researchers advocate a 24-hour rest period after every night shift. Knauth, Rohmert and Rutenfranz (1980, p. 399), for example, state:

"The number of consecutive night shifts must be limited; preferably only single night shifts should be interspersed in the shift plan.... Each night shift must be followed by $24 \mathrm{~h}$ of free time.... To avoid accumulating sleep deficits, lack of sleep after the day sleep should be immediately compensated during the following night."

This strong recomendation is partly based on the senior author's extensive research on shift workers' sleep schedules (and is closely related to their advocating rapidly rotating shifts). The research on sleep schedules, however, has a methodological difficulty (see annotated bibliography, Knauth and Rutenfranz 1981\}.

Tilley et al. (1982, p. 632) report that the average duration of sleep for workers on night, morning and afternoon shifts were $51 / 2,6$, and 7 hours, respectively. Thus, a rest period during the day is not as refreshing as a rest period at night.

Many workers prefer long, rigorous work periods if they are eventually rewarded by a long rest period. For example, senior pilots of ten select the most rigorous flight schedules because vacation allowances are highly favorable for those who fly those routes. (See Moore-Ede, Sulzman and Fuller 1982, p. 330; also Patkai and Dahlgren 1981, p. 245 in Reinberg, $V$ ieux and Andlauer 1981.) 


\subsection{SPEED OF ROTATION AND PERFORMANCE}

A considerable volume of controversial literature addresses speed of rotation of shifts. The main points in this controversy are as follows:

Slow Rotation (work one shift for 3-4 weeks before rotating to the next shift). According to the advocates of slow rotation, slow rotation gives one's body enough time to adjust to working at night and sleeping during the day; this adjustment makes both work and sleep more efficient.

- Moderate rotation (rotate about once per week). Once-per-week rotation is common in the United States.

- Rapid rotation (rotate every 1-2 days). Many European researchers advocate rapid rotation. They say one's circadian rhythms never fully adjust to night work, partly because workers revert to the normal dayt ime schedule during days off. They say that since it takes about a week for one's circadian rhythms to adjust to a new shift, with weekly rotation a worker's circadian rhythms are still unadjusted most of the time anyway. With rapid rotation one's circadian rhythms essentially remain fixed on the normal dayt ime schedule, so sleep is efficient on days off. Finally, these researchers say a worker should not work more than 1-2 consecutive night shifts and that night shifts should always be followed directly by days of $f$ -- rapid rotation allows such a schedule for night shifts.

\subsection{FIELD STUDIES ON SPEED OF ROTATION AND PERFORMANCE}

In this section, two documented field studies on speed of rotation and perfornance are examined.

\subsubsection{Field Study at a Potash Factory in Utah}

At a potash factory in Utah, productivity, worker health and job satisfaction improved, and turnover declined after their shift schedule changed (Czeister, Moore-Ede and Coleman 1982). In the former schedule, workers rotated (backward) to the next 8-hour shift once per week. Thirtythree workers then volunteered for a new schedule that rotated (forward) at the same speed, once per week. Fifty-two workers volunteered for a new schedule that rotated (forward) once every three weeks.

Statistically significant improvements in performance and job satisfaction were attributed only to the schedule that rotated once every three weeks. These results provide evidence that slow rotation improves performance. However, the authors themselves treat these results with caution, stating p. 462): "However, the design of any specific work schedule must, of course, take into consideration both the nature of the work and the specific needs of the workers." Caution is also advised because the performance measures were not tied directly to the workers on the 3-week rotation schedule: the produc- 
tion measures were for the entire plant, whereas only one-third of the workers were on the 3-week rotation schedule. (This report is discussed further in Section 5.1.1 and in the annotated bibliography.)

\subsubsection{Field Study in a Food Processing Factory in England}

In a field study at a food processing factory in England (Pocock, Sergean and Taylor 1980), sickness absences increased when the workers changed from a weekly rotating schedule to a rapidly rotating schedule. The authors attribute the increase in sickness absence directly to the speed of rotation. On the other hand, the workers liked the rapidly rotating schedule. (One indication of this is that "other absences" did not increase.) The authors conclude:

"The sharp increase in sickness absence ... suggests that although the men may have liked rapid rotation, they found it more demanding. If these results are confirmed in other studies, they would indicate that the popularity of rapid rotation ought not to be the only factor that management should consider when deciding to adopt it."

American air traffic controllers have two types of shift schedules that match the two schedules examined in this field study. As in this study, many air traffic controllers prefer the rapidly rotating schedule. The official position of the FAA, however, is that there are no discernibie differences in performance between the two types of schedules and that worker satisfaction maintains adequate motivation and performance. (See Section 6.1.1.)

\subsection{OTHER STUDIES OF SPEED OF ROTATION AND PERFORMANCE}

Rapid rotation has been gaining popularity in Europe and is advocated by a number of European researchers. Among them are Rutenfranz, Knauth and Colquhoun (1976, p. 338), who state their reasons as follows:

"The circadian rhythm is not significantly disturbed by a single nightshift. The ... (adaptation of circadian rhythms to night work) requires more than seven consecutive nightshifts.... Even during nightshift periods of several weeks no complete ... (adaptation) of some physiological functions (e.g., body temperature, heart frequency) could be observed.... Furthermore, for psychosocial reasons most workers need either to change their shift, or to have some rest days, after no more than one week (of nightshift)."

Norwegian researchers Vokac et al. (1981 p. 64) make the following argument for rapid rotation:

"In any rotating system the night shift period (requiring an altered sleep time) accounts, on average, for only about a quarter of the total length of the rotation cycie; normal sleep/wake habits are maintained in the remaining three quarters (morning and afternoon shift periods, and free days).... (Since one's circadian rhythms are on the normal daytime 
schedule three quarters of the time, rather than disrupt the rhythms just for one quarter of the time, it is best simply to leave the rhythms on the normal schedule all of the time. This can be done by rotating rapidiy.) Short periods of not more than 2-3 consecutive night shifts seem therefore preferable to larger periods."

Moore-Ede, Sulzman and Fuller (1982, p. 335-336) agree with the European researchers on some points:

"In scheduling shift workers, managers should decide whether total readjustment to each shift is required (i.e., slow rotation) or no adjustment at all (i.e., rapid rotation). The schedules that change once a week seem to be the most pernicious, because the individual is always in a state of readjustment to a new schedule."

Finally, Folkard (1981, p. 369) suggests that there is no single proper speed of rotation; the proper speed of rotation depends on the type of task perf ormed:

"(T)he results reviewed in this paper favour 'permanent' systems for simple perceptual-motor tasks, but rapidly rotating ones for more cognitive, memory-loaded tasks. However, these conclusions must be regarded as extrenely tentative."

Most conclusions concerning speed of rotation must be regarded as tentative because of the lack of adequate data. 


\subsection{DIRECTION OF ROTATION AND PERFORMANCE}

Whereas the other chapters in this report summarize the literature without reaching policy conclusions, this chapter reaches a policy conclusion. This chapter addresses the question: "Is there sufficient evidence to recommend the adoption of forward rotating shifts?" It concludes that the evidence favoring forward rotation is weak.

The main points from $P N L$ 's review of the literature in this area are as follows:

- The relative merits of forward vs. backward rotation for employee shift schedules is an issue that is rarely addressed directly in the literature.

- No author explicitly advocates backward rotation for shift schedules.

- One major report explicitly advocates forward rotation for shift schedules: Czeisler, Moore-Ede and Coleman reported in Science, July 1982, on an experimental change in the shift schedule at a potash factory in Utah. This experiment, however, fails to provide adequate evidence for forward rotation.

- Workers often revert to the normal daytime schedule on days off. For these workers, much of the progress in gradually and consistently resetting their circadian rhythms in a forward direction will be lost, and thus the advantage of a forward rotating schedule will be reduced.

- There is usually a rest period between rotations. Any presumed advantage of a forward rotating schedule might be small compared to the recuperation gained by a longer rest period.

- Jet-lag experiments and isolation-chamber experiments have been cited to justify forward-rotating shift schedules. PNL concludes, however, that these experiments offer insufficient evidence to justify forward-rotating shift schedules.

- In contrast to Czeisler, Moore-Ede and Coleman's circadian principle of repeatedly resetting one's internal clock to match a repeatedly changing work/sleep schedule, some European researchers advocate leaving one's internal clock fixed on the normal time.

- In an experiment at a factory in England, $i 11$ ness and absences were lower on a backward-rotating shift schedule than on a forward-rotating schedule.

\subsection{FIELD STUDIES ON DIRECTION OF ROTATION AND PERF ORMANCE}

In this section, two documented field studies addressing direction of rotation and performance are examined. 


\subsubsection{Field Study at the Potash Factory in Utah}

The field study at the Utah potash factory not only compared two speeds of rotation (as discussed in Section 4.1.1), it also compared two directions of rotation. As was mentioned before, the authors concluded that performance and job satisfaction improved when workers changed from a backward to a forward rotating shift schedule. This experiment, however, fails to provide adequate evidence for favoring forward rotation over backward rotation, for three reasons:

(1) The "circadian" principles" that the authors wished to apply required that the shift schedule change by no more than 1 or 2 hours per day; thus, an employee would begin work at 8 AM one day, 9AM the next day, 10AM the third day, etc. After trying such a schedule and finding it unacceptable for social reasons, the employees at the potash plant abandoned this schedule and reverted to the ordinary practice of rotating in 8-hour increnents. An 8-hour increment, however, is beyond the confirmed range of applicability of the "circadian principle" on which the authors based their justification.

(2) To have practical application to shift scheduling, the authors' circadian principles should be expanded to include the effects of rest periods.

(3) At the potash factory, the new forward rotating shift schedules were of two types: in one schedule workers rotated forward to the next shift every week, in the other they rotated forward once every 3 weeks. Because the statistically significant results on satisfaction and productivity were all for the 3-week rotation scheme, it is more difficult to discern the degree to which the beneficial effects of the new shift schedule resulted from forward rotation and to what degree they resulted from slow (21-day) rotation. (For additional information, see Annotated Bibliography, Czeisler, Moore-Ede and Coleman 1982).

\subsubsection{Field Study at the Food Processing Factory in England}

The field study at the English food processing plant explicitly compared two speeds of rotation (as discussed in Section 4.1.2). The two shift schedules, however, also differed on direction of rotation. The rapidly rotating schedule was also a forward rotating schedule, and the slowly rotating schedule was also a backward rotating schedule. The backward (slowly) rotating schedule produced fewer sickness absences.

Although it would be unreasonable to infer from this evidence that backward rotation produces fewer sickness absences, one can reasonably infer that a change from a backward to a forward rotating schedule is not always a change for the better (since rapid rotation can overwhelm any presumed benefits of forward rotation).

\subsection{LABORATORY EXPERIMENTS ON DIRECTION OF ROTATION AND PERFORMANCE}

In this section, experiments on direction of rotation and its effect on performance are discussed. 


\subsubsection{Experiment on the Circadian Rhythms of Rest Periods}

The theory that justifies advocating forward rotating shift schedules requires that a worker's circadian rhythms adapt to each successive new shift as he rotates his work periods forward around the clock. To do this successfully, the worker would have to continue with his work schedule on his days off. Most workers, however, for social reasons, revert to the normal daytime schedule on their days off. For these workers, much of progress they might have been made during the workweek in adapting their rhythms is lost during days off.

The speed with which circadian rhythms revert to the normal cycle on days off was investigated by Vokac et a1. (1981). In their experiment, six subjects were put on a rapidly rotating schedule. Body temperature and urinary excretions of adrenaline, noradrenaline and other chemicals were monitored. The authors concluded that even though there was some adaptation of these circadian rhythms to the work schedule, on days off they reverted "suddeniy" to the normal daytime cycle.

This research indicates that the "circadian principles" used to justify forward rotation take inadequate account of the circadian effect of rest periods.

The length of rest periods must also be considered when examining the causes of changes in performance levels. Whenever a shift rotates, either backward or forward, the length of the rest period between shifts is changed; there is of ten a rest period of one to four days between rotations. The rest period between shifts rotating backward may be longer than the rest period between shifts rotating forward. One must consider the possibility that the beneficial effects of this increased rest might outweigh the potential negative effects of backward rotation.

The different lengths of rest periods between rotations can be illustrated by the following example. Assume that two workers both work the morning shift, both have one day off, and both rotate to a new shift. The worker that rotates forward to the af ternoon shift will have 24 hours off. The worker that rotates backward to the night shift will have 32 hours off. In this example, the worker on the backward rotating shift has more time to recuperate.

\subsubsection{Jet-Lag and I solation-Chamber Experiments}

Jet-lag experiments are generally designed as in the following hypothetical example. The subject's body temperature (or some other bodily function or ability that has a circadian rhythm) is measured every hour or two for several days to determine the time of day of its peak value, say 7PM. The subject is then flown from New York to Paris, and his body temperature is measured every hour or two for several days after the flight. On the first day after the flight, the peak in body temperature will typically remain close to 7PM New York time, but after 3-6 days the peak will occur at 7PM Paris time. The number of days required before the peak to occurs at 7PM Paris time is considered to be the adjustment time. 
Isolation-chamber experiments, often conducted in deep caves or underground bunkers, have provided an extensive body of literature on human circadian rhythms (Xlein and Wegmann 1980, p. 7). These experiments are conducted in rooms that are isolated in such a way that a subject in them has no way of knowing the time of day. Wake and sleep periods can then be determined in two ways: (1) the researcher can artificially create "daytime" and "nighttime" anytime, for example, by asking the subject to wake up and turn the lights on, or to turn the lights out and go to sleep, and (2) the subject himself can be allowed to wake and sleep as he likes. In each case, the subjects circadian rhythms are measured.

Jet-lag and isolation-chamber experiments resemble rotating shifts in that the wake/sleep schedule is shifted. Although these experiments provide some useful information, they do not give a clear indication that forward-rotating shifts are significantly better, for the following reasons:

- The analogy between these kinds of experiments and shiftwork is inexact: in shiftwork the daily time cues are inconsistent (e.g., one sleeps during the day and eats at odd hours).

- The lessons provided by jet-lag experiments and isolation-chamber experiments are not always clear. Some experts say the two types of experiments provide the same lesson: forward rotation is better. Another expert says in effect (since his is not directly concerned with shift scheduling) that proper interpretation of the two types of experiments provide the same lesson: backward rotation is better. Other experts say that the results of jet-lag experiments inexplicably contradict the results of isolation-chamber experiments. Still another expert says that some physiological processes and abilities adapt more quickly after westward flight (which corresponds to rotating forward), while other processes and abilities adapt more quickly after eastward flight (which corresponds to backward rotation). (These expert opinions taken from Klein and Wegmann 1980 , pp. 17-23.) 


\subsection{SHIFT SCHEDULING IN THE AIRLINE INDUSTRY}

Airline pilots and air traffic controllers, like nuclear plant staff, have irregular shift schedules, are highly skilled, and bear a heavy responsibility for public safety. Therefore, literature on the airline industry was examined for potential application to the nuclear industries. Studies of pilots and air traffic controllers suggest that sleep deprivation might have more effect on safety than jet lag or rotation of shifts. To collect information on shift scheduling and safety, the federal agencies that oversee the airline industry use methods that might be adapted and adopted by the NRC.

\subsection{AIR TRAFFIC CONTROLLERS AND PILOTS}

Two general working populations for which there are shift scheduling concerns in the airline industry are first, the air traffic workforce and airway facility technicians, and second, the aircraft crews. Shift scheduling practices for these two workforces differ primarily in their regularity. The air traffic controllers work predictable, regular schedules, whereas the aircrews frequently work odd schedules crossing multiple time zones in different directions with long or short work days, variable workloads, and variable rest periods. Each of these airline industry groups faces problems of shift scheduling in relation to work performance, the effects of which can be related to similar circumstances in the nuclear industry.

\section{1 .1 Air Traffic Controllers}

Ain traffic controllers work two basic shift rotation patterns (Reighard 1983). One rotation consists of two 5-day (40-hour) weeks on the afternoon shift, 2 weeks on the morning shift, and 1 week on the night shift. This. shift schedule is referred to as the "Straight 5;" it is a backward rotating shift, rotating once per week. Each workday is 8 hours long and workdays are separated by 16 hours off duty. Workweeks are separated by 2 days off.

The second basic shift schedule is one that consists of a workweek consisting of 2 consecutive afternoon shifts, then 2 morning shifts, and finally, I night shift. This shift schedule is called "2-2-1" or "rattler;" it is a backward rotating, rapidly rotating shift schedule. The controversial feature of this schedule is that no 2 work periods are separated by a full 16 hours. The longest separation is 14 or 15 hours and the shortest is 9 or 10 hours. These quick turnarounds result in compression of the 40-hour workweek into an 88-hour period, leaving 80 hours (or nearly half of a 7-day week) off duty between workweeks.

The FAA management claims that neither work pattern is superior to the other in terms of "...biochemical and physiological measurements (stress indicators) taken during research..." (Reighard 1983). They do claim that the 2-2-1 pattern is preferred by many controllers, apparently because of the 
extended off-duty period that follows the sequence. The FAA imposes no standard practice on their facilities throughout the country. Each facility is free to establish its own practice, and a recently implemented FAA human relations program has encouraged worker participation in developing work schedules.

Accurately assessing the true effectiveness of FAA shift scheduling policies is difficult at this time because of the continuing effects of the 1981 air traffic controllers strike and subsequent reduction in the controller workforce. In contrast to the FAA management view set forth in recent Congressional testimony, the head of the National Transportation Safety Board, Jim Burnett, was quoted on March 15, 1983, as expressing concern for safety in the air traffic control system because of increased traff ic demands on less experienced controller workforce. Many controllers in heavy traffic areas were reported to be working six days per week with little vacation. Therefore they were apparently not able to maintain the more benign and regular schedules used at less busy facilities.

Because of these temporary problems of the system, studies conducted on controllers before the strike may be more representative of circumstances in the nuclear power industry than are newer studies.

\section{1 .2 Airline Pilots}

As indicated earlier, shift scheduling practices of flight crews are closely regulated. Nevertheless, wide variations in schedules can and do occur even within the letter of the regulatory policy. For example, aircrews on international airlines may cross multiple time zones on long flights with few takeoffs and landings (high workload periods) scheduled for each duty period. On the other hand, aircrews on regional or feeder airlines may stay within a single time zone but may have to make a dozen or more takeoffs and landings in one shift. A multitude of research studies has been conducted to understand the diverse operational conditions experienced by airline crews. The major results of the research may be summarized by saying that shifts in time zones or work schedules may impair performance, but sleep deprivation may well be the most important factor in both cases.

\subsection{DATA COLLECTION IN THE AIRL INE INDUSTRY}

The focus of this literature review is on research results, not on data collection methods. Nonetheless, this section is directly relevant to the object of the research project, which is to recommend an NRC policy position concerning shift scheduling and overtime. If the NRC were to conclude that insufficient data exist at present on which to base an NRC policy position, it might wish to rectify the situation by collecting the relevant data. Alternatively, if the NRC were to adopt a policy position based on availble data, it might also wish to collect additional data at the same time in order to further justify or modify its position in the future. In either case, the collection of additional data is important. The data collection methods of the FAA are 
FAA are particulariy relevant because of the similarities between the roles of the FAA and the NRC, and the similarities between the airline and nuclear power industries. The three most relevant FAA data collection methods, which are decribed below, are 1) accident investigation teams, 2) mishap reporter amnesty, and 3) the Aviation Safety Reporting System. (The data collection methods of the Department of Transportation for the trucking industry are described briefly in Mackie and Miller 1978, p. 51.)

\subsubsection{Accident Investigation Teams}

The National Transportation Safety Board is charged with investigating airline accidents. This federal board has assembled multidisciplinary teams of investigators who can quickly respond to the scene of any airline accident. Once there, they immediately gather all available information about such factors as the aircraft condition, weather, aircrew qualifications, and airway status. They then reconstruct the exact circumstances of the accident, determine its direct and indirect causes, and then issue immediate action recommendations to remedy the conditions that led to the mishap. Since the multidisciplinary team consists of personnel as diverse as human factors specialists, medical doctors, and engineers, the recommendations are frequently wide ranging. If public safety is affected, they may even have economic consequences as severe as grounding of an entire aircraft type pending some mechanical check or modifications. Two important aspects of all these investigations are the crew qualifications and their recent work schedules.

\subsubsection{Mishap Reporter Amnesty}

Several times over the past few decades, the FAA has set up temporary programs providing amnesty to pilots or controllers who report unsafe events or conditions that otherwise would involve self-incrimination with severe legal or regulatory penalties. The underlying philosophy of these programs is that it is best to detect the occurrence of uns afe acts or events to correct relevant policies or practices before a severe accident occurs. Past amnesty programs have involved such hazardous events as near-midair collisions that might normally go unreported by pilots who fear losing their licenses because they may have made a mistake. The FAA's enlightened view is that such human errors frequently have underlying causes that could be corrected through system changes. For example, a mistake by a pilot who has been on duty for many hours may indicate a need for changes in the regulations pertaining to shift scheduling.

One proposed solution for the problem of assessing the true safety of the current, post-strike air traffic control system is an amnesty for controllers who report hazardous events. Post-strike reports of such events have decreased significantly from pre-strike report levels, and some observers attribute this difference to fears of the present controller workforce of retribution by management. It is therefore felt that an amnesty for workers reporting critical incidents will provide a more accurate picture of the system's safety than does the formal reporting process. 
Some type of amnesty system might also be useful in the nuclear industry. Data on operational errors collected through the annesty system could then be related to shift scheduling practices to determine which, if any, are superior or inferior. Such information could potentially provide a sound basis for regulatory policy or could, at least, help direct specific research aimed at formulating better policies.

\subsubsection{NASA Aviation Safet y Reporting System}

The Aviation Safety Reporting System (ASRS), operated through the National Aeronautics and Space Administration (NASA), is a volunt ary, confidential reporting system available to all users of the national aviation system. It is similar to the amnesty systems described above because the FAA offers a limited waiver of disciplinary action to participants who may have inadvertently violated a Federal Air Regulation. It is different fram the amnesty systems in that the program is managed and operated by NASA, an independent agency, to increase the flow of information into the program. Safety reports may be submitted about any situations or occurrences that may affect air safety.

As described by Lyman and Orlady (1981), reports are submitted to ASRS on a structured form that asks for information about such things as aircraft characteristics, weather, experience, type of operation, and air traffic control. Space is also provided for the reporter to describe in his/her own words the circumstances of the incident, what happened, and why. NASA safety analysts review the report for completeness and criticality of the reported incident. If an analyst believes it appropriate, he may contact the reporter for additional information. When satisfied that the report is as complete as possible, the analyst removes the reporter's name and any other persons or organizations who may have been ident ified. The analyst then processes the report, preparing it for entry into the ASRS data base. After a safety report leaves the analyst's possession, there is no opportunity to obtain additional information about the incident. To assure the reporter's confidentiality, the analyst never attempts to corroborate the circumstances of the reported incident by contacting other parties. All data collected on the forms are entered into a computerized data base.

Since "Duty/Scheduling" is one of the key words used in the data base, reported events $c$ an be analyzed in terms of shift scheduling. In addition, some of the most interesting results of this system are the reporters' suggestions for solutions. In many cases these solutions may lead directly to simple, yet effective, regulatory policy changes.

It would appear that a system similar to the ASRS could provide useful information to the NRC if it were properly conceived and presented to the industry. Probably the most effective system would have to use an organization that is independent of the NRC to collect and analyze the reports, just as the FAA uses NASA for that purpose. The reporters must have faith in the conf jdentiality of the reporting system if it is to be effective. Once the system is in place, valuable shift scheduling data could be collected to support formation of regulatory policies. (See also Finalyson and Ims 1983.) 


\section{APPENDIX A}

TERMINOLOGY FOR DIRECTION OF SHIFT ROTATION 


\section{APPENDIX A}

\section{TERMINOLOGY FOR DIRECTION OF SHIFT ROTATION}

The terminology for specifying the direction of shift rotation is confusing because there are four sets of terms for the same phenomena, each set having been borrowed from a different field of endeavor. Unfortunately, some of the terms for the same phenomenon sound as though they refer to precisely their opposites (e.g., "forward rotation" is analogous to "phase delay" and a traveller setting his watch backward.). The four fields of endeavor are 1) shift scheduling, 2) laboratory research, 3) transmeridian airplane travel, and 4) trigonometry. (Trigonometric terminology will not be discussed here.) Because the terms used within each field of endeavor make sense within their own context, the following discussion will deal with each context separately. A final chart summarizes the sets of terms.

\section{A.1 SHIFT SCHEDULING TERMINOLOGY}

Rotating shifts typically have three shifts: morning (08.00 to 16.00), afternoon (16.00 to 24.00$)$, and night (24.00 to 08.00$)$.

A forward rotating shift schedule is one in which a worker works these three shifts in the following order: ... morning/afternoon/niaht/morning/ afternoon/night/morning .... (the series can start and end at any of the three periods of the day).

A backward rotating shift schedule is one in which a worker works these shifts in the opposite order: ... morning/night/afternoon/morning/night/after. noon/morning/night ....

The following chart is an example of a forward rotating shift schedule for a worker, where the $X^{\prime}$ 's indicate days of working a particular shift, or days off:

Morning
Afternoon
Night


The following is an example of a backward rotating shift schedule:

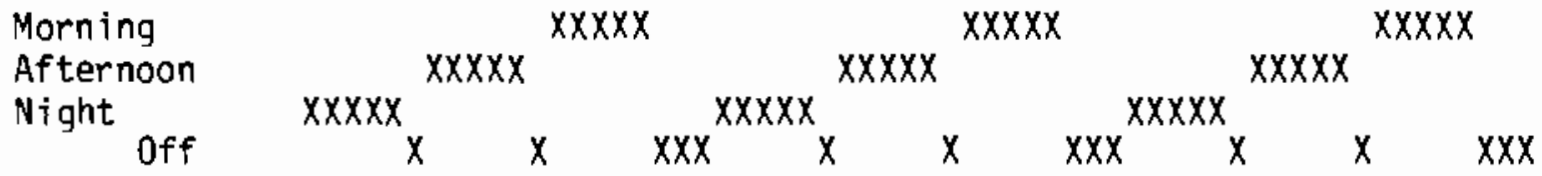

For ease of comparison later, these schedules can be redrawn as follows (where $M=$ morning, $A=$ afternoon, and $N=$ night):

Forward

Backward

Before rotation

After Rotation

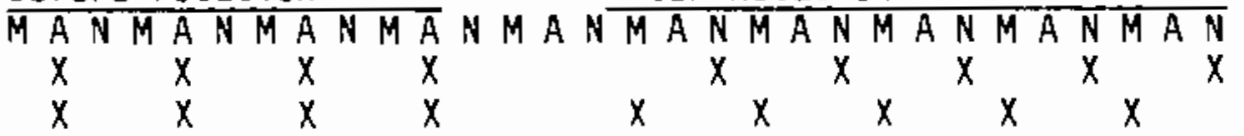

\section{A.2 LABORATORY RESEARCH TERMINOLOGY}

Laboratory research on circadian rhythms typically uses laboratory animals that are placed in an isolation chamber so they have no way of knowing the rea? time of day. The researcher then can simulate daytime by turning on a 1 ight in the chamber and can simulate nighttime by turning it off. The research typically begins with a pre-test session in which the researcher turns the light on and off at times that correspond to the real night and day, for example turns the lights on at $6 \mathrm{AM}$ and off at $6 \mathrm{PM}$. During the test session, however, the researcher will either delay switching the lights, e.g., switch them at 7AM and 7PM, or will switch the Tights in advance of the pre-test times, e.g., at 5AM and 5PM. Hence the terms "phase delay" and "phase advance." Phase delay and phase advance are represented graphically below where asterisks mark the real $6 \mathrm{AM}$ and $6 \mathrm{PM}$, and $\mathrm{X}^{\prime} \mathrm{s}$ indicate when the light is turned on in the isolation chamber:

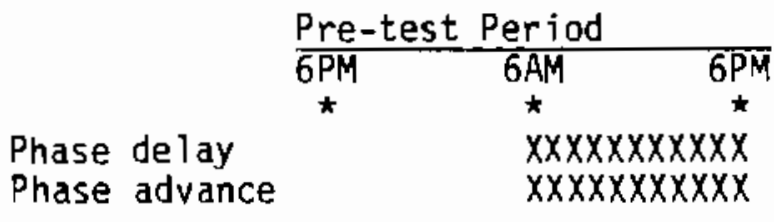

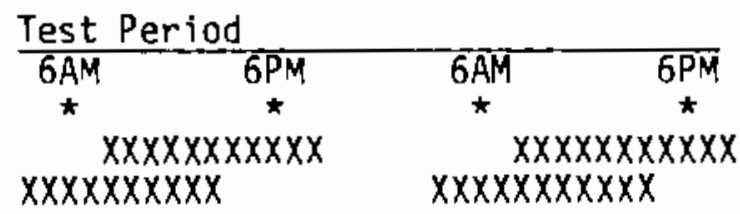




\section{A.3 TRANSMERIDIAN AIRPLANE TRAVEL}

Crossing several time zones quickly in a jet plane is often compared to rotating shift schedules and to laboratory tests of circadian rhythms. In the following table, two flights are compared: New York to Los Angeles, and New York to Paris. The asterisks mark New York time; the X's indicate the period from 6AM to 6PM (daytime) at the traveler's (changing) location.

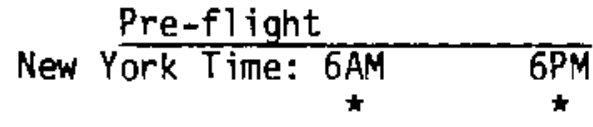

NY to LA (East to West;

set watch back)

$x \times x \times x \times x \times x \times x$

NY to Paris (West to

East; set watch forward) $x \times x \times x \times x \times x \times x$
Post-flight

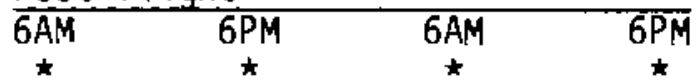

$x \times x \times x \times x \times x \times x$

$x \times x \times x \times x \times x \times x$

$x \times x \times x \times x \times x \times x$

$x \times x \times x \times x \times x \times x$

\section{A.4 SUMMARY}

Visual inspection shows that the upper section of each chart corresponds to the upper section of the other charts, and similarly for the lower sections. The sets of terms are summarized below:

Shift Scheduling

Upper Forward Rotation

Lower Backward Rotation
Laboratory

Research

Phase Delay

Phase Advance
Transmeridian Travel

East to West travel set watch back

West to East trave? set watch ahead

For defining examples of the usage of these terms, see Czeisler, Moore-Ede and Coleman, 1982; Science, Pp. 460, 461, and 462 note $\# 9$; and Moore-Ede, Sulzman and Fuller, 1982, The Clocks That Time Us, p. 121. 


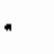

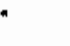


APPENDIX B

NRC POLICY ON WORKING HOURS 


\section{APPENDIX B}

NRC POLICY ON WORKING HOURS

The most recent NRC policy statement on the working hours of nuclear power plant staff is contained in Generic Letter 82-12 of June 15, 1982. A copy of the policy statement from this letter appears on the following page of this appendix. This same policy statement was published in the June 1, 1982, Federal Register, 47 FR 23836. 


\section{POLICY ON FACTORS CAUSING FATIGUE OF OPERATING PERSONNEL AT NUCLEAR REACTORS}

Licensees of operating plants and applicants for operating licenses shall establish controls to prevent situations where fatigue could reduce the ability of operating personnel to keep the reactor in safe condition. The controls should focus on shift staffing and the use of overtime--key job-related factors that influence fatigue.

The objective of the controls would be to assure that, to the extent practicable, personnel are not assigned to shift duties while in a fatigued condition that could significantly reduce their mental alertness or their decision making capability. The controls shall apply to the plant staff who performed safety-related functions (e.g., senior reactor operators, reactor operators, health physicists, auxiliary operators, and key maintenance personnel).

Enough plant operating personnel should be employed to maintain adequate shift coverage without routine heavy use of overtime. The objective is to have operating personnel work a normal 8-hour day, 40-hour week while the plant is operating. However, in the event that unforeseen problems require substantial amounts of overtime to be used, or during extended periods of shutdown for refueling, major maintenance or major plant modifications, on a temporary basis, the following guidelines shall be followed:

a. An individual should not be permitted to work more than 16 hours straight (excluding shift turnover time).

b. An individual should not be permitted to work more than 16 hours in any 24hour period, nor more than 24 hours in any 48-hour period, nor more than 72 hours in any seven day period (all excluding shift turnover time).

c. A break of at least eight hours should be allowed between work periods (including shift turnover time).

d. Except during extended shutdown periods, the use of overtime should be considered on an individual basis and not for the entire staff on a shift.

Recognizing that very unusual circumstances may arise requiring deviation from the above guidelines, such deviation shall be authorized by the plant manager or his deputy, or higher levels of management. The paramount consideration in such authorization shall be that significant reductions in the effectiveness of operating personnel would be highly unlikely.

In addition, procedures are encouraged that would allow licensed operators at the controls to be periodically relieved and assigned to other duties away from the control board during their tour of duty. 


\section{APPENDIX C}

SUMMARY CHART OF IMPORTANT REPORTS ON SHIFT SCHEDULING 


\section{APPENDIX C}

SUMMARY CHART OF IMPORTANT REPORTS ON SHIFT SCHEDULING

In Table C.l, the important articles on shift scheduling are listed alphabetically by author. Full references to the articles are in the bibliography and reference list. The columns are divided into three groups, as follows:

I. SHIFT SCHEDULING VARIABLES

1. Hours worked per 24-hour period

2. Hours worked per 48 -hour period

3. Hours worked per week

4. Hours worked per month

5. Fixed vs, rotating shift

6. Forward vs, backward rotating shift

7. Fast vs. slow rotation

8. Hours of rest between work periods

9. Time of day

10. Other

I1. PERFORMANCE AND MEdiating VARIABLES

1. Performance/safety

2. Performance-related measures

3. Alertness/fatigue

4. Sleep

5. Vigilance

6. Memory

7. Physiological measures

8. Attitude toward shift schedule

9. Job satisfaction

10. Social/family life

11. Absenteeism

12. Attrition

13. Dther

III. INDUSTRY

1. Nuclear power

2. Commercial airline

3. Nuclear Navy

4. Other military

5. Nursing

6. Transportation

7. Police officers and fire fighters

8. Petrochemical

9. Fossil-fuel power

10. Other

C. $?$ 
The letters $C, E$, and $X$ on the chart are used as follows:

$$
\begin{aligned}
& C=\text { Cause } \\
& E=\text { Effect } \\
& X=\text { Industry } .
\end{aligned}
$$

For example, if a report on airline pilots shows that performance is degraded after 12 continuous hours of work, then hours of work is the cause (C), and performance is the effect (E); thus, a " $C$ " is entered under the column for "hours of work in a 24-hour period" and an "E" is entered under the column for "performance." Since the report is about airline pilots, an "X" is entered under the column for "commercial airline."

Table C.1 shows PNL's cataloging of the important reports only. All reports have been catalogued in the bibliography in the same manner. 
TABLE C.1. Important Articles on Shift Scheduling

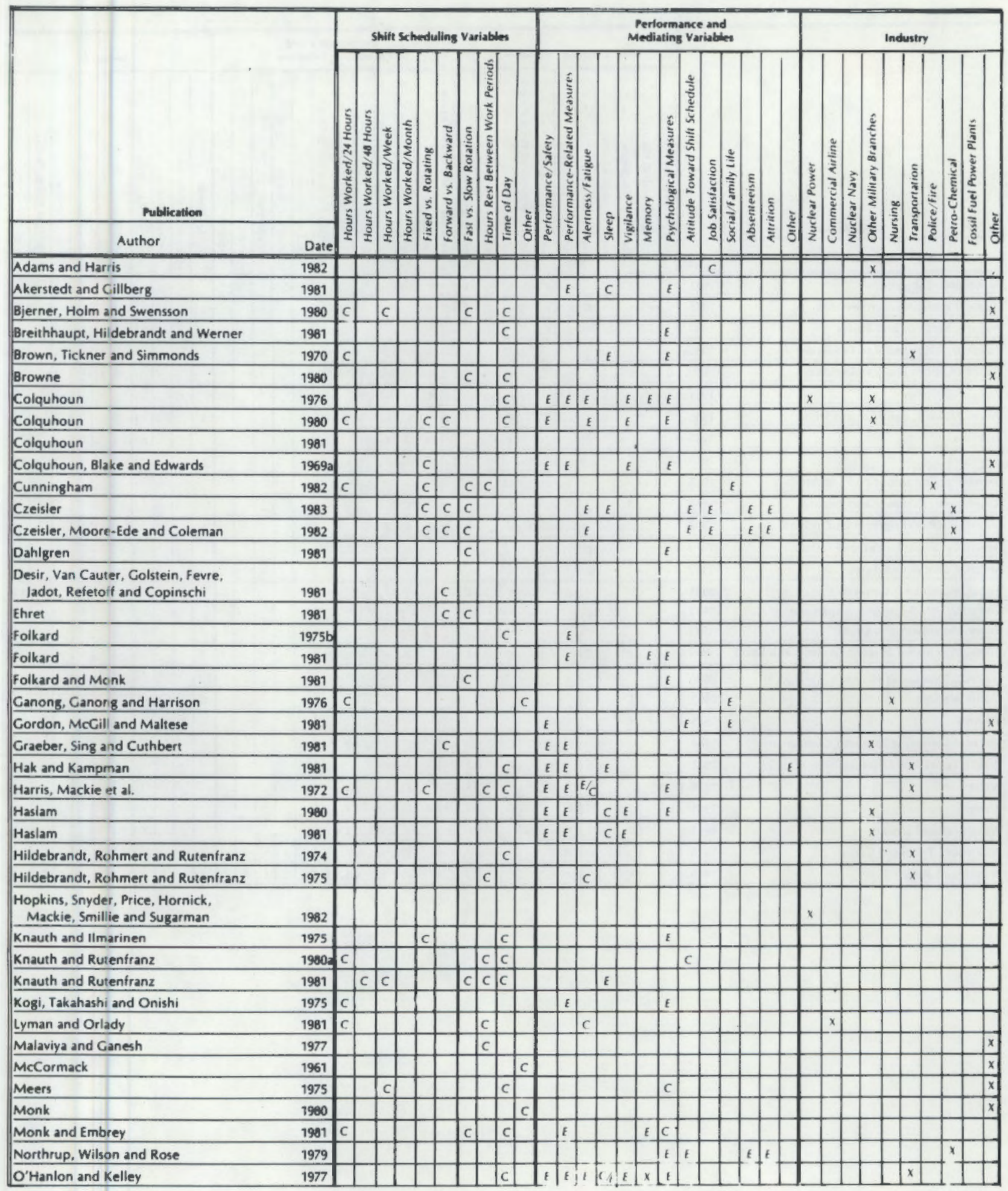

(a) $C=$ cause; $E$ = effect; $X=$ industry. 
TABLE C.I. (contd)

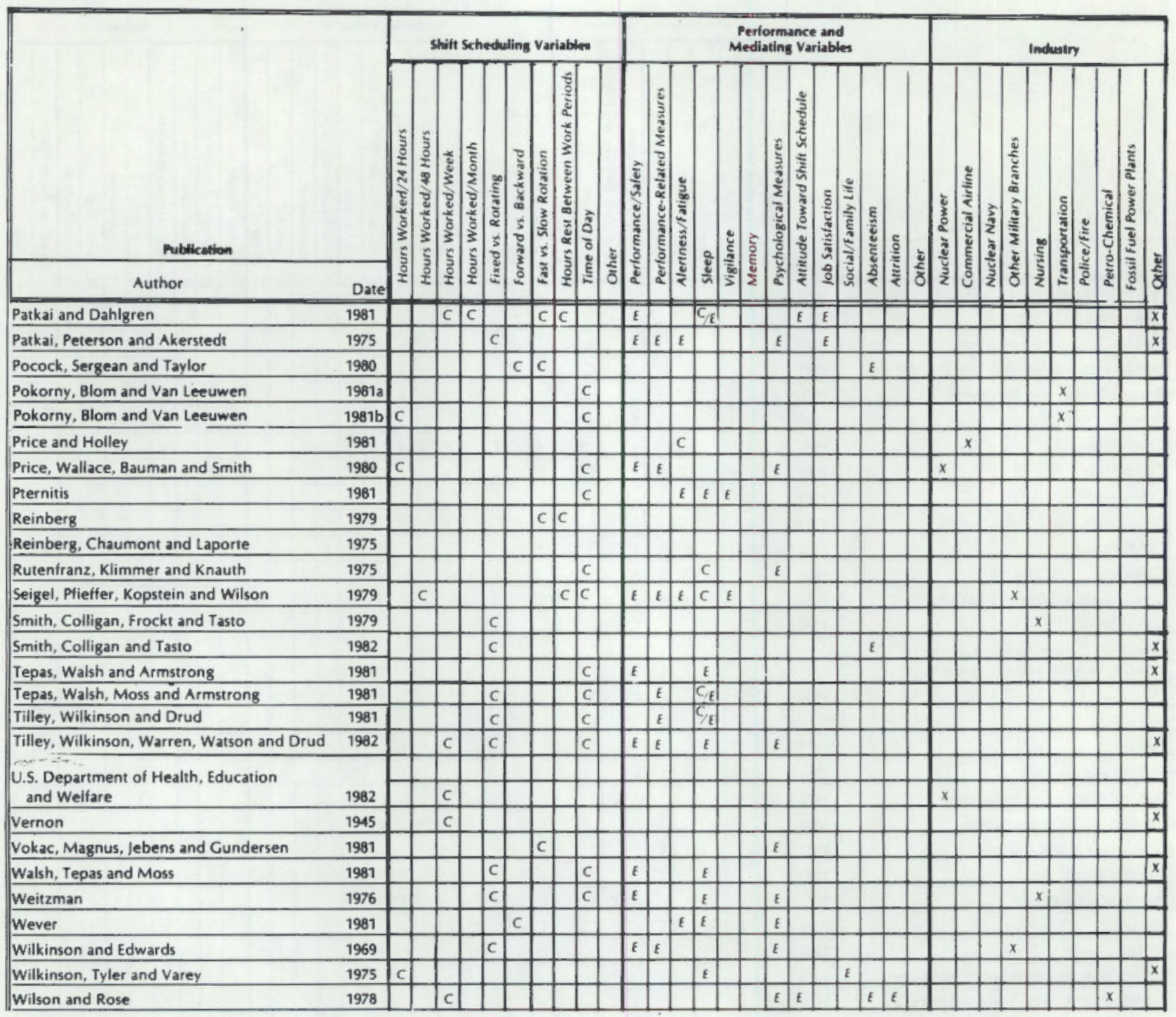


APPENDIX D

ANNOTATED BIBLIOGRAPHY 
AKERSTEDT and TORSVALL. 1978. "Experimental Changes in Shift Schedules -Their Effects on Well-Being."

Sumary: Swedish steelworkers preferred a shift schedule that was more physically demanding because it offered better off-the-job social life.

Objective: To analyze the effect of 2 shift schedules on "well-being." The first shift schedule had 4 crews, rotated every 2-3 days, and had days off on various days of the week. The second shift schedule had 3 crews, rotated once per week, and had weekends off. "Well-being" was measured by quantity and quality of sleep, gastrointestinal complaints, sickness absence, irritability, mood, and attitude toward shift schedule.

Method: A questionnaire was used to study steelworkers at a Swedish plant befora and after a change in shift schedule due to a work slowdown.

Findings: Even though the second schedule (weekly rotation) was physically more punishing, the workers perferred it, probably because it improved their social/family life. The change from the first shift scheduie (1-2 day rotation) to the second schedule (weekly rotation) resulted in a moderate decrease in both physical and mental well-being, and in sleep length. The reasons for these changes are not clear. However, one possible explanation is that the weekly-rotating schedule causes an accumulation of fatigue and/or other negative effects. In contrast, social complaints decreased after the change. This might reflect the fact that the second shift schedule, which had a more regular pattern and weekends off, facilitates planning and participating in fanily and social activities.

Comment/Evaluation: The conclusions stated above are derived from statistically significant tests based on particular questions. However, other questions in the questionnaire that contained only slightly different wording yielded statistically insignificant results. This curious result suggests that the conclusions should be treated cautiously. 
BROWN, TICKNER, and SIMMONOS. 1970. "Effect of Prolonged Driving on Overtaking Criteria."

Sumary: This study provides some quantitative evidence that after 8 to 12 hours of driving, drivers take greater risks in passing vehicles.

Objective: To assess the effect of 12 hours of driving on driver performance.

Method: Six experienced drivers drove for 4 three-hour sessions. There were short breaks between sessions. An observer rode in the car during the 1 st and 4th sessions, but not the 2 nd and 3 rd sessions. The observer noted near accidents, risky overtaking maneuvers, overtaking frequency, and average speed. Criteria for risky overtaking were 1) forward visibility was too restricted, or 2) the maneuver appeared to be incapable of completion unless one or more of the other vehicles changed speed. The subjects were unaware that their overtaking performance was being assessed.

Drivers were also asked to perform a vigilance task: to report the appearance of faint 1 ight-signals that were occasionally displayed on the interior and wing mirrors of the car simultaneously. Oral temperature was also mea sured.

Findings/Conclusions: More "risky" maneuvers were attempted during the 4 th session than during the lst session, as is shown in Table D.1.

TABLE D.1. Data Obtained During the 1st and 4th Sessions of Car Driving

\begin{tabular}{|c|c|c|c|c|c|}
\hline Session & $\begin{array}{l}\text { Risky Overtaking } \\
\text { Maneuvers (mean } \\
\text { number per session) }\end{array}$ & $\begin{array}{l}\text { Overtaking } \\
\text { Frequency } \\
(\%)\end{array}$ & $\begin{array}{l}\text { Average } \\
\text { Speed } \\
\text { (mph) }\end{array}$ & $\begin{array}{l}\text { Vigilance } \\
\text { Response } \\
\text { Time (sec) }\end{array}$ & $\begin{array}{l}\text { Temper- } \\
\text { ature } \\
\text { (C) }\end{array}$ \\
\hline $\begin{array}{l}\text { lst } \\
4 \text { th }\end{array}$ & $\begin{array}{l}3.2 \\
4.8\end{array}$ & $\begin{array}{l}33 \\
24\end{array}$ & $\begin{array}{l}45 \\
41\end{array}$ & $\begin{array}{l}6.2 \\
4.6\end{array}$ & $\begin{array}{l}35.0 \\
35.8\end{array}$ \\
\hline
\end{tabular}

However, Table 0.1 also shows that overtaking frequency and average speed were both lower for the 4 th session. These 2 indicators suggest that the drivers were taking fewer risks during the 4th session. At the same time, the drivers' vigilance response rate actually improved (this might have been due to a practice effect). None of the results in Table D.I were statistically significant. Near accidents were too few and were not reported here.

Comments/Evaluation: This study provides some evidence that drivers take greater risks in passing vehicles after 8 to 12 hours of driving. However, due to the small sample size, somewhat contradictory results, and several methodological problems, the evidence is weak. 
1

$+$ 
CZEISLER, MOORE-EDE and COLEMAN. 1982. "Rotating Shift Work Schedules That Disrupt Sleep Are Improved by Applying Circadian Principles."

Surmary: This is the only major article PNL has found that explicitly advocated forward rotation for shift schedules. The article reports on an experiment at a potash factory in Utah. The experiment, however, does not provide adequate grounds for advocating forward rotation.

Objective: To show that performance and job satisfaction can be improved by adopting a forward rotating shift.

Method: Workers at the potash factory originally had a backward rotating shift schedule, rotating to the next 8-hour shift once each week. Then, some of the employees adopted forward rotating shift schedules. There were two types of forward rotating schedules: one rotated forward each week, the other rotated forward every 3 weeks.

Results: The statistically significant results concerning satisfaction and productivity were all for the 21-day rotation scheme. The direct comparison between forward-and backward-rotating shift schedules of equal length (one week) yielded no statistically significant results. That fact makes it more difficult to discern the degree to which the beneficial effects of the new shift schedule were due to the direction of rotation (forward vs, backward) and to what degree they were due to the speed of rotation (1 week vs. 21 days).

Comment: The authors based their prediction that forward rotation would produce better results on two "circadian principles." Many Eurpean researchers have ibandoned the first principle, and the potash workers themselves abandoned a shift schedule based on the second principle.

The first principle is that work and sleep are generally more efficient during their usual phases in one's circadian cycle. If one must change his/her work/sleep cycle, then it is most efficient to change it in such a way that one's circadian cycle can make the corresponding change quickly; in that way one's work/sleep cycle will once again correspond to his/her circadian cycle. Many European researchers have abandoned this first circadian principle. Instead, they advocate rotating through all three shifts so quickly that one's circadian rhythms remain fixed on the normal daytime rhythm.

The second principle is that people's circadian rhythms generally adapt more quickly if one's wake/sleep cycle is lengthened (which corresponds to a forward-rotating shift), rather than shortened. This principle is based primarily on the fact that most people's endogenous, free-running circadian rhythms have a cycle of about 25 hours (instead of 24 ); thus one's natural body rhythms are already longer than the normal day, and so lengthening the wake/sleep period is only following nature's own predilections.

Strictly speaking, however, the second principle applies only to a two-hour range around the natural 25-hour rhythm, i.e., only to shortening the wake/ sleep period to as few as 23 hours, or to lengthening it to as many as 27 
CZEISLER, MOORE-EDE and COLEMAN (continued)

hours. The authors state: "(one's internal clock) can usually be entrained (reset) by periodic environmental time cues that are within 1 to 2 hours of the endogenous period of 25 hours." The importance of this 23 to 27 hour range to the authors' principles is stated in the introduction to the article: "Because ... most rotating work schedules are outside the (23 to 27 hour) range of entrainment ... we postulated that a practical and effective intervention would be to resolve this aspect of the shift work problem."

The authors' practical intervention was a schedule that started at 8 AM one day, 9AM the following day, and so on. But the workers rejected this schedule, as the authors state in a footnote: "The 21-day ... (forward rotation) schedule was originally designed so that work hours were shifted gradually by 1 or 2 hours per day for 5 days until the new shift time was attained. This procedure was eliminated after a month when it proved inconvenient for the workers' family life and car pooling arrangements: thereafter an 8-hour ... (forward rotation) was undertaken on every $21 \mathrm{st}$ day." Since a shift schedule based on the authors' second circadian principle was impractical, the potash factory's shift schedule became like most other rotating work schedules, shifting 8 hours at once, and thus failing to "resolve this aspect of the shift work problem." 
FOLKARD, MONK, RNAUTH and RUTENFRANZ. 1976. "The Effect of Memory Load on the Circadian Variation in Performance Efficiency Under a Rapidly Rotating Shift System."

Summary: This experiment refutes the "conventional wisdom" that body temperature is positively correlated with all types of performance.

Objective: To assess the relationship between body temperature and performance on three different tasks, with three different memory-load requirements.

Method: A simple search test was devised that systematically varied memoryload requirement. A two-, four-, or six-letter target (combination) was given at the top of each page, followed by lines of various letter combinations. The object of the test was to find all occurrences of the target within the listing. Four times during each working shift the subjects were given the tests, and their body temperature was measured.

Findings: Low memory-load performance was positively correlated with body temperature $(+0.83)$, while high memory-load performance was negatively correlated $(-0.58)$. Both correlations were statistically significant at the .02 level. Figure D.1 is a graph of the results.

Comment/Evaluation: This experiment refutes the "conventional wisdom" that body temperature is positively correlated with all types of performance. Rather, it provides evidence that performance might be inversely related to temperature, might bear no relation to temperature, or might closely parallel temperature, depending upon the short-term memory load of the task under consideration. 
FOLKARD, MONK, KNAUTH and RUTENFRANZ (cont.)

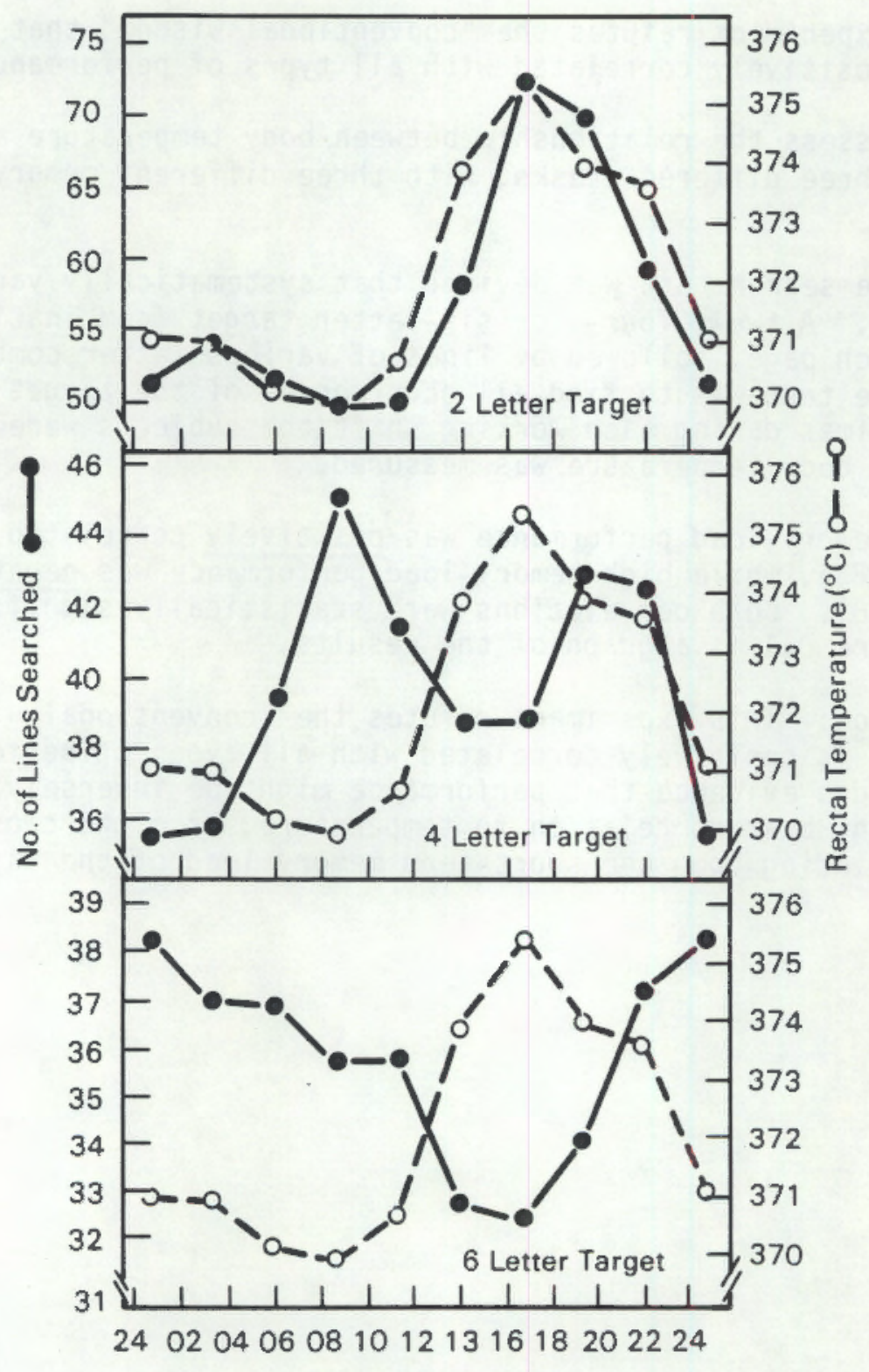

Time of Day

FIGURE D.1. Body Temperature and Three Levels of Memory-Load Tasks (Rentos and Shephard 1976 , p. 174)(a)

(a) Body temperature is indicated by the dotted lines and open circles. Twoletter, 4-letter, and 6-letter memory tests are indicated by solid lines. 
HILDEBRANDT, ROHMERT and RUTENFRANZ. 1974. "12 \& 24 Hour Rhythms in Error Frequency of Locomotive Drivers and the Influence of Tiredness."

Summary: This highly quantitative study of German railroad engineers shows that vigilance reaches a low point between $3 \mathrm{AM}$ and $6 \mathrm{AM}$, and another low point about 1PM. These low points in performance are especially pronounced for engineers who had already worked several hours before reaching those critical times of day.

Objective: To assess the effect of (1) number of hours worked, and (2) time of day, on error frequency.

Method: This highly quantitative study was made possible by the requirement that a particular safety device be installed in locomotives of the Federal German Railway. Although the description of the device is unclear, PNL's understanding is as follows. The device is intended to assure that the engineer is alert; if he/she is not, the brakes of the locomotive will be operated automatically. Periodically, a warning light appears on the control panel. If this warning light is not heeded by pushing a button within 2.5 (or 25?) seconds, an accoustic warning signal (hooter) is sounded. If the engineer then fails to push the button within an additional 2.5 (or 30 ?) seconds, the brakes of the locomotive will be operated automatically. Additional devices recorded the time of day when the hooter was sounded and when the brakes were operated automatically. All of these data were matched with the hour of the day when the engineer started work. (Apparently the speed of the locomotive was also recorded, because errors occurring at speeds of less than $25 \mathrm{~km} / \mathrm{hr}$ were omitted from the study.)

Data were collected for a total of about 6,000 work hours by 1,000 different drivers on 10 locomotives. During that period the hooters were sounded about 20,000 times, for an average of 3.1 times per hour, and the brakes were automatically operated over 2,000 times.

\section{Findings:}

Automatic compulsive braking. Rates of automatic compulsive braking showed peaks between $3 A M$ and $6 A M$, and another peak at 1PM. The rates were computed by dividing the number of brakings by the total distance driven by all locomotives during each hourly period. The average of the 24 rates is equated to 100 in Figure D.2. The horizontal scale measures the time of day. Figure D.2 shows the relative frequency of automatic compulsive braking, as a percent of the day's average, for each hour of the day. 
HILDEBRANDT, ROHMERT and RUTENFRANZ (continued)

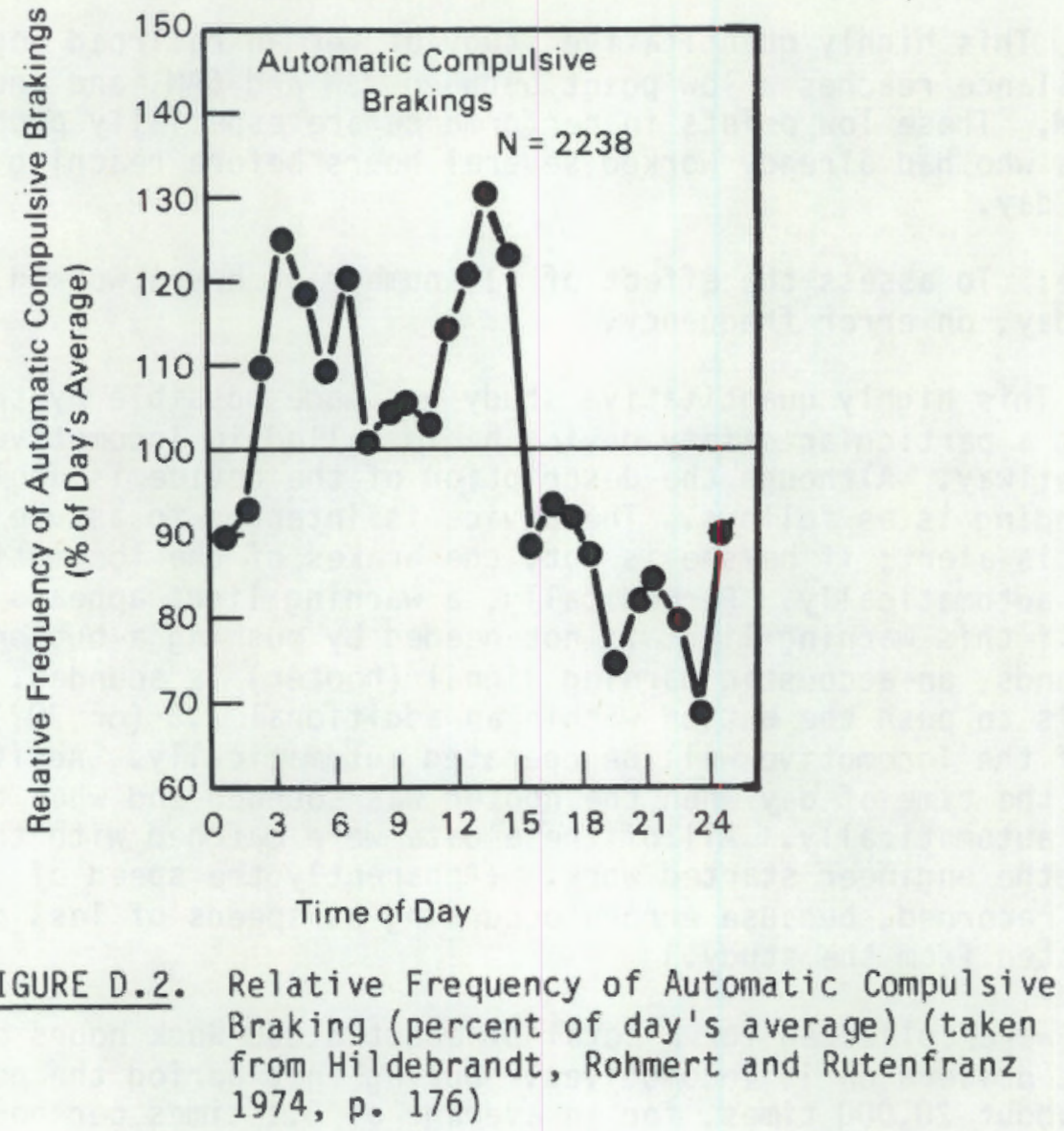

Soundings of the hooter. The frequency of the sounding of the hooter showed a clear peak at 1PM. This finding, however, is of no consequence, since it is caused largely by the fact that daylight makes the warning light less visible. (For the same reason, Figure 0.2 might overstate somewhat the degree of inattention of engineers at 1PM. Daylight, however, would not affect ability to hear the hooter.)

Holding time of day (and hence brightness of daylight) constant, it is possible to compare the error frequencies of engineers who had been on duty for different numbers of hours. Figure $D .3$ shows the frequencies of the hooter sounding between 1-2PM (1300-1400) and between 2-3PM (1400-1500). (The regression line is shown as a dotted line in the figure.) Both frequencies appear to be highly correlated with clocking on time. 
HILDEBRANDT, ROHMERT and RUTENFRANZ (continued)

The effect of the number of hours worked $c$ an also be seen in Figure 0.4 , in which the error frequency for the 1st, 2nd and 3rd hours of a shift are compared with the error frequency for the $4 \mathrm{th}$, 5th and 6 th hours of a shift. In almost all cases, the error frequency is higher toward the latter part of a shift. Furthermore, the peak error frequency at $3 A M$ is almost nonexistent for workers who have oniy been working for 0 to 3 hours. (This finding has implications for workers who work an afternoon shift and work overtime into the night shift.)

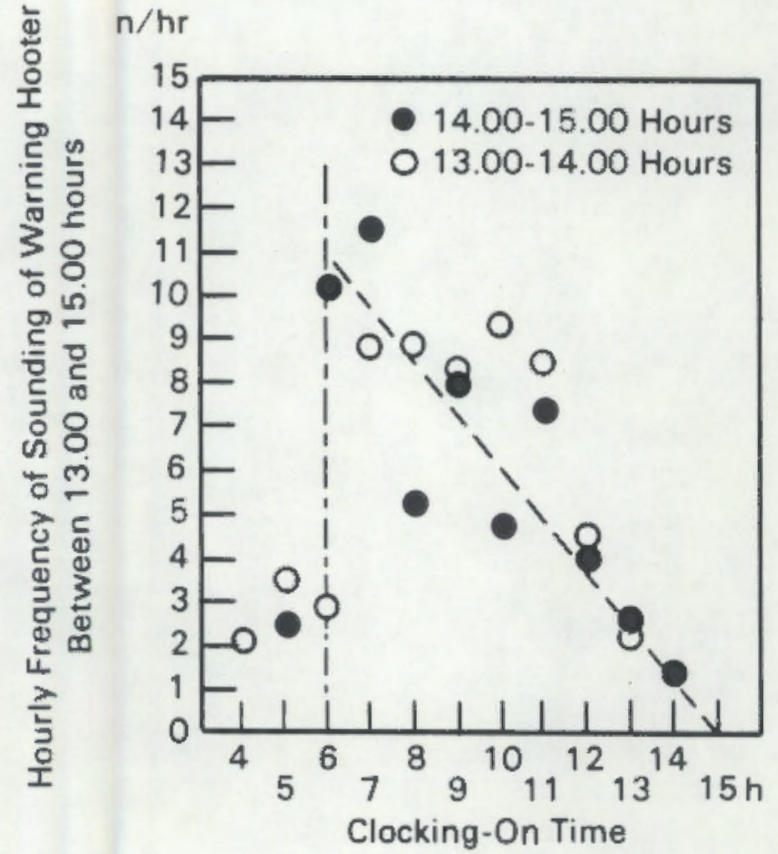

FIGURE D.3. Hourly Frequency of Sounding of Warning Hooter Between 1 PM and 3 PM (related to time of day when shift
started)

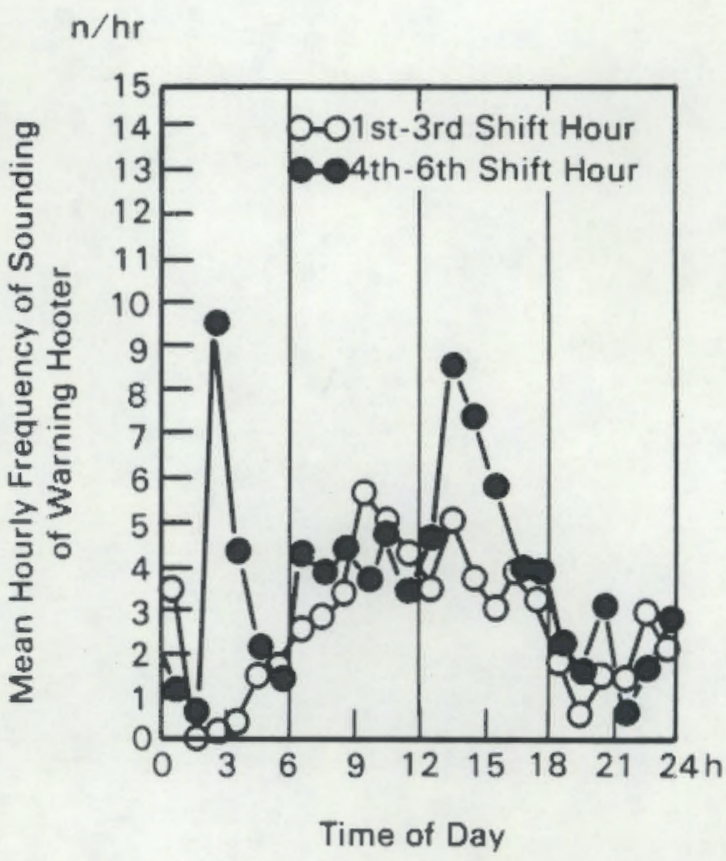

FIGURE 0.4 . Hourly Frequency of Sounding of Warning

(a) Source: Hildebrandt, Rohmert and Rutenfranz 1974, pps. 178 \& 179.

Evaluation: On the whole, this highly quantitative experiment appears to be methodologically sound. Statistical tests are unnecessary; the sample size is so large that any test would undoubtedly indicate statistical significance. The effect of daylight on the visibility of the warning light, however, must be considered in interpreting the results. 


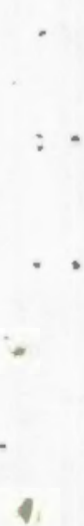


KNAUTH and RUTENFRANZ. 1981. "Duration of Sleep Related to the Type of Shift Work." In Reinberg, Vieux and Andlauer 1981.

Summary: Thousands of sleep diaries of shift workers showed that day sleep averages less than three hours in length. The authors conclude that to avoid sleep deprivation, there should be few night shifts in succession and night shifts should be followed by days off. This is an important argument in the authors' advocacy of rapidly rotating shift schedules. However, the study has a methodological problem.

Objective: To determine the timing and duration of sleep associated with various shift schedules.

Method: Shift workers were asked to fill out a printed diary form each day over a period of 8 consecutive days, writing down the times of working, traveling to and from work, leisure, as well as sleeping during nighttime and daytime.

Results: The study confirms the findings of most other authors that day sleeps are shorter than night sleeps (see Figure 0.5 ). The mean night sleep in connection with morning shifts is shorter than 8 hours. Day sleep before the first night shift averaged 2 hours in length, but the preceding night's sleep averaged 8.8 hours; so the total was nearly 11 hours. Day sleep between two night shifts averaged 6 hours. Day sleep after the last night shift averaged 4 hours. Night sleep before a day shift averaged only 7 hours.

Conclusion: "( $T$ )here should be few night shifts in succession, or if longer night shift periods seem to be unavoidable, allowance should be made for at least the chance of recuperative sleep by having several days off at the end of a run of night shifts. A better solution is to have one day off after each night shift so that compensation can be immediate. Furthermore, morning shifts should not begin too early or sleep deficits will again occur."

Evaluation: This article presents much useful data. The conclusion that there should be few night shifts in succession is an important argument in the authors' advocacy of rapidly rotating shifts. The strength of this conclusion, however, is limited by a methodological problem: the sample included no permanent night shifts, and most likely included few slowly rotating shifts so there are no data to indicate whether workers on those shift schedules can adapt their sleep schedules appropriately. The data only show that the sleep schedules of workers on rapid rotation would not be suitable for slow rotation. Workers on rapidly rotating schedules, however, might deliberately reduce daytime sleep after a night shift knowing that the sleep deficit can be made up soon. 
KNAUTH and RUTENFRANZ (cont.)

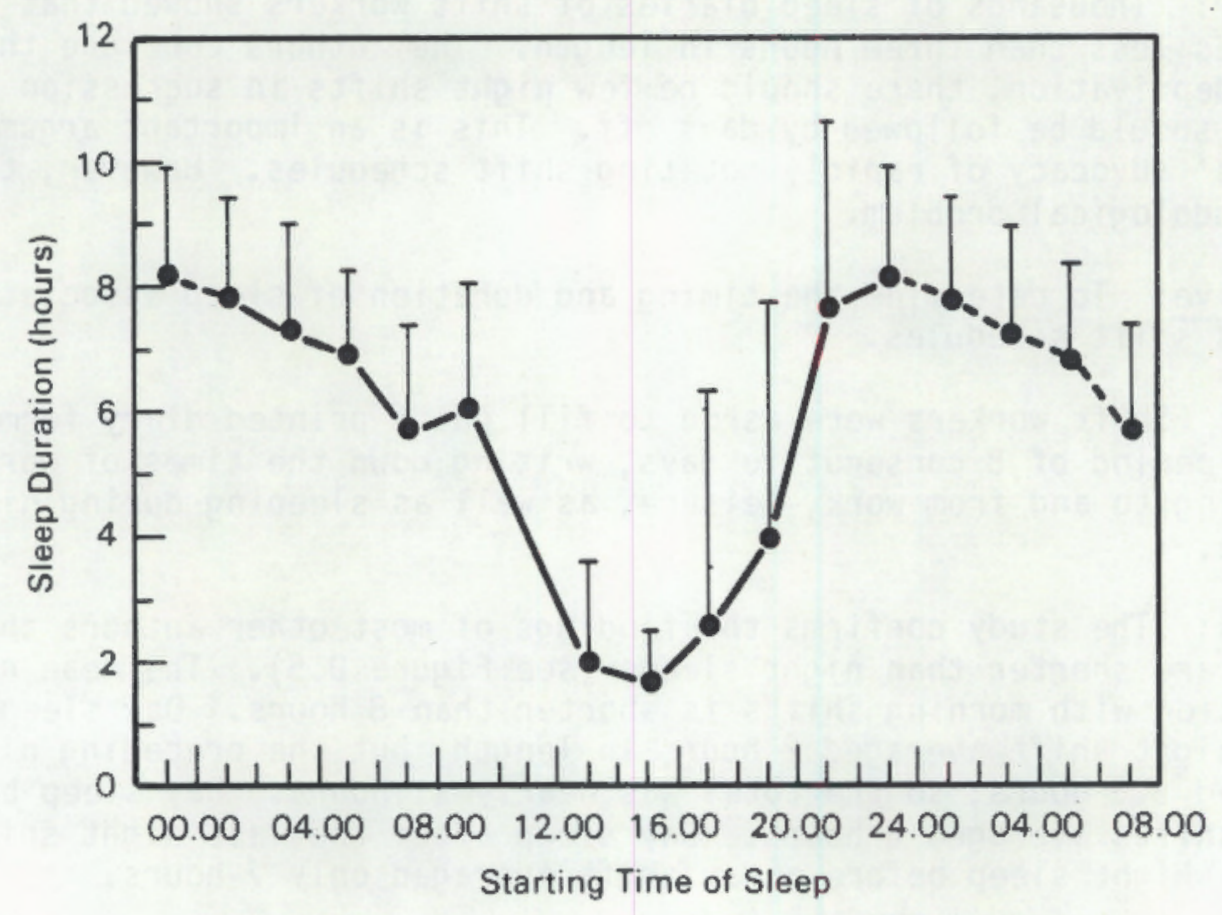

FIGURE D.5. Sleep Duration of Shiftworkers as a Function of Time of Beginning of Sleep (vertical lines = standard deviation) (Reinberg, Vieux and Andlauer 1981, p. 166) 
MACKIE and MILLER. 1978. "Relationships Between Length of Time Driving, Time of Day, and Certain Kinds of Accidents." Chapter 7 in Effects of Hours of Service, Regularity of Schedules, and Cargo Loadings on Truck and Bus Driver Fatique.

Summary: The authors conclude that the probability a truck accident occurring increases with increased driving time.

Objective: To assess the effect of number of hours of driving time on the probability of a truck accident occurring.

Method: In 1974, the Bureau of Motor Carrier Safety, using an accident report form, collected reports from truckers who had had accidents that resulted in death, injury, or property damage in excess of $\$ 2,000$. The report form requested information on the number of hours the driver had been driving at the time of the accident, and how long he would have driven had the accident not occurred. The form also asked the driver's condition at the time of the accident, with a provision to check "dozed at the wheel," which had been checked by several hundred drivers.

The authors compared the actual percentage of accidents with the "expected" percentage of accidents by visual inspection of the graphs shown in Figures $0.6,0.7$, and 0.8 . The "expected" percentage of accidents is the percentage of accidents that would occur after each number of hours of driving time if driving time had no effect on the probability of an accident. Because the actual number of accidents exceeds the "expected" number of accidents for longer driving times, the probability of an accident evidently does increase as driving time increases. This is true for all three types of accidents:

1) "dozing driver" accidents (Figure D.6), 2) single-vehicle accidents (Figure D.7), and 3) multiple-vehicle accidents (Figure 0.8). (Note: In Figures D.6, 0.7 , and 0.8 , the authors use percentages rather than the absolute numbers of accidents.)

Results: Since the actual number exceeded the expected number toward the latter half of the graph, the authors concluded that the probability of an accident increases with increased driving time.

Comment: The authors' data are adequate to support convincingly their conclusions. However, the authors did have better data available for calculating the "expected" values in Figures $0.6,0.7$, and 0.8 . The authors used data from accident reports on the number of hours the driver had driven before the accident and the number of additional hours the driver expected to drive had the accident not occurred. Slightly better estimates of the "expected" values might have been obtained from the authors' random sample of drivers' logs. 
MACKIE and MILLER (cont.)

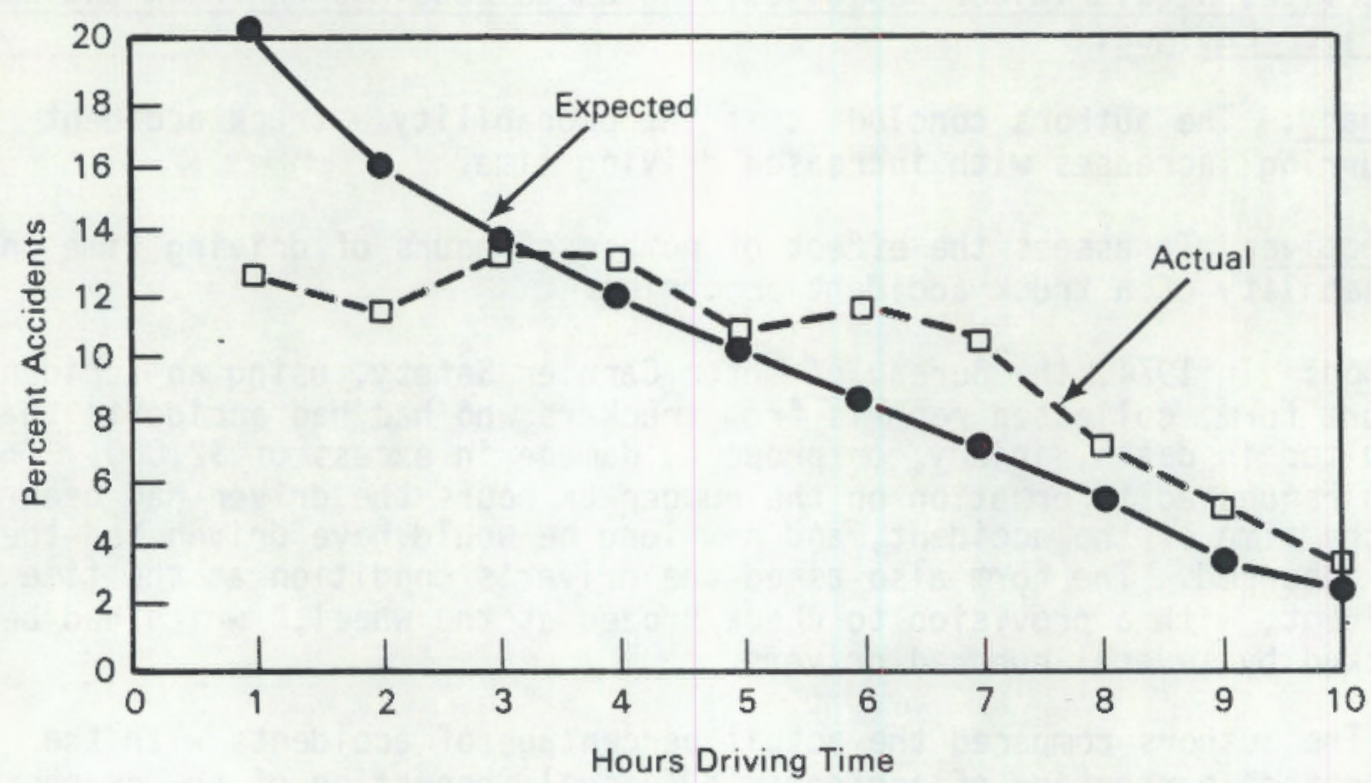

FIGURE D.6. Expected Versus Actual Percentage of Accidents by Driving Time for Dozing-Driver Accidents ( $N=406)$ (Mackie and Miller 1978, p. 54)

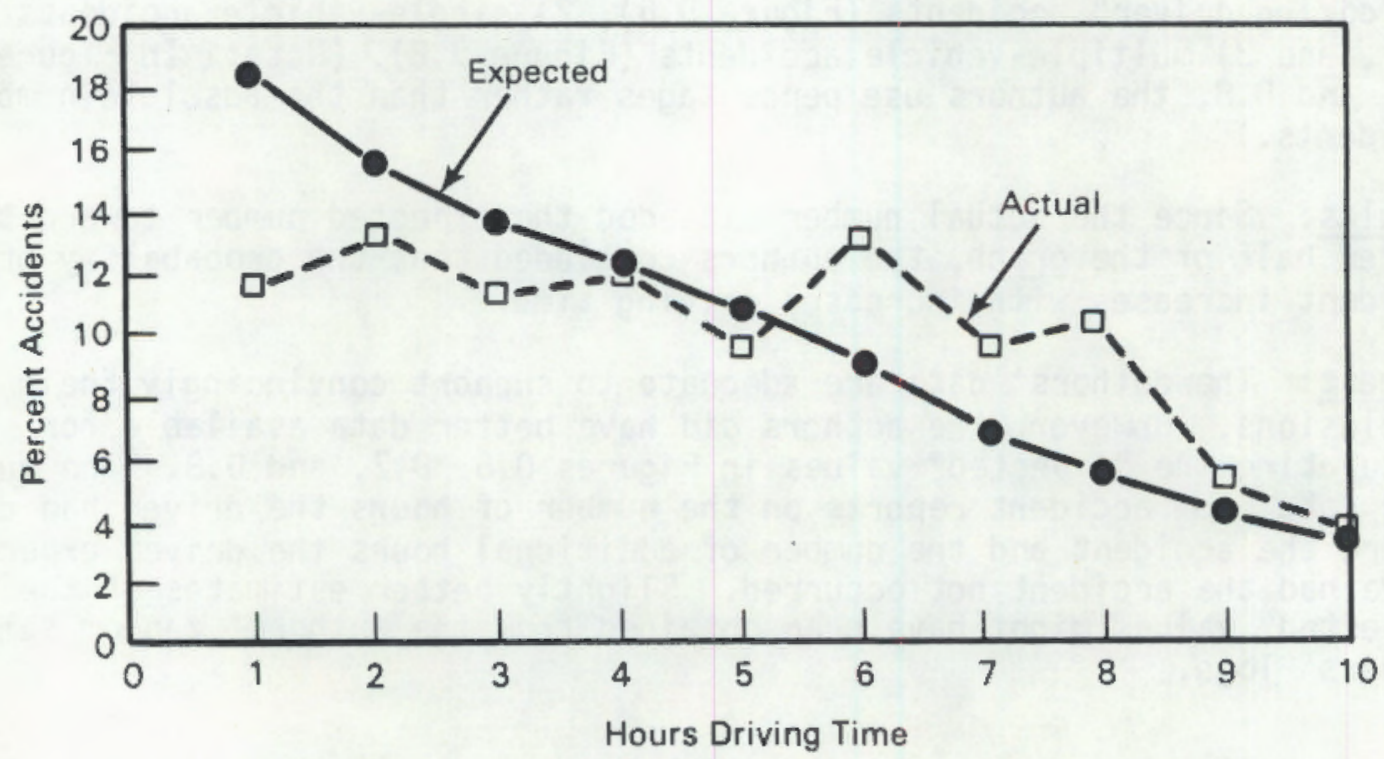

FIGURE D.7. Expected Versus Actual Percentage of Accidents by Driving Time for the Single-Vehicle Accident Sample ( $N=226$ accidents) (Mackie and Miller 1978, p. 59) 
MACKIE and MILLER (cont.)

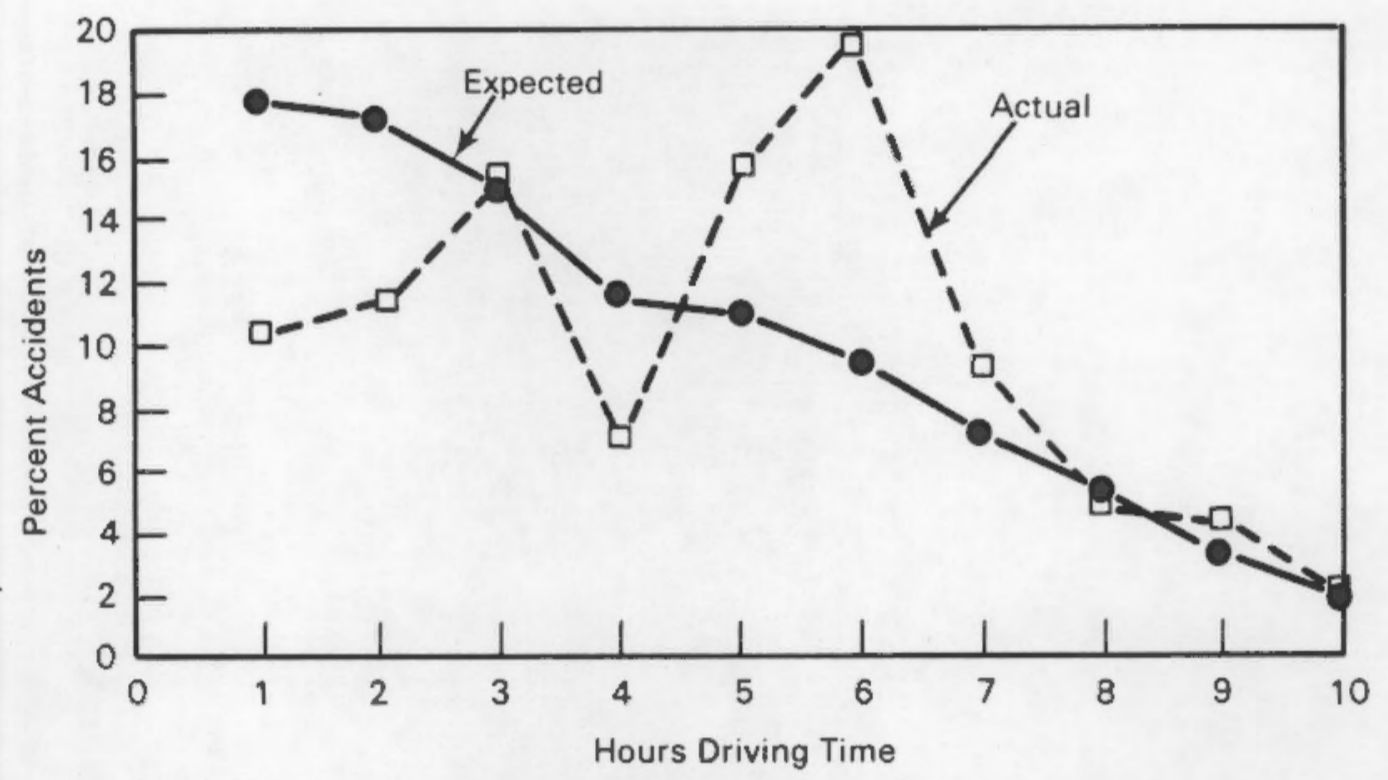

FIGURE D.8. Expected Versus Actual Percentage of Accidents by Driving Time for Accidents Involving Another Vehicle $(\mathrm{N}=116$ accidents) (Mackie and Miller 1978 , p. 60) 

SMITH, COLLIGAN, FROCKT and TASTO. 1979. "Occupationa1 Injury Rates Among Nurses as a Function of Shift Schedule."

Summary: This major effort by the U.S. National Institute for Occupational Safety and Heaith attempted to assess the effect of various shift schedules on occupational injuries. Unfortunately, the results are uninterpretable.

Objective: To assess the effect of four different shift schedules on injury rates. The four shift schedules were: permanent morning, permanent afternoon, permanent night, and rotating (the speed of rotation was not stated; it probably varied among the 12 hospitals studied).

Method: Shift scheduling information was combined with data on occupationa injury over a 6-month period taken from the records of 1,200 nurses in 12 hospitals throughout the United States. All nurses were full-time nonsupervisory personnel who had been in the employ of their respective hospitals for at. least 6 months prior to the study.

Findings: The incidence of the total number of injuries by shift were:

$\begin{array}{ll}\text { Permanent day } & 16.8 \\ \text { Permanent afternoon } & 15.7 \\ \text { Permanent night } & 18.0 \\ \text { Rotating } & 23.3\end{array}$

The rotating shift had the highest incidence. The differences between the rotating shift and the three permanent shifts were statistically significant. The differences among the three permanent shifts were not statistically significant. This evidence seems to indicate that rotating shifts "cause" more injuries. This interpretation is made difficult by the finding that nurses on rotation shifts had significantly more cuts, bruises, and punctures, but significantly fewer sprains and strains. The authors considered several possible explanations, but in the end were unable to explain why the results should be different for the different types of injury.

Comment: Despite the large sample and careful research design, without an explanation of different results for the different types of injury, the interpretation and implications of this major research project will remain unclear.

This report is one of a series of reports describing a major study of shift work conducted by the National Institute for Occupational Safety and Health, which is an agency of the U.S. Department of Health and Human Services. The other major industry in the overall study was the food processing industry (see Smith, Colitigan and Tasto 1982). 


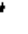


SMITH, COLLIGAN, and TASTO. 1982. "Health and Safety Consequences of Shift Work in the Food Processing Industry."

Sumary: This major study by the U.S. National Institute for Occupational Safety and Health confirmed quantitativeiy that, compared with workers on permanent day and permanent afternoon shifts, workers on permanent night and rotating shifts have more trouble sleeping, have more illness absences, and have more injuries.

Objective: To assess the effect of four different shift schedules on sleep, health, on-the-job injuries, eating patterns, and the use of alcohol and tobacco. The four shift schedules were: permanent morning, permanent

afternoon, permanent night, and rotating (the speed of rotation was not stated; it probably varied among the 8 food processing sites studied).

Method: Data were collected by self-administered questionnaires and by observation of employee health, safety and absence records. To recruit work sites for the study, national organizations of food processing employers were conta:ted for potential participants. The work sites selected represent other companies that volunteered to participate. As such, they cannot be considered to be a representative sample. Employees had to have been on their current shift for at least 6 months to be included in the study. Workers were paid $\$ 5$ for completing the questionnaire; 885 workers responded, for a response rate of $60 \%$.

\section{Findirgs:}

Sleep disturbance. Permanent night workers averaged the least amount of sleep per 24 hours (6.4 hours). Night and rotating workers reported less uninterrupted sleep, and more trouble getting back to sleep once awakened. Tables 0.2 and 0.3 show sleep quality for workers on the four shift schedules.

\section{IABLE D.2. Sleep Quality For Workers on Four Shifts}

Shift

Percent getting less sleep than desired

$\begin{array}{cccc}\text { Morn. } & \text { Afternoon } & \text { Night } & \text { Rotating } \\ 52 & 32 & 52 & 47 \\ 7.0 & 7.4 & 6.4 & 6.8\end{array}$

Average hours of sleep

7.0 
SMITH, COLLIGAN and TASTO (cont.)

TABLE 0.4. Percentage of Shift Workers Reporting

Select Sleep Characteristics

Shift

\begin{tabular}{rrrr}
\hline Morn. & Afternoon & Night & Rotating \\
29 & 36 & 43 & 40 \\
20 & 30 & 38 & 21 \\
68 & 79 & 45 & 32 \\
20 & 17 & & \\
3 & 6 & 24 & 9
\end{tabular}

Health complaints. Only 4 of the 43 self-reported health complaints yielded statistically significant differences, and these 4 were divided among the various shifts.

Eating behavior. Day workers reported the best appetite, with over 93\% reporting a good to excellent appetite. Afternoon and rotating shift workers had the poorest appetite. Rotating workers were asked if their appetites were worse when working on a particular shift; $53 \%$ indicated that night shift produced the worst appetite. There were no differences across shifts in the percentages of workers who drank alcohol or used tobacco.

Health and safety records. The records of 1009 workers were examined. The percentages of male workers with one or more sickness absences in a 6 -month period were as follows:

$\begin{array}{ll}\text { Permanent morning } & 41 \\ \text { Permanent afternoon } & 61 \\ \text { Permanent night } & 52 \\ \text { Rotating } & 71\end{array}$

The mean number of sickness absence days for male workers during a 6-month period were as follows:

$\begin{array}{ll}\text { Permanent morning } & 3.0 \\ \text { Permanent afternoon } & 6.0 \\ \text { Permanent night } & 4.9 \\ \text { Rotating } & 6.1\end{array}$


SMITH, COLLIGAN and TASTO (cont.)

The percentages of male workers having one or more injuries in a 6-month period were as follows:

$\begin{array}{ll}\text { Permanent morning } & 18 \\ \text { Permanent a fternoon } & 26 \\ \text { Permanent night } & 15 \\ \text { Rotating } & 38\end{array}$

Generally, the results of this study indicate that night and rotating shift work, compared to morning work and afternoon shift work, was associated with increased problems relative to personal behavior of the worker, sick absence and work-related injuries.

Comment. This article is one of a series of articles describing a major study on the health and safety implications of shift work in the United States. The study was conducted by The National Institute for Occupational Safety and Health, which is an agency of the U.S. Department of Health and Human Services. The other major occupational group in the overall study was nursing (See Smith, Colligan, Frockt and Tasto 1979). Although much research has been conducted in Europe on health and safety implications of shift work, prior to this study, only one limited shift work study had been conducted in the United States.

Evaludtion. Although this study is a major source of information on this topic, the authors admit that the methodology used does not provide the basis for answering many of the questions raised, especially since it cannot adequately control for self-selection to, or attrition from, particular shifts. These methodological problems could be handled by a prospective, longitudinal study. 
TILLEY et al. 1982. "The Sleep and Performance of Shift Workers."

Summary: The sleep and performance of workers on the night shift are lower than that of workers on the morning or afternoon shifts. Furthermore, the performance of workers on night shift degenerates somewhat over the course of a week. The authors conclude that successive night shifts should be minimized by adopting a rapidly rotating shift schedule. Although the evidence supports the conclusion to some degree, the evidence is weak.

Objectives: To show the effect of five successive days of working each of three shifts (morning, afternoon and night) on (1) electroencephalogram (EEG, "brainwave") recordings of shift workers during their sleep at home, and (2) simple performance tests.

Method: Two groups of six workers on weekly rotating shift schedules were studied for three weeks, i.e., for one complete shift cycle. During the entire three weeks, the following two types of measurements were taken:

(1) EEG recordings were made for each of the five nights for each of the three shifts. (Electrodes were attached to the subject's head before they retired at night.)

(2) Subjects were asked to subjectively rate the quality of their sleep.

(3) Each day the subjects were given two simple performance tests: an unprepared reaction time test and a four-choice serial reaction-time test.

\section{Results concerning sieep:}

- Average duration of sleep for workers on the night, morning and afternoon shifts was $51 / 2,6$, and 7 hours, respectively.

- Among the three shifts, no significant differences existed in quality of sleep as measured by the percent of sleep time in various types of sleep as mea sured by the EEG (Stage W, REM, Stages 1, 2, 3 and 4 sleep).

- Among the three shifts, differences existed in the temporal sequencing of the various types of sleep (but the authors did not explain why this might be important).

- Sleep during the night shift was considered the least refreshing, and there was no discernable difference between morning and afternoon shifts.

Results concerning performance:

- Performance for the night shift was usually the worst. Performance for the afternoon shift was often the best.

- Performance for the night shift usually deteriorated over the course of the week.

- Neither of these results concerning performance was statistically significant, according to the the statistical tests the authors used. 
Conclusion: The authors conclude: "( $T$ ) he best compromise is probably a short-rotation shift cycle with afternoon or rest days preceding and following the night shift. Under this type of system, the loss of sleep experienced during the night shift is only allowed to build up over a relatively short period and will be recovered during the next nocturnal sleep period."

Evaluation:

- Inexplicably, the authors reported no attempt to find a relationship between their two primary measures: sleep and performance.

- The authors report than none of the results using performance measures was statistically significant. Their statistical tests, however, did not account for individual differences; this lack would increase the variance unnecessarily. More appropriate statistical tests might well have indicated statistically significant results.

- If more appropriate statistical tests had indicated statistically significant results, the results would have provided some evidence for the authors' conclusions. However, the evidence still would be weak. Even though night shift performance may be lower than the other shifts, and even though it continues to decline throughout the week, a more relevant criterion is whether nighttime performance is at any time unacceptably low. Even though nighttime performance might be lower than that of the other shifts, it still might be well within the requirements of the situation. Furthermore, the maximum percentage difference between the worst of the night shift and the best (to exaggerate the comparison) of either of the other two shifts is onty $20 \%$, which was an absolute difference of $(3-2.5=0.5$ seconds.

To justify a strong advocacy of rapidly rotating schedules, the authors would have to explain why 0.5 seconds is important; they do not do this. This is basically the limitation of all laboratory experiments: it is difficult to demonstrate how laboratory results are indicative of performance in the plant or on the factory floor. 


\section{REFERENCES AND B IBLIOGRAPHY}

Aanonsen, A. 1964. Shift Work and Health. Universitetsforlaget, 0slo, Norway.

Adams, J., T. Brown and P. Colquhoun et al. 1972. "Nychthemeral Rhythms and Air Trooping: Some Preliminary Results from 'Exercise Medex.'" In Aspects of Human Efficiency: Diurnal Rhythm and Loss of Sleep. The English Universities Press Limited. Distributed in the United States by Crane, Russak \& Co., New York, New York.

Adams, N. E. and L. S. Harris. 1982. A Model and Field Test of the Relationships Between Task Characteristics, Task Environment, Intrinsic and Extrinsic Job Satisfaction, Job Stress and Self-Reported Job Performance. National Technical Information Service, Springfield, Virginia.

Adum, 0. 1975. "Shiftwork of the Professional Drivers." In Experimental Studies in Shift Work, W. P. Colquhoun, S. Folkard, P. Knauth, and J. Rutenfranz, eds., pp. 273-276. Westdeutscher Verlag, Opladen, West Germany.

Advisory Group for Aerospace Research and Oevelopment (AGARD - part of NATO). 1973. "Behavioral Aspects of Aircraft Accidents." In Proceedings of AGARD Conference No. 132. Available from the Defense Technical Information Center, Cameron Station, Alexandria, Virginia.

Agervold, M. 1976. "Shift Work - A Critical Review." Scandinavian Journal of Psychology. 17:181-188.

Airline Pilots Association (ALPA). 1963. "Flight Time - Duty Time Regulations." ALPA Presentation to FAA, ALPA Flight Time-Duty Study Committee, Federal Aviation Administration, Washington, D.C.

Akerstedt, T. 1980a. "Interindividual Differences in Adjustment to Shiftwork." In Studies of Shiftwork, W. P. Colquhoun and J. Rutenfranz, eds. pp. 121-130. Taylor \& Francis Ltd., London, England.

Akerstedt, T. 1980b. "Inversion of the Sleep/Wakefulness Pattern: Effects on Circadian Variations in Psychophysiological Activation." In Studies of Shiftwork, eds. W. P. Colquhoun and J. Rutenfranz, eds., pp. 65-Bo. Taylor \& Francis Ltd., London, England.

Akerstedt, T. and J. E. Froberg. 1975. "Work Hours and $24 \mathrm{~h}$ Temporal Patterns in Sympathetic-Adrenal Medullary Activity and Self-Rated Activation." In Experimental Studies in Shift Work, W. P. Colquhoun, S. Folkard, P. Knauth, and J. Rutenfranz, eds., pp. 78-93. Westdeutscher Verlag, Opladen, West Germany.

Akerstedt, T. and J. E. Froberg. 1976. "Shift Work and Health - Interdisciplinary Aspects." In Shift Work and Health - A Symposium, P. G. Rentos and $R$. Shepard, eds. National Institute for Occupational Safety and Health (NIOSH) Pub lication 76-203. Department of Health, Education and We lf are, Cincinatti, Ohio. 
Akerstedt, T., J. Froberg, L. Levi, L. Torsvall and K. Zamore. 1977. Shift Work and Well-Being. Laboratory for Clinical Stress Research Report, Stockholm, Sweden.

Akerstedt, T. and M. Gillberg. 1981. "The Circadian Pattern of Unrestricted Sleep and Its Relation to Body Temperature, Hormones, and Alertness." In The Twenty-Four Hour Workday: Proceedings of a Symposium on Variations in Work-Sleep Schedules, L. Johnson, D. I. Tepas, W. P. Colquhoun and M. J. Colligan, eds., pp. 605-624. National Institute for Occupational Safety and Health (NIOSH) Publication 81-127. U.S. Department of Health and Human Services, Cincinatti, Ohio.

Akerstedt, T. and L. Torsvall. 1978. "Experimental Changes in Shift Schedules - Their Effects on Wel] Being." Ergonomics. 21(10):849-856.

Akerstedt, T. and L. Torsva11. 1980. "Experimental Changes in Shift Schedules - Their Effects on Well Being." In Studies of Shiftwork, W. P. Colquhoun and J. Rutenfranz, eds., pp. 355-362. Taylor \& Francis Ltd., London, England.

Akerstedt, T, and L. Torsvall. 1981a. "Age, Sleep and Adjustment to Shif twork". In Sleep 1980: Circadian Rhythms, Oreams, Noise and Sleep, Neurophysiology and Therapy. W. P. Koella, ed. Published by S. Karger, New York. Avajlable from the Defense Technical Information Center, Cameron Station, Alexandria, Virginia.

Akerstedt, T. and L. Torsva11. 1981b. "Shift Work: Shift Dependent Well-Being and Individual Differences." Ergonomics. 24(4):265-273.

Aldama, P. H. 1977. "Flight Fatigue: Neourophysiological Data of Diagnostic Interest." Arch of Neurobiology. 25:1-27.

Allenspach, F. R. and L. P. Crocker. 1980. "Guidelines for Utility Management Structure and Technical Resources: Draft Report for Interim Use and Comment." NUREG-0731, Nuclear Regulatory Commission, Washington, D.C.

Alluisj, E. A. 1967. "Methodology in the Use of Synthetic Tasks to Assess Comp lex Performance." Human Factors. 9:375-384.

Alluisi, E. A. 1969. "Sustained Performance". In Principles of Skill Acquisition. E. A. Bilodeau, ed., Academic Press, New York, pp. 59-101.

Alluisi, E. A. 1972. "Influence of Work-Rest Scheduling and Sleep Loss on Sustained Performance." In Aspects of Human Efficiency: Diurnal Rhythm and Loss of Sleep. The English Universities Press Limited. Distributed in the United States by Crane, Russak \& Company, New York, New York.

Alluisi, E. A. and W. D. Chiles. 1967. "Sustained Performance, Work-Rest Scheduling, and Diurnal Rhythms in Man." Acta Psychologica. (Scandinavia) (27) :436-442. 
Alluisi, E. A., W. D. Chiles and T. J. Hall. 1964. "Combined Effects of Sleep Loss and Demanding Work - Rest Schedules on Crew Performance." AMRL-TDR-6463, Aerospace Medical Research Laboratories, Wright-Patterson Air Force Base, Ohio.

Alluisi, E. A., W. D. Chiles, T. J. Hall and G. R. Hawkes. 1963. "Human Group Performance During Confinement". AMRL-TDR-63-87, Aerospace Medical Research Laboratories, Wright-Patterson Air Force Base, Ohio.

Alluisi, E. A., G. D. Coates and B. B. Morgan. 1977. "Effects of Temporal Stressors on Vigilance and Information Processing." In Vigilance: Theory, Operational Performance, and Physiological Correlates, ed. R. R. Mackie. Plenum Press, New York, New York.

Anderson, C. R. 1977. "Locus of Control, Coping Behaviours, and Performance in a Stress Setting. A Longitudinal Study." Journal of Applied Psychology. (62):446-451.

Angersbach, K. 1980. "A Retrospective Cohort Study Comparing Complaints and Diseases in Day and Shift Workers." In Studies of Shiftwork, W. P. Colquhoun and J. Rutenfranz, eds., pp. 363-376. Taylor \& Francis Ltd., London, England.

Angiboust, R. and M. Gouars. 1972. "Tentature d'Evaluation de l'Efficacite' Operationelle du Personnel de l'Aeronautique Militaire au Cours de Veille's Nocturnes." In Aspects of Human Efficiency: Diurnal Rhythm and Loss of Sleep. The English Universities Press Limited. Distributed in the United \$tates by Crane, Russak and Company, New York, New York.

Anonymous. 1978. "Sinking Spells." In U.S. Army Aviation Digest. $24: 12-13$.

Anonymous, 1980a. "Shiftworking: The General Picture." In Studies of Shiftwork, W. P. Colquhoun and J. Rutenfranz, eds., pp. 3-16. Taylor and Francis Ltd., London, England.

Anonymous. 1980b. "The Economics of Shiftworking and Problems Facing Management." In Studies of Shiftwork, W. P. Colquhoun and J. Rutenfranz, eds., pp. 427-438. Taylor and Francis Ltd., London, England.

Aschoff, J. 1980. "Features of Circadian Rhythms Relevant for the Design of Shift Schedules." In Studies of Shiftwork, W. P. Colquhoun and $\mathrm{J}$. Rutenfranz, eds., pp. 19-34. Taylor and Francis Ltd., London, England.

Aschoff, J. 1981. "Circadian Rhythms: Interference With and Dependence on Work-Rest Schedules." In The Twenty-Four Hour Workday: Proceedings of a Symposium on Variations in Work-STeep Schedules, L. Johnson, 0 . I. Tepas, W. P. Colquhoun and M. J. Colligan, eds., pp. 13-50. National Institute for Occupational Health (NIOSH) Publication 81-127. U.S. Department of Health and Human Services, Cincinatti, Ohio. 
Aschoff, J. G., H. Giedke, E. Poppel, and R. Wever. 1972. "The Influence of Sleep-Interruption and of Sleep-Deprivation on Circadian Rhythms in Human Performance." In Aspects of Human Efficiency: Diurnal Rhythm and Loss of Sleep. The English Universities Press Limited. Distributed in the United States by Crane, Russak \& Co., New York, New York.

Aschoff, J. G., K. Hoffman, H. Pohl and R. Wever, 1975, "Re-entrainment of Circadian Rhythms After Phase Shifts of the Zeitgeber." Chronobiologia. $2: 23-78$.

Austin, W. P., et a1. 1965. "Aircrew Fatigue in International Jet Transport Dperations". In Human Engineering Technical Memorandum 8. pp. 1-76, Aeronautical Research Laboratories, Australian Defense Scientific Service, Department of Supply, Australia.

"Aviation Mishap Review." January 1983. Flight Lines. Internal Newsletter of the U.S. Coast Guard, Washington, D. C. Pp. 14-16.

Axelson, R. and U. Lundberg. 1975. "Working Environment of Operating Personnel in a Nuclear Power Plant: Pilot Study Report No. TA 875-R1." Professor Sten Luthander, Engineering Office, Broma, Sweden.

8ader, D. 1973. Report of the Committee on Flight Time Limitations. Civil Aviation Authority, London, England, pp. 1-65.

Baker, M. A., D. H. Holding and M. Loeb. 1984. "Noise, Sex and Time of Day Effects in a Mathematical Task." Ergonomics. 27(1):67-80.

Banderet, L. E., J.W. Stokes, R. Francesconi, D. M. Kowal and P. Naitoh. 1981. "Artillery Teams in Simulated Combat: Performance and Other Measures." In The Twenty-Four Hour Workday: Proceedings of a Symposium on Variations in Work-Sleep Schedules, L. C. Johnson, D. I. Tepas, W. P. Colquhoun and $M$. J. Colligan, eds., pp. 581-604. National Institute for 0ccupational Health (NIOSH) Publication 81-127. U.S. Department of Health and Human Services, Cincinatti, Ohio.

Banks, 0. 1980. "Continuous Shift Work: The Attitudes of Wives." In Studies of Shiftwork, W. P. Colquhoun and J. Rutenfranz, eds., pp. 299-314. Taylor \& Francis Ltd., London, England.

Barreca, N. E. 1972. "Flying Fatigue." U.S. Army Aviation Digest. 23:1416.

Barwood, A. J. 1961. Independent Investigation of Work-Load and Working. Flying Personnel Research Committee Air Ministry, Great Britain, pp. 1-15.

Bauman, M. B., R. F. Pain and M. K. Davidson. 1983. Survey and Analysis of Work Structure in Nuclear Power Plants. EPRI-NP-3141, Electric Power Research Institute, PaTo A7to, California.

Beare, A. N. et. al. 1983. Criteria for Safety-Related Nuclear Power Plant Operator Actions: Initial Simulator to Field Data Calibration. NUREG/CR3092, Nuclear Regulatory Commission, Washington, D.C. 
Beatty, J., S. K. Ahern and R. Katz. 1977. "Sleep Deprivation and the Vigilance of Anesthesiologists During Simulated Surgery." In Vigilance,

R. R. Mackie, ed., Plenum Press, New York, New York, pp. 511-528.

Beck, R. 1964. "Jet Crew Fatigue." Airline Pilot Association Presentation, January 31, 1984, pp. 1-25.

Behar, I., D. A. Kimball and D. A. Anderson. 1976. "Dynamic Visual Acuity in Fatigued Pilots." Report No. 76-24, U. S. Army Aeromedical Research Laboratories, Wright-Patterson Air Force Base, Ohio.

Benson, A. J. 1970. Rest and Activity Cycles for the Maintenance of Efficiency of Personnel Concerned with Military Flight Operations. AGARD Conference Proceedings No. 74. Available from the Defense Technical Information Center, Cameron Station, Alexandria, Virginia.

Berkhout, J. 1970. "Simulated Time-Zone Shifts and Performance Ability: Behavioral, Electroencephalographic and Endocrine Effects of Transient." In Rest and Activity Cycles. NATO/AGARD CP-74-70. Available from the Defense Technical Information Center, Cameron Station, Alexandria, Virginia.

Berkun, M. 1964. "Performance Decrement Under Psychological Stress." Human Factors. $6(1): 21-30$.

Berliner, D. S. 1975. "Joint Committee on Aviation Pathology: VIII. Crew Rest and Nap-0f-the-Earth Flying." Aviation, Space, and Environmental Medicine. 46:1267-1270.

Billings, C. et. al. 1964. "Medical Aspects of Business Aviation." Aerospace Medicine. $37: 783$.

Billings, C., R. C. Chase, J. J. Eggspuehler, and R. J. Gerke. 1968. "Studies of Pilot Performance: II Evaluation of Performance During Low Altitude Flight in Helicopters." Aerospace Medicine. 39:19-31.

Bio Technology, Inc. 1980. Review of Staffing Requirements for Near-Term Operating License Facilities. Prepared by Bio Technology, Inc., Fall Church, Virginia, for the Nuclear Regulatory Comission, Washington, D.C.

Bjerner, B., A. Holm and A. Swensson, 1980. "Diurnal Variation in Mental Performance: A Study of Three Shift Workers." In Studies of Shiftwork, W. P. Colquhoun and J. Rutenfranz, eds., pp. 255-262. Taylor \& Francis Ltd., London, England.

Blake, M. J. F. 1967. "Time of Day Effects On Performance in a Range of Tasks." Psychonomic Science. 9:349-350.

B lake, M. J. F. and D. W. J. Corcoran. 1972. "Introversion-Extraversion and Circadian Rhythms." In Aspects of Human Efficiency: Diurnal Rhythm and Loss of Sleep. The English Universities Press Limited. Distributed in the United States by Crane, Russak \& Company, New York, New York. 
Bockhold, G. and D. R. Roth. 1978. Performance Measurement System for Training Simulators. EPRI NP-783, Prepared by General Physics Corporation for the Electric Power Research Institute, Palo Alto, California.

Bott, T. F., G. L. Hutto, D. K. Baer and P. Haas. 1981. Criteria for Safety Related Nuclear Power Plant Operator Actions: Pressurized Water Reactor Field Data Collection. ORNL/Sub-7688/1 Interim Reports. Prepared for the Nuclear Regulatory Comission, Washington, D.C.

Bott, T. F., E. Kozinsky, C. Crowe, and P. M. Haas. 1981. "Criteria for Safety Related Nuclear Power Plant Operator Actions: Initial Pressurized Water Reactor Simulator Exercises." NUREG/CR-1908, Nuclear Regulatory Comission, Washington, D.C.

Boyle, R. J. 1979. "Will 12-Hour Shift Solve Operator Morale Problem?" Electric Power and Light. $57(11): 32$.

Breithaupt, H., G. Hildebrandt, D. Dohre, R. Josch, U. Sieber and M. Werner. 1980. "Tolerance to Shift of 5 leep, as Related to the Individual's Circadian Phase Position." In Studies of Shiftwork, W. P. Colquhoun and J. Rutenfranz, eds., pp. 177-184. Taylor \& Francis Ltd., London, England.

Breithhaupt, H., G. Hildebrandt and M. Werner. 1981. "Circadian Type Questionnaire and Objective Circadian Characteristics." In Night and Shift Work Biological and Social Aspects, A. Reinberg, N. Vieux and P. Andlauer, eds., pp. 435-440. Pergamon Press, EImsford, New York.

Brictson, C. A., W. McHugh, and P. Naitoh. 1974. "Prediction of Pilot Perfor $\rightarrow$ mance: Biochemical and Sleep-Mood Correlates Under High Work-Load Conditions." In Simulation and Study of High Work load Operations. NAT0/AGARD $\mathrm{CP}-146$, the Defense Technical Information Center, Cameron Station, Alexandria, Virginia.

Brigham, F. R. and E. Bohr. 1978. "Analysis and Presentation of Human Error in Electricity Distributional Switching Systems." Ergonomics. 21(5):405.

Brigham, F. R. and L. Laios. 1975. "Operator Performance in Control of a Laboratory Process Plant." Ergonomics. 18(1):53-66.

Brinton, R. D. May 1983. "Effectiveness of the Twelve-Hour Shift." Personnel Journal. pp. 393-398.

Brockhold, G. and D. R. Roth. 1978. Performance Measurement System for Training Simulators: Interim Report. EPRI-NP-783, the Electric Power Research Institute, Palo Alto, California.

Brody, E. W. 1981. "Nursing Curricula Fuel Shortage." Modern Healthcare. $11(5): 133-134$.

Brown, D. 1975. "A Survey of the Sociological Implications of Studies of Male Shiftworkers." Journal of Occupational Psychology. 48(4):231-240. 
Brown, F. M. and R. Graeber, eds. 1982. Rhythmic Aspects of Behavior. pp. 213-240, Lawrence Erlbaum Assoc. Inc., Hillsdale, New Jersey.

Brown, I. D. 1967. "Measurement of Control Skills, Vigilance, and Performance on a Subsidiary Task During 12 Hours of Car Driving." Ergonomics. $10(6): 665-673$.

Brown, I. D., A. H. Tickner and D. C. V. Simmonds. 1970. "Effect of Prolonged Driving on Overtaking Criteria." Ergonomics. (13):239-242.

Browne, J. J. 1979. "Simplified Scheduling of Routine Work Hours and Days Off." Industrial Engineering. 11(12):27-29.

Browne, R. C. 1980. "The Day and Night Performance of Teleprinter Switchboard Operators." In Studies of Shiftwork, W. P. Colquhoun and J. Rutenfranz, eds., pp. 249-254. Taylor \& Francis Ltd., London, England.

Bruusgaard, A. 1969. "Shift Work as an Occupational Health Problem." In On Night and Shift Work, ed. A. Swensson, pp. 9-14. Institute of OccupationaT Health, Stockholm, Sweden.

Buck, L. and C. B. Gibbs. 1972. "Sleep Loss and Information Processing." In Aspects of Human Efficiency: Diurnal Rhythm and Loss of Sleep, ed. W. P. Colquhoun, pp. 47-58. The English Universities Press Limited. Distributed in the United States by Crane, Russak \& Company, New York, New York.

Buck, L., R. Leonardo and F. Hyde. 1981. "Measuring Impaired Performance With the NRC 'Stressalyzer'." Applied Ergonomics. 12:231-236.

Buley, L. E. 1970. "Experience With a Physiologically Based Formula for Determining Rest Periods on Long-Distance Air Trave1." Aerospace Medicine. $41: 680-683$.

Burcher, W. R. and L. L. Lawrence. 1982. An Analysis of Alternate Work Schedules in Selected Air Force Civil Engineering Squadrons. National Technical Information Service, Springfield, Virginia.

Business Week. December 14, 1978. "Embattled Unions Strike Back at Management." Business Week. p. 56.

Business Week. October 15, 1979. "A Full-Time Job--Weekends Only." Editorial, Business Week. pp. $150 \& 152$.

Cahil1, A. L. and C. F. Ehret. 1981. "Chronobiological Consequences of Various Shiftwork Schedules." International Journal Chronobiology. (7):213.

Caille, E. J. P. et al. 1972. "Loss of Sleep and Combat Efficiency: Effects of the Work/Rest Cycle." In Aspects of Human Efficiency: Diurnal Rhythm and Loss of Sleep, ed. W. P. Colquhoun, pp. 177-194. The English Universities Press Limited. Distributed in U.S. by Crane, Russak \& Company, New York.

Calvasina, E. J. and W. R. Boxx. 1975. "Efficiency of Workers on the FourDay Work Week." Academy of Management Journal. 18:605-610. 
Cameron, C. 1968. "A Questionnaire Study of Fatigue in Civil Aircrew." Department of Supply, Australian Defense Scientific Service, Aeronautical Research Labs, Melbourne, Australia.

Cameron C. 1973. "A Theory of Fatigue". Ergonomics. 16:633-648.

Campbe11, K. B. and R. T. Wilkinson. 1981. "Sleep in the Natural Environment: Psychological Recording and Analyzing Techniques." In The Twenty-Four Hour Workday: Proceedings of a Sympos jum on Variations in Work-Sleep Schedules, L. C. Johnson, D. I. Tepas, W. P. Colquhoun and M. J. Colligan, eds., pp. 721753. National Institute for Occupational Health (NIOSH) Publication 81-127. U.S. Department of Health and Human Services, Cincinatti, Ohio.

Carpenter, J. and P. Cazamian. 1977. Night Work: Its Effects on the Health and Welfare of the Worker. International Labor Organization, Geneva, Switzer land.

Cash, W. 8., Jr. 1979. "How to Calculate An Employee Relations Index." Personnel Journal. 58:172-174, 183-184.

Chakoff, H. E. 1979. "Licensee Performance Evaluation: Phase II." NUREG/CR-0979, Prepared by Teknekron Research Inc., Available from the National Technical Information Service, Springfield, Virginia.

Chakoff, H. E. et. al. January and February 1981. "A Methodological Approach to Nuclear Licensee Performance Evaluation." Nuclear Safety. January and February 22(11).

Chiles, W. 0., E. A. Alluisi and 0. S. Adams. 1968. "Work Schedule and Performance During Confinement." Human Factors. 10:143-196.

Clark, D. 1979. "Safety-Fatigue". Rotor \& Wing International. 13:10-12.

Coates, G. D. 1974. "Interactions of Continuous Work and Sleep Loss with the Circadian Rhythm-II." In Sustained Performance and Recovery During Continuous Operations. B. B. Morgan and C. D. Coates, eds., Interim Technical Report ITR 74-2. Available from the National Technical Information Service, Springfield, Illinois.

Coates, G. D. and E. A. Alluisi. 1970. "Studies of Performance Assessment and Enhancement (Annual Progress Report Sept. 1969-Aug. 1970)." Performance Research Lab., Louisville University, Louisville, Kentucky.

Coates, G. D., R. H. Kirby, N. K. Eberhardt and S. J. Miller. 1979. "Physiological Influences Upon the Work Performance of Men and Women." ITR-79-22, Air Office of Scientific Research, Bolling Air Force Base, Washington, 0 . $C$.

Collier, H. E. 1980. "Preventive Hygiene of Night Workers, and Selection of Night Workers." In Studies of Shiftwork, W. P. Colquhoun and J. Rutenfranz, eds., pp. 97-98. Taylor \& Francis Ltd., London, England. 
Colligan, M. J. 1981. "Methodological and Practical Issues Related to Shiftwork Research." In The Twenty-Four Hour Workday: Proceedings of a Symposium on Variations in Work-Sleep Schedules, L. C. Johnson, D. I. Tepas, W. P. Colquhoun and M. J. Colligan, eds., pp. 261-268. National Institute for Occupational Safety and Health (NIOSH) Publication 81-127. U.S. Department of Health and Human Services, Cincinatti, Ohio.

Collins, J. H. 1981. Identification of the Nuclear Operator Problem at Ontario Hydro and Suggested Solutions. Available from the Defense Technical Information Center, Cameron Station, Alexandria, Virginia.

Collins, W. E. 1976. Some Effects of Sleep Deprivation on Tracking Performance in Static and Oynamic Environments. FAA-AM-76-12, Prepared for the U.S. Department of Transportation, Federal Aviation Administration, Office of Aviation Medicine, Alexandria, Virginia. Available from the National Technical Information Service, Springfield, Virginia.

Colquhoun, W. P. 1970. "Circadian Rhythms, Mental Efficiency and Shift Work". Ergonomics. 13:558-560.

Colquhoun, W. P. 1971. Biological Rhythins and Human Performance. Academic Press, London, England.

Colquhoun, W. P., ed. 1972. Aspects of Human Efficiency: Diurnal Rhythm and Loss of Sleep. Proceedings of a conference held at Strasbourg in July $\overline{1970}$ under the aegis of the NATO Scientific Affairs Division. The English Universities Press Limited. Oistributed in the United States by Crane, Russak \& Co., New York, New York.

Colquhoun, W. P. 1976. "Accidents, Injuries and Shift Work." In Shift Work and Health - A Symposium Held at Cincinnati, Ohio on June 12 and 13,1975 . P. G. Rentos, and R. D. Shephard, eds., PP. 160-175. National Institute for Occupational Safety and Health (NIOSH), Cincinnati, Ohio.

Colquhoun, W. P. 1980. "Simulated Shiftwork." In Studies of Shiftwork, W. P. Colquhoun and J. Rutenfranz, eds., Pp. 191-224. Taylor \& Francis Ltd., London, England.

Colquhoun, W. P. 1981. "Shiftwork Discussion and Conclusion." In The TwentyFour Hour Workday: Proceedings of a Symposium on Variations in Work-STeep Schedules, L. C. Johnson, D. I. Tepas, W. P. Colquhoun and M. J. Colligan, eds., pp. 755-761. National Institute for Occupational Health (NIOSH) Publication 81-127. U.S. Department of Health and Human Services, Cincinatti, Ohio.

Colquhoun, W. P. 1982. "Biological Rhythms and Performance." In Biological Rhythms, Sleep, and Performance, ed. W. B. Webb, pp. 59-86. John Wiley \& Sons, New York, New York.

Colquhoun, W. P., M. J. F. Blake and R. S. Edwards. 1968a. "Experimental Studies of Shift-Work I: A Comparison of 'Rotating' and 'Stablized' 4-Hour Shift Systems." Ergonomics. 11(5):437-453. 
Colquhoun, H. P., M. J. F. Blake and R. S. Edwards. 1968b. "Experimental Studies of Shift-Work II: Stablized 8-Hour Shift Systems." Ergonomics. $11(6): 527-546$.

Colquhoun, W. P., M. J. F. Blake and R. S. Edwards. 1969a. "Experimental Studies on Shift Work." In On Night and Shift Work, ed. A. Swensson. National Institute of Occupational Health, Stockholm, Sweden.

Colquhoun, W. P., M. J. F. Blake and R. S. Edwards. 1969b. "Experimental Studies of Shift-Work III: Stablized 12-Hour Shift Systems." Ergonomics. 12(6):865-882.

Colquhoun, W. P. and R. S. Edwards. 1980. "Circadian Rhythms of Body Temperature in Shiftworkers at a Coalface." In Studies of Shiftwork, W. P. Colquhoun and J. Rutenfranz, eds., pp. 42-48. Taylor \& Francis Ltd., London, Engl and.

Colquhoun, W. P. and S. Folkard. 1980. "Personality Differences in BodyTemperature Rhythm, and Their Relation to its Adjustment to Night Work." In Studies of Shiftwork, W. P. Colquhoun and J. Rutenfranz, eds., pp. 143149. Taylor \& Francis Ltd., London, England.

Colquhoun, W. P., S. Folkard, P. Knauth, and J. Rutenfranz, 1975. Experimental Studies in Shift Work. Westdeutscher Verlag, 0laden, West Germany.

Colquhoun, W. P., P. Hamilton and R. S. Edwards. 1980. "Effects of Circadian Rhythm, Sleep Deprivation, and Fatigue on Watch-Keeping Performance During the Night Hours." In Studies of Shiftwork, W. P. Colquhoun and J. Rutenfranz, eds., pp. 225-262. TayTor \& Francis Ltd., London, England.

Colquhoun, W. P. and J. Rutenfranz, eds. 1980. Studies of Shiftwork. Taylor \& Francis Ltd., London, England.

Conroy, R. T. W. L. and J. N. Mills. 1969. "Circadian Rhythms and Shift Working." In On Night and Shift Work, ed. A. Swensson, pp. 42-46. National Institute for Occupational Health, Stockholm, Sweden.

Corkindale, K. G. G. 1973. Behavioural Aspects of Aircraft Accidents. AGARD Conference Proceedings No. 132, Available from the National Technical Information Service, Springfield, Virginia.

Crane, J. E. 1961. "Survey of Fatigue and Tension Among Jet Crews." Stamf ord, Connecticut.

Crane, J. E. 1963. "The Time Zone Fatigue Syndrome." The Flying Physician. 7:19-22.

Creamer, L. R., 0. E. Wheeler and R. F. Gabriel. 1970. "Human Error Research and Analysis Program: Data Analys is and Fatigue Studies." AD-869-266. Available from the Defense Technical Information Center, Cameron Station, Alexandria, Virginia. 
Cunningham, J. B. 1982. "Compressed Shift Schedules: Altering the Relationship Between Work and Non-Work." Public Administration Review. 42(5):438447.

Czeisler, C. A. July 31, 1982. "Sleep Cycles Affect Job, Study Says." Los Angeles Times.

Czeisler, C. A. 1983. Testimony 8efore the Subcomnittee on Investigations and Oversight of the Committee on Science and Technology, March 23, 1983, U, S. House of Representatives, Washington, D.C.

Czeisier, C. A. and C. Guilleminault. 1980. REM Sleep: Its Temporal Distribution. Raven Press, New York, New York.

Czeis"er, C. A., M. C. Moore-Ede and R. M. Coleman. 1982. "Rotating Shift Work Schedules That Disrupt Sleep Are Improved by Applying Circadian

Principles." Science. 217(4558):460-463.

Czeis er, C. A., G. S. Richardson, R. M. Coleman, J. C. Zimmerman, M. C. MooreEde. W. C. Dement and E. D. Weitzman. 198la. "Chronotherapy: Resetting the Circadian Clocks of Patients With Delayed Sleep Phase Insomnia." Sleep. $4: 1-21$.

Czeis er, C. A., G. S. Richardson, J. C. Zimmerman, M. C. Moore-Ede and E. D. Weitzman. 1981b. "Entrainment of Human Circadian Rhythms by Light-Dark Cyc"es: A Reassessment." Photochem. Photobiol. 34:239-247.

Czeis er, C. A., E. D. Weitzman, M. C. Moore-Ede, J. C. Zimmerman and R. S. Knauer. 1980. "Human Sleep: Its Duration and Organization Depend on Its Circadian Phase." Science. 210:1264-1267.

Dahlgren, K. 1981. "Adjustment of Circadian Rhythms to Rapidly Rotating Shift Work - A Field Study of Two Shift Systems." In Night and Shift Work Biological and Social Aspects. A. Reinberg, N. Vieux and P. AndTauer, eds., pp. 357-364. Pergamon Press, Elmsford, New York.

Davis, L. T., T. J. Mazour and R. Zaret. 1981. Analysis, Conclusions and Recommendations Concerning 0perator Licensing. NUREG/CR-1750, Prepared by Personnel Decisions, Inc. for the Nuclear Regulatory Commission, Washington, D.C.

Day, K. 1983. "Statement of Potential Testimony." Testimony before the Subcommittee on Investigations and Oversight of the Committee on Science and Technology, U.S. House of Representatives, Washington, D.C., March 23, 1983.

Day, N. R. 1976. "Fatigue in the Safety Equation." Business and Commerical Aviation. pp. 148-161. 
DeHart, R. L. 1967. "Work-Rest Cycle in Aircrewmen Fatigue." Aerospace Medicine. 37:1174-1179.

DeLa Mare, G. and S. Shimmin. 1964. "Preferred Patterns of Duty in a Flexible Shift-Working Situation." Occupational Psychology. 38:203-214.

Desir, D., E. Van Cauter, J. Golstein, M. Fevre, C. Jadot, S. Refetoff and G. Copinschi. 1981. "Adaptation of the Nycthemeral Variations of Pituitary and Related Hormones after Transmeridian Transportation in Normal Man." In Night and Shift Work - Biological and Social Aspects. A. Reinberg, N. Vieux and P. Andlauer, eds., pp. 365-366. Pergamon Press, Elmsford, New York.

Dexter, H. E. 1975. "Pilot Fatigue Study: A First Look." Air Line Pilot. (June):18-19.

Dinges, 0. 1981. "Performance after Naps in Sleep-Conducive and Alerting Environments." In The Twenty-Four Hour Workday: Proceedings of a Symposium on Variations in work-Sleep Schedules, L. C. Johnson, D. I. Tepas, W. P. Colquhoun and M. J. Colligan, eds., pp. 677-692. National Institute for Occupational Safety and Health (NIOSH) Publication 81-127. U.S. Department of Health and Human Services, Cincinatti, Ohio.

DiSalvo, R., A. Gery and J. Pittman. 1982. A Feasibility Study of Using Licensee Event Reports for a Statistical Assessment of the Effect of Overtime and Shift Work on Operator Error. NUREG-0872 Rx, Nuclear Regulatory Commission, Washington, 0 . C.

Dobbins, D. A. et. al. 1963. "Vigilance Under High-Way Oriving Conditions". Perceptual and Motor Skills. 16:38.

Dowd, P. J. and F. H. Brunstetter. 1980. Crew Stress and Fatigue in the Pave Low III System. SAM-TR-80-26. School of Aerospace Medicine, Brooks Air Force Base, Texas.

Duncan, C. E., M. G. Sanders and K. A. Kimball. 1980. Evaluation of Army Aviator Human Factors (Fatigue) in a High Threat Environment. Report No. 80-8, U.S. Army Aeromedica] Research Laboratory, Fort Rucker, Alabama.

Dunham, R. B. 1977. "Shift Work: A Review and Theoretica? Analysis". Academy of Management Review. 2:624-634.

Dunham, R. B. 1979. Community Structure and the Experiences of Shift Workers. Report No. OLM91-55-76-70-1, Employment and Training Administration, Washington, $D C$.

Dunnette, M. D. 1976. Handbook of Industrial and Organizational Psychology. Rand, Santa Monica, California.

Ehrenstein, w. and W. Muller-Limmroth. 1975. "Changes in Sleep Patterns Caused by Shift Work and Traffic Noise." in Experimental Studies in Shift Work, W. P. Colquhoun, S. Folkard, P. Knauth and J. Rutenfranz, eds., pp. $\overline{48-5} 6$. Westdeutscher Verlag, Opladen, West Germany. 
Enret, C. F. 1983. Overcoming Jet Lag. Berkley Publishing Corporation, New York, New York.

Enret, C. F. 1981. "New Approaches to Chronohygiene for the Shift Worker in The Nuclear Power Industry." In Night and Shift Work: Biological and Social Aspects, A. Reinberg, N. Vieux and P. Andlauer, eds., pp. 263-270. Pergamon Press, Elmsford, New York.

Ehret, C. F. 1983. "Future Perspectives for the Application of Chronobiological Knowledge in Occupational Work Scheduling." Testimony before the Subcomittee on Investigations and Oversight of the Committee on Science and Technology, U.S. House of Representatives, Washington, D.C., March 23, 1983.

Ehret, C. F. and A. L. Cahi1l. 1981. Patterns of Shift Work in the Power Industry: The Need for Circadian Chronohygiene in Bioengineering at the ManMachine Interface. NUREG/CP-0031, Vol. 2. Nuclear Regulatory Comission, Washington, D.C.

Ehret, C. F., D. R. Groh and J. C. Meinert. 1978. "Circadian Dyschronism and Chronotypic Ecophilia as Factors in Aging and Longevity." In Aging and Biological Rhythms, H. V. Samis and S. Capobianco, eds., pp. 185-213. Plenum Publishing Co., New York, New York.

Ehret, C. F., D. R. Groh and J. C. Meinert. 1980. "Considerations of Diet on Alleviating Jet Lag." In Proceedings of the NATO Advanced Study of Institute on Principles and Applications of Chronobiology to Shifts in Schedules with Emphasis on Man. L. E. Scheving and F. Halberg, eds., Sijhoff and Noordhoff, International Publishers, the Netherlands.

Ellingstad, V. S and N. W. Heimstra. 1970. "Performance Changes During the Sustained Operation of a Complex Psychomotor Task." Ergonomics. 13(6):693705 .

Embrey, D. E. 1983. The Use of Performance Shaping Factors and Quantified Expert Judgment in the Evaluation of Human Reliability: An Initial Appraisal. NUREG/CR-2986, Nuclear Regulatory Comnission, Washington, D.C.

Endo, S., T. Yamamoto and M. Sasaki. 1981. "Effects of Time Zone Changes on Sleep." In The Twenty-Four Hour Workday: Proceedings of a Symposium on Varjations in Work-S leep Schedules, L. C. Johnson, D. I. Tepas, W. P. Colquhoun and M. J. Colligan, eds., pp. 517-548. National Institute for Occupational Safety and Health (NIOSH) Publication 81-127. U.S. Department of Health and Human Services, Cincinatti, Ohio.

Enright, 3. T. 1965. "Synchronization and Ranges of Entrainment". In Circadian Clocks. North Holland Publishing Company, Amsterdan, North Holland, pp. 112-124.

Evensen, D. A. 1982. Ship's Force Overhaul Management System: An Evaluation of Its Effects on Shipboard Authority. Available from National Technical Information Service, Springfield, Virginia. 
Finlayson, F. C. and J. Ims. 1983. "Nuclear Power Safety Reporting System". Volumes I and II, NUREG/CR-3119, Nuclear Regulatory Commission, Washington, D.C.

Finley, B. H., R. G. Webster and A. D. Swain. 1974. "Reduction of Human Errors in Field Test Programs." Human Factors. 16:215-222.

Finn, P. 1981. "The Effects of Shift Work on the Lives of Employees." Monthly Labor Review. $104: 31$.

Finnegan, J. P., T. W. Rettig and G. A. Rau. 1979. The Role of Personnel Errors in Power Plant Equipment Reliability. EPRI-AF-1041, Electric Power Research Institute, Palo Alto, California.

Folkard, S. 1975a. "Diurnal Variation in Logical Reasoning." Brit. J. Psychol. 66:1-8.

Folkard, S. 1975b. "The Nature of Diurnal Variations in Performance and Their Implications for Shift Work Studies." In Experimental Studies in Shift Work, W. P. Colquhoun, S. Folkard, P. Knauth and J. Rutenfranz, eds., pp. 113-122. Westdeutscher Verlag, Opladen, West Germany.

Folkard, S. 1981. "Shiftwork and Performance." In The Twenty-Four Hour Workday: Proceedings of a Symposium on Variations in Work-Sleep Schedules, L. C. Johnson, D. I. Tepas, W. P. Colquhoun and M. J. Colligan, eds., pp. 347374. National Institute for Occupational Safety and Health (NIOSH) Publication 81-127. U.S. Department of Health and Human Services, Cincinatti, Ohio.

Folkard, S. and T. H. Monk. 1979. "Shiftwork and Performance." Human Factors. 21:483-492.

Folkard, S. and T. H. Monk. 1980. "Shiftwork and Performance." In Studies of Shiftwork, W. P. Colquhoun and J. Rutenfranz, eds., pp. 263-272. Taylor \& Francis Ltd., London, England.

Folkard, S. and T. H. Monk. 1981. "Individual Differences in the Circadian Response to a Weekly Rotating Shift System." In Night and Shift Work 8 iological and Social Aspects. A. Reinberg, N. Vieux and P. Andlauer, eds., pp. 367-374. Pergamon Press, Elmsford, New York.

Folkard, S., T. H. Monk, P. Knauth and J. Rutenfranz. 1976. "The Effect of Memory Load on the Circadian Variation in Performance Efficiency Under a Rapidly Rotating Shift System." Ergonomics. 19(4):479-488.

Folkard, S., T. H. Monk and M. C. Lobban. 1979. "Towards a Predictive Test of Adjustment to Shift Work." Ergonomics. 22:79-91.

Folkard, S., T. H. Monk and M. C. Lobban. 1980a. "Short- and Long-Term Adjustment of Circadian Rhythms In 'Permanent' Night Nurses." In Studies of Shiftwork, W. P. Colquhoun and J. Rutenfranz, eds., pp. 49-64. Taylor \& Francis Ltd., London, England. 
Folkard, S., T. H. Monk and M. C. Lobban. 1980b. "Towards a Predictive Test of Adjustment to Shiftwork." In Studies of Shiftwork, W. P. Colquhoun and J. Rutenfranz, eds., pp. 163-176. Taylor \& Francis Ltd., London, England.

Foret, J., 0. Benoit and B. Merle. 1981. "Circadian 'Profile' of Short and Long Sleepers." In The Twenty-Four Hour Workday: Proceedings of a Symposium on Variations in Work-Sleep Schedules, L. C. Johnson, D. I. Tepas, W. P. Colquhoun and M. J. Colligan, eds., pp. 625-640. National Institute for Occupational Health (NIOSH) Publication 81-127. U.S. Department of Health and Human Services, Cincinatti, Ohio.

Foret, J. and G. Latin. 1972. "The Sleep of Train Drives: An Example of the Effects of Irregular Work Schedules on Sleep." In Aspects of Human Efficiency: Diurnal Rhythm and Loss of Sleep." The English Universities Press Limited. Distributed in the U. S. by Crane, Russak \& Company, New York, New York.

Fort, A., M. T. Harrison and J. N. Mills. 1973. "Psychometric Performance: Circadian Rhythms and the Effects of Rising Body Temperature." Journal of Psychology. 231:114-115.

Fort, A. and J. N. Mills. 1972. "Influence of Sleep, Lack of Sleep and Circadian Rhythm on Short Psychometric Tests." In Aspects of Human Efficiency: Diurnal Rhythm and Loss of Sleep. The English Universities Press Limited. Distributed in the United States by Crane, Russak \& Company, New York, New York.

Fournet, M. G. June 1983. "The 12-Hour Shift: A Workable Alternative." The Police Chief. pp. 57-59.

Frank, J. A. 1981. The Effects of Economic Change on Employees Health and Absenteeism. Report No. DLMA91-06-79-45-1, Employment and Training Administration, Washington, $D C$.

Frazier, T. W., J. A. Rumel and H. S. Liscomb. 1968. "Circadian Variability in Vigilance Performance." Aerospace Medicine. 30:383-395.

Freivalds, A. 1981. "Quantification and Desynchronization of Human Performance Circadian Rhythms." In AIIE Proceedings, Spring 1981. pp. 146-155.

Froberg, J. 0. 1981. "Shift Work and Irregular Working Hours in Sweden: Research Issues and Methodological Problems." In Twenty-Four Hour Workday: Proceedings of a Symposium on Variations in Work-S leep Schedules, L. C. Johnson, D. I. Tepas, W. P. Colquhoun and M. J. Colligan, eds., pp. 289304, National Institute for Occupational Safety and Health (NIOSH)

Publication 81-127. U.S. Department of Health and and Human Services, Cincinatti, Ohio. 
Froberg, J., C. G. Karlsson, L. Levi and L. Lidberg. 1972. "Circadian Variations in Performance, Psychological Ratings, Catecholamine Excret ion and Urine Flow During Prolonged Sleep Deprivation." In Aspects of Human Efficiency: Diurnal Rhythm and Loss of Sleep. The English Universities Press Limited. Distributed in the United States by Crane, Russak \& Co, New York, New York.

Froberg, J., C. G. Karlsson, L. Levi, L. Lidberg and K. Seeman. 1969. "Circadian Rhythms in Catecholamine Excretion, Psychomotor Performance, and Ratings of Stress and Fatigue During a 75-Hour Vigil." In On Night and Shift Work, ed. A. Swensson, pp. 47-63. National Institute of Occupational Health, Stockho 1m, Sweden.

Frost, P. J. and J. Muhammad. 1979. "Shift Work, Attitudes, and Reported Behavior: Some Associations Between Individual Characteristics and Hours of Work and Leisure." Journal of Applied Psychology. 64(1):77-81.

Fuller, C. A., F. M. Sulzman and M. C. Moore-Ede. 1978. "Thermoregulation is Impaired in an Environment Without Circadian Time Cues." Science. 199:794796.

Fuller, C. A., F. M. Sulzman and M. C. Moore-Ede. 1981. "Shift Work and the Jet-Lag Syndrome: Conflicts Between Environmental and Body Time." In The Twenty-Four Hour Workday: Proceedings of a Symposium on Variations in WorkSleep ScheduTes, L. C. Johnson, D. I. Tepas, W. P. Colquhoun and M. J. Colligan, eds., pp. 305-320. National Institute for Occupational Health (NIOSH). Publication No. 81-127. U.S. Department of Health and Human Services, Cincinatti, Ohio.

Gale, A. and J. Edwards. 1981. Physiological Correlates of Human Behavior. Academic Press, Inc., New York, New York.

Ganong, W. L., J. M. Ganong and E. T. Harrison. 1975. "Twelve-Hour Shift: Better Quality, Lower Cost." Journal of Nursing Administration. 6(2):1729.

Gartner, W. B. and M. R. Murphy. 1976. "Pilot Workload and Fatigue: A Critical Survey of Concepts and Assessment Techniques." NASA TN D-8365, National Aeronautic and Space Administration, Washington, D.C.

Gaunt, J. A. July 1980. "The Relationship Between Overtime and Safety". Professional Safety. pp. 11-15.

Gensler, T. D., A. R. Sweeny and J. P. Stretch. July 1981. Stress Factors in USAFE: A Survey. U.S. Department of Air Force, Office of Surgeon General, Washington, D.C.

Gerathewoh1, S. J. 1974. "Simple Calculator for Determining the Physiological Rest Period After Jet Flights Involving Time Zone Shifts." Aerospace Medicine. pp. 28, 37. 
Gilmer, B. and E. L. Deci. 1976. Industrial and Organizational Psychology. McGraw-Hil1, New York, New York.

Glenville, M., R. Broughton, A. M. Wing and R. T. Wilkinson. 1978. "Effects of Sleep Deprivation on Short Duration Performance Measures Compared to the Wilkinson Auditory Viligance Task." Sleep. 1:169-176.

Glenville, M. and R. T. Wilkinson. 1979. "Portable Devices for Measuring for Performance in the Field: The Effects of Sleep Deprivation and Night Shift on the Performance." Ergonomics. 22:927-233.

Gordon, G., W. McGill and J. Maltese. 1981. "Home and Community Life of a Sample of Shift Workers." In The Twenty-Four Hour Workday: Proceedings of a Symposium on Variations in Work-Sleep Schedules, L. C. Johnson, D. I. Tepas, W. P. Colquhoun and M. J. Colligan, eds., pp. 435-450. National Institute for Occupational Safety and Health (NIOSH) Publication 81-127. U.S. Department of Health and Human Services, Cincinatti, Ohio.

Graeber, R. C., H. C. Sing and B. N. Cuthbert. 1981. "The Impact of Transmeridian Flight on Deploying Soliders." In The Twenty-Four Hour Workday: Proceedings of a Symposium on Variations in Work-Sleep Schedules, L. C. Johnson, D. I. Tepas, W. P. Colquhoun and M. J. Coliligan, eds., pp. 641-676. National Institute for Occupational Safety and Health (NIOSH) Publication 81127. U.S. Department of Health and Human Services, Cincinatti, Ohio.

Grandjean, E. 1968. "Fatigue: Its Physiological and Psychological Significance." Ergonomics. 11(5):427-436.

Grandjean, E. P., G. Wotzka, R. Schaad and A. Gilgen. 1971. "Fatique and Stress in Air Traffic Controllers." Ergonomics. (14):159-165.

Guillerm, R., E. Radziszewski and A. Reinberg. 1975. "Circadian Rhythms of Six Healthy Young Men Over a 4-Week Period with Night-Work Every $48 \mathrm{~h}$ and a $2 \%$ C02 Atmosphere", Experimental Studies in Shift Work. W. P. Colquhoun, S. Folkard, P. Knauth and J. Rutenfranz, eds., pp. 123-130. Westdeutscher Verlag, Opladen, West Germany.

Haas, P. M., and T. F. Bott. 1979. Criteria for Safety-Related Nuclear Plant Operator Actions: A Preliminary Assessment of Available Data. NUREG/CR-0901, Nuclear Regulatory Commission, Washington, D.C.

Haider, M., M. Kundi and M. Koller. 1981. "Methodologica? Issues and Problems in Shift Work Research." In The Iwenty-Four Hour Workday: Proceedings of a Symposium on Variations in Work-STeep Schedules, L. C. Johnson, D. I. Tepas, W. P. Colquhoun and M. J. Colligan, eds., pp. 197-220. National Institute for Occupational Safety and Health (NIOSH) Publication 81-127. U.S. Department of Health and Human Services, Cincinatti, Ohio.

Hale, H. B., C. A. Anderson, E. W. Williams and E. Tanne. 1968. "EndocrineMetabolic Effects of Unusually Long or Frequent Flying Missions in C-130E or C-1358 Aircraft". Aerospace Medicine. 39:561-570. 
Hale, H. B., B. 0. Hartman, O. A. Harris, R. E. Miranda and E. W. Williams. 1973. "Physiologic Cost of Prolonged Double-Crew Flights in C-5 Aircraft." Aerospace Medicine. 44:999-1008.

Hale, H. B., B. O. Hartman, O. A. Harris, B. N. Smith, E. W. Williams, R. E. Miranda and J. M. Hosenfeld. 1972. "Physiologic Stress During 50-hour Double-Crew Missions in C-14l Aircrafts." Aerospace Medicine. 43:293-299.

Ha11, R. E., J.R. Fragola and W. J. Luckas. 1981. 1981 NRC/BNL/IEEE Standards Workshop on Human Factors and Nuclear Safety. The Man-Machine Interfact and Human Reliability: An Assessment and Projection. NUREG/CP0035, U.S. Nuclear Regulatory Commission, Washington, D.C.

Hall, R. E., J. Fragola and J. Wreatha11. 1982. Post Event Human Decision Errors: Operator Action Tree/Time Reliability Correlation. NUREG/CR-3010, Nuclear Regulatory Commission, Washington, D.C.

Hamilton, P., R. T. Wilkinson and R. S. Edwards. 1972. "A Study of Four Days Partial Sleep Deprivation." In Aspects of Human Efficiency: Diurnal Rhythm and Loss of Sleep. The English Universities Press Limited. Oistributed in the United States by Crane, Russak \& Co., New York, New York.

Harris, W. 1977. "Fatigue, Circadian Rhythm, and Truck Accidents." In Vigilance: Theory, Operational Performance, and Physiological Correlates, ed. R. R. Mackie, PP. 133-146. Plenum Press, New York, New York.

Harris, W. and R. R. Mackie. Nov. 1972. A Study of the Relationship Among Fatigue, Hours of Service, and Safety Operations of Truck and Bus Oriving TFina! Report - Phases I and II). Report No. BMCS-RD-71-2. U.S. Department of Transportation, Federa] Highway Administration, Bureau of Motor Carrier Safety, Washington, DC.

Hartley, L. R. and E. Shirley. 1976. "Color-Name Interference at Different Times of Day." Journal of Applied Psychology. 61(1):119-122.

Hartman, 8. 0. Undated. "Management of Irregular Rest and Activity." AGARD Lecture Series No. 105, Sleep, Wakefulness and Circadian Rhythm. Available from the Defense Technical Information Center, Cameron Station, Alexandria, Virginia.

Hartman, B. 0. 1965. "Fatigue Effects in 24-Hour Simulated Transport Flight Changes in Pilot Proficiency". SAM-TR-65-16, U.S. Air Force School of Aerospace Medicine, Brooks Air Force Base, Texas.

Hartman, B. 0. 1971. "Field Study of Transport Aircrew Workload and Rest." Aerospace Medicine. 42:817-821.

Hartman, B. O., R. A. Benel and W. F. Storm. 1980. A Review of USAFSAM Studies Employing Multiple-Task Performance Devices. Report No. SAM-TR-8016. School of Aerospace Medicine, Brooks Air Force Base, Texas. 
Hartman, B. 0. and G. K. Cantre11. 1967. "MOL: Crew Performance on Demanding Work-Rest Schedules Compounded by Sleep Deprivation." Report No. SAM-TR-67-99, U.S. Air Force School of Aerospace Medicine, Brooks Air Force Base, Texas.

Hartman, B. 0. and J.P. E1lis. 1979. "Arousal and Sleep Disturbance: Biological Disturbance: Biological Considerations". In AGARO Lecture Series No. 105. Sleep, Wakefulness and Circadian Rhythm. Available from the Defense Technical Information Center, Cameron Station, Alexandria, Virginia.

Hartman, B. 0. and D. G. Simons. 1979. "Fatigue Effects in 24-hour Simulated Transport Flight: Changes in Pilot Proficiency." Paper presented at the Aerospace Medical Association Annual Meeting, May 1964, France.

Hartman, B. 0., W. F. Strom, J. E. Vanderveen, E. Vanderveen, H. B. Hale and R. R. Bollinger. 1974. "Operational Aspects of Variations in Alertness." NATO-AGARD, AGARDograph No. 189. Available from the National Technical Information Service, Springfield, Virginia.

Hashimoto, K. and E. Grandjean, eds. 1971. Methodology in Human Fatigue Assessment. Taylor \& Francis Ltd., London, England.

Haslam, D. R. 1981. "The Military Performance of Soldiers in Continuous Operations: Exercises 'Early Call' I and II." In The Twenty-Four Hour Workday: Proceedings of a Symposium on Variations in Work-Sleep Schedules, L. C. Johnson, D. I. Tepas, W. P. Colquhoun and M. J. Colligan, eds., pp. 549-580. National Institute for Occupational Safety and Health (NIOSH) Publication 81127. U.S. Department of HeaTth and Human Services, Cincinatti, Dhio.

Hauty, G. T. and T. Adams. 1965. "Pilot Fatigue: Intercontinental Jet Flight 1 Oklahoma - Tokyo." AM 65-16, Federal Aviation Agency, Office Aviation Medicine, Oklahomo City, Oklahoma.

Hauty, G. T. and T. Adams. 1966a. "Phase Shifts of the Human Circadian System and Performance Deficit During the Periods of Transition: 1. East-West Flight." Aerospace Medicine. 37:668-674.

Hauty, G. T. and T. Adams. 1966b. "Phase Shifts of the Human Circadian System and Performance Deficit During the Periods of Transition: 2. West-East Flight." Aerospace Medicine. 37:1027-1033.

Hauty, G. T. and T. Adams. 1966. "Phase Shifts of the Human Circadian System and Performance Deficit During the Periods of Transition: 3. North-South Flight". Aerospace Medicine. 37:1257-1262.

Hauty, G. T and F. L. Smith. 1972. "Psychological Correlates of Physiological Circadian Periodicy." In Aspects of Human Efficiency: Diurnal Rhythm and Loss of Sleep. The English Universities Press Limited. Distributed in the United States by Crane, Russak \& Co., New York, New York. 
Hauty, G. T., D. K. Trites and W. J. Berkley. 1965. Bionedical Survey of ATC Facilities. 2. Experience and Age. Report No. FAA-AM-65-6. Civil Aeromedical Institute, Oklahorna City, Dk lahoma.

Hawkins, F. H. 1978. Sleep and Body Rhythm Disturbance in Long-Range Aviation: The Problem and a Search for Relief. HF-P1P07-036. Schiphol Airport (C), P.0. Box 75577, Holland.

Hendrix, W. H., and N. K. Ovalle. 1981. Effect of Work Schedule, and Description of Career Intention on Organizational Effectiveness. Report No. AU-AFIT-LS-5-81. Air Force Institute of Technology, Wright-Patterson Air Force Base, School of Systems and Logistics, Ohio.

Herbert, A. 1983. "The Influence of Shift Work on Leisure Activities. A Study of Repeated Measurement". Ergonomics. 26(6):565-574.

Herbert, M. J. and W. E. Jaynes. 1964. "Performance Decrement in Vehicle Driving." Journal of Engineering Psychology. (3):1-8.

Hibler, N. S. 1977. The Effects of Stress on State Anxiety in Air Traffic Controllers (Doctoral thesis). Report No. AFIT-CI-78-30. Air Force Institute of Technology, Wright-Patterson Air Force Base, Ohio.

Higgins, E. A., W. D. Chiles, J. M. McKenzie, P. F. Iampietro, et al. 1975. The Effects of a 12-Hour Shift in the Wake-Sleep Cycle on Physiological and Biochemical Responses and on Multiple Task Performance. Report No. FAA-AM75-10. Prepared for the U.S. Department of Transportation, Federal Aviation Administration, Office of Aviation Medicine, Washington, D.C.

Hildebrandt, G. and P. Engle. 1972. "The Relation Between Diurnal Variations in Psychic and Physica] Performance." In Aspects of Human Efficiency: Diurnal Rhythm and Loss of Sleep. The English Universities Press Limited. Distributed in the United States by Crane, Russak \& Co., New York, New York.

Hildebrandt, G., W. Rohmert and J. Rutenfranz. 1974. "12 and 24 Hour Rhythms in Error Frequency of Locomotive Drivers and the Influence of Tiredness." International Journal of Chronobiology. 2:175-180.

Hi]debrandt, G., W. Rohmert and J. Rutenfranz. 1975. "The Influence of Fatigue and Rest Period on the Circadian Variation of Error Frequency In Shift Workers (Engine Drivers)." In Experimental Studies in Shift Work, pp. 174-187. Westdeutscher Verlag, 0pladen, West Germany.

Hildebrandt, G. and I. Stratmann. 1979. "Circadian System Response to Night Work in Relation to the Individual Circadian Phase Position." International Archives of Occupational and Environmental Health. 43:73-83.

Hockey, G. R. J. and W. P. Colquhoun. 1972. "Diurnal Variation in Human Performance: A Review." In Aspects of Human Efficiency: Diurnal Rhythm and LosS of Sleep. The English Universities Press Limited. Distributed in the United States by Crane, Russak \& Co., New York, New York. 
Hoddes, E., V. Zarcone, H. Smythe, R. Phillips and W. C. Dement. 1973. "The Quantification of Sleepiness: A New Approach." Psychophysiol. 10:431436 .

Holley, D. C., C. M. Winger, C. W. Deroshia, M. P. Heinold and D. M. Edgar. 1981. Effects of Circadian Rhythm Phase Alleration on Physiological and Psychological Variables: Implications to Pilot Performance. NASA-TM-81277, National Aeronautics and Space Administration, Moffett Field, California.

Hopkins, C. 0. 1982. "HFS Study Group Completes Long-Range Plan for Nuclear Regulatory Commission." Human Factors Society Bulletin. 25(12):1-4.

Hopkins, C. 0., H. L. Snyder, H. E. Price, R. J. Hornick, R. R. Mackie, R. J. Smillie and R. C. Sugarman. August 1982. Critical Human Factors Issues in Nuclear Power Regulation and A Recommended Comprehensive Human Factors LongRange Plan Vols. I-III. NUREG/CR 2833. Prepared by Human Factors Society, Inc. for the Nuclear Regulatory Commission, Washington, D.C.

Hurst, R. 1976. Pilot Error: A Professional Study of Contributory Factors. Scribner, New York, New York.

Ilmarinen, J., F. Klimt and J. Rutenfranz. 1975. "Circadian Variations of Maximal Aerobic Power." In Experimental Studies in Shift Work, W. P. Colquhoun, P. Knauth and J. Rutenfranz, eds., Pp. 265-272. Westdeutscher Verlag, Opladen, West Germany.

Imhoff, C. H, and K. R. Byers. 1982. Hanford Patrol Manpower and Shift Structure Analysis. Prepared for Rockwell Hanford Operations under contract to the J.S. Department of Energy by Pacific Northwest Laboratory, Richland, Washington.

Institute of Medicine. 198la. Airline Pilot Age, Health, and Performance. National Academy Press, Washington, D.C.

Institute of Medicine. 1981b. Research on Stress and Human Health. National Academy Press, Washington, D.C.

Ivancevich, J. M. 1974. "Effects of the Shorter Workweek on Selected Satisfaction and Performance Measures." Journal of Applied Psychology. 59(6):717-721.

Jamel, M. 1983. "Shift Work Related to Job Attitudes, Socia? Participation and Withdrawal Behavior: A Study of Nurses and Industrial Workers." Personnel Psychology. 34(3):535-547.

Jame T, M. and S. M. Jamel, 1982. "Work and Nonwork Experiences of Employees on Fixed and Rotating Shifts: An Empirical Assessment." Journal of Vocational Behavior. 20(3):282-293.

Japan Association of Industrial Health, Shift Work Committee. 1979. "Opinion of Night and Shift Work." Journal of Science of Labour. 55(Part II):1-36. 
Jensen, R. S. 1982. "Pjlot Judgment: Training and Evaluation." Human Factors. 24(1):61-73.

Jerison, J. H. and R. M. Pickett. 1963. "Vigilance: A Review and Re-evaluation." Human Factors. 5(3):211.

Johnson, L. C. 1979. "Sleep Disturbance and Performance." In AGARD Lecture Series No. 105, Sleep, Wakefulness and Circadian Rhythm. pp. 8/1-8/17. Available from the Defense Technical Information Center, Cameron Station, Alexandria, Virginia.

Johnson, L. C. 1981. "On Varying Work/Sleep Schedules: Issues and Perspectives as Seen by a Sleep Researcher." In The Twenty-Four Hour Workday: Proceedings of a Symposium on Variations in Work-Sleep Schedules, L. C. Johnson, D. I. Tepas, W. P. Colquhoun and M. J. Colligan, eds., pp. 403-418. National Institute for Occupational Safety and Health (NIOSH) Publication 81127. U.S. Department of Health and Human Services, Cincinatti, Ohio.

Johnson, L. C. 1982. "Sleep Deprivation and Performance." In Biological Rhythms, Sleep, and Performance, ed. W. B. Webb, pp. 111-142. John WiTey \& Sons, New York, New York.

Johnson, L. C. and P. Naitoh, 1974. "The Operational Consequences of Sleep Deprivation and Sleep Deficit." AGARDograph No. 192, The Operational Consequences of Sleep Deprivation and Sleep Deficit. Available from the Defense Technical Information Center, Cameron Station, Alexandria, Virginia.

Johnson, L. C., P. Naitoh, A. Lubin and J. Moses. 1972. "Sleep Stages and Performance." In Aspects of Human Efficiency: Diurnal Rhythm and Loss of Sleep. The English Universities Press Limited. Distributed in the United States by Crane, Russak \& Co., New York, New York.

Johnson, L. C., D. I. Tepas, W. P. Colquhoun and M. J. Colligan. 1981a. Biological Rhythms, Sleep and Shift Work: Advances in Sleep Research, Vol. 7. Spectrum, New York, New York.

Johnson, L. C., D. I. Tepas, W. P. Colquhoun and M. J. Colligan. 1981b. The Twenty-Four Hour Workday: Proceedings of a Symposium on Variations in WorkSleep Schedules. U.S. Department of Health and Human Services. Public Health Service, Centers for Disease Control. National Institute for Occupational Health (NIOSH) Publication No. 81-127. Cincinatti, Ohio.

Johnson, R. C. 1982. Manpower Requirements in the Nuclear Power Industry, 1982-1991. Oak Rjdge Associated Universities, Oak Ridge, Tennessee.

Jones, J. 1983. "Testimony of the American Nurses' Association on Rotating Shift Work." Testimony before the subcomittee on Investigations and Oversight of the Committee on Science and Technology, U.S. House of Representatives, Washington, D.C., March 23, 1983.

Juin, G. 1963. "Schedule Shifts." NASA-TT-F-8461, Presented at the 7th National Conference on Occupational Medicine, September 1962, Paris, France. 
Kafka, M. 1942. Flying Health. Military Service Publishing Company, Harrisburg, Pennsylvania.

Kapoor, T. N., J. Mohan, et a1. 1979. "An Experimental Study of Motivational Determinants of Fatigue." Psychological Studies. 24(1):12-23.

Karney, 0. H. 1976. "Flight Limits and Crew Rest." U.S. Army Aviation Digest. $22: 38-89$.

Karney, O. H. and P. Thompson. 1976. "Fatigue." U.S. Army Aviation Digest. $22: 28-34$.

Keele, S. W. 1974. "Attention and Human Performance." Ergonomics. 17(5): 700-701.

Kelly, R. J. and M. F. Schneider. 1982. "The Twelve-Hour Shift Revisited: Recent Trends in the Electric Power Industry." In Shiftwork: Its Practices and Improvement. K. Kogi, Minra and Saito, eds., pp. 369-384. Center for Academic Publications Japan, Tokyo, Japan.

Khashimoto, K., K. Kogi and E. Grandjean. 1975. Methodology in Human Fatigue Assessment. Taylor and Francis Ltd., London, England.

Kibler, A. W. 1965. "The Relevance of Vigilance Research to Aerospace Monitoring Tasks." Human Factors. 7(2):93-99.

Kjellberg, A. 1977. "Sleep Deprivation, Arousal, and Performance." In Vigilance: Theory, Operational Performance, and Physiological Correlates. R. R. Mackie, ed., Plenum Press, New York, New York.

Klein, K. E., H. Bruner, E. Gunther, O. Jovy, et al. 1972. "Physiological Changes Caused by Desynchronization Following Transzonal Air Travel." In Aspects of Human Efficiency: Diurnal Rhythm and Loss of Sleep. The English Universities Press Limited. Oistributed in the United States by Crane, Russak \& Company, New York, New York.

Klein, K. E., H. Bruner, H. Holtmann, J. Stolze, W. D. Steinhoff and H. M. Wegmann. 1970. "Circadian Rhythm of Pilots' Efficiency and Effects of Multiple Time Zone Travel." Aerospace Medicine. 41:126-132.

Klein, K. E., R. Hermann, P. Kulinski and H. M. Wegman. 1977. "Circadian Performance Rhythms: Experimenta? Studies in Air Operations." In Vigilance: Theory, Operational Performance, and Physiological Correlates, ed. R. R. Mackie. PTenum Press, New York, New York.

Klein, K. E. and H. M. Wegmann. 1979a. "Circadian Rhythms in Air Operations." AGARO Lecture Series No. 105, Sleep, Wakefulness and Circadian Rhythm. Oefense Technical Information Center, Cameron Station, Alexandria, Virginia.

Klein, K. E. and H. M. Wegmann. 1979b. "Circadian Rhythms of Human Performance and Resistance: Operational Aspects." AGARD Lecture Series No. 105, Sleep, Wakefulness and Circadian Rhythm. Available from the Defense Technical Information Center, Cameron Station, Alexandria, Virginia. 
Klein, K. E. and H. M. Wegmann. 1980. Significance of Circadian Rhythms in Aerospace Operations. AGAROograph No. 247, Available from the Defense Technical Information Center, Cameron Station, Alexandria, Virginia.

Klein, K. E., H. M. Wegmann and H. Bruner. 1968. "Circadium Rhythm Indices of Human Performance." Aerospace Medicine. 39:512-518.

Kleitman, N. 1967. Sleep and Wakefulness. University of Chicago Press, Chicago, Illinois.

Knapp, S. C., ed. 1978. Operational Helicopter Aviation. AGARD Conference Proceedings No. 255. Available from the Defense Technical Information Center, Cameron Station, Alexandria, Virginia.

Knauth, P. and J. I Imarinen. 1975. "Continuous Measurement of Body Temperature Ouring a Three-Week Experiment with Inverted Working and Sleeping Hours." In Experimental Studies in Shift Work, W. P. Colquhoun, 5. Folkard, P. Knauth and J. Rutenfranz, eds., pp. 66-73. Westdeutscher Verlag, Opladen, West Germany.

Knauth, P., E. Kiesswetter, S. Bruder, H. P. Romberg and J. Rutenfranz. 1981. "Oay Sleep During the Morning and Ouring the Afternoon Between Experimental Night Shifts." In Sleep 1980: Circadian Rhythms, Dreams, Noise and Sleep, Neurophysiology and Therapy. W. P. Koella, ed., pp. 198-202, S. Karger, New York, New York.

Knauth, P., W. Rohmert and J. Rutenfranz. 1980. "Systematic Selection of Shift Plans for Continuous Production with the Aid of Work-Physiological Criteria." In Studies of Shiftwork, W. P. Colquhoun and J. Rutenfranz, eds., pp. 399405. Taylor \& Francis Ltd., London, England.

Knauth, P. and J. Rutenfranz. 1980a. "Experimental Shiftwork Studies of Permanent Night, and Rapidly Rotating, Shift Systems." In Studies of Shiftwork, W. P. Colquhoun and J. Rutenfranz, eds., pp. 81-93. Taylor \& Francis Ltd., London, England.

Knauth, P. and J. Rutenfranz. 1980b. "The Effects of Noise on the Sleep of Nightworkers." In Studies of Shiftwork, W. P. Colquhoun and J. Rutenfranz, eds., pp. 111-120. Taylor \& Francis Ltd., London, England.

Knoerchen, R., E. M. Gundlach and G. Hildebrandt. 1975. "Circadian Variations of Visual Sensitivity and Negative Responsiveness to Light in Man." In Experimental Studies in Shift Work, W. P. Colquhoun, S. Folkard, P. Knauth and J. Rutenfranz, eds., pp. 244-253. Westdeutscher Verlag, Opladen, West Germany.

Koella, W. P., ed. 1981. Sleep 1980: Circadiam Rhythms, Dreams, Noise and Sleep, Neurophysiology and Therapy. Fifth European Congress of Sleep Research, September 2-5, Amsterdam. Published by S. Karger, New York, New York. Available from the Defense Technical Information Center, Cameron Station, Alexandria, Virginia. 
Kogi, K. 1981. "Research Motives and Methods in Field Approaches to Shift Work." In The Twenty-Four Hour Workday: Proceedings of a Symposium on Variations in Work-S leep Schedules, L. C. Johnson, D. I. Tepas, W. P. Colquhoun and M. J. Colligan, eds., pp. 269-288. National Institute for Occupational Safety and Health (NIOSH) Publication 81-127. U.S. Department of Health and Human Services, Cincinatti, Ohio.

Kogi, K., T. Miura and H. Saito, eds, 1982. Shiftwork: Its Practice and Improvement. Proceedings of the Sixth International Symposium on Night and Shif twork. Journal of Human Ergology, Vol. 11, Center for Academic Publications Japan, Tokyo, Japan.

Kogi, K., M. Takahashi and N. Onishi. 1975. "Experimental Evaluation of Frequent Eight-Hour Versus Less Frequent Longer Night Shifts." In Experimental Studies in Shift Work, W. P. Colquhoun, S. Folkard, P. Knauth and J. Rutenfranz, eds., pp. 103-112, Westdeutscher Verlag, Opladen, West Germany.

Koller, M., M. Kundi and R. Cervinka. 1980. "Field Studies at an Austrian 0il Refinery I: Health and Psychosocial Wellbeing of Workers Who Orop Out of Shiftwork." In Studies of Shiftwork, W. P. Colquhoun and J. Rutenfranz, eds., pp. 335-348. Taylor \& Francis Ltd., London, England.

Kopstein, F. F., A. I. Siegel and L. B. Wilson. 1979. Human Performance in Continuous Operations: Volume II. Management Guide. Written by Applied Psychological Services, Inc. for U.S. Army Research Institute for the Behavioral and Social Sciences, Research Product 30-4b. Available from Defense Technical Information Center, Cameron Station, Alexandria, Virginia.

Kozinsky, E. J. 1981. "Human Factors Research Using the EPRI Performance Measurement System." Presented at CSNI meeting, October 1981, Charlotte, North Carolina. In Workshop Proceedings, CSNI Report No. 63, NUREG/CP0031 , Vol. 2., Nuclear Regulatory Commission, Washington, D.C.

Kreiger, D. T. and H. Hauser, 1978. "Comparison of Synchronization of Circadian Corticosteroid Rhythms by Photoperiod and Food." Proc. National Academy of Science. 75:1577-1581.

Kronauer, R. E., C. A. Czeisler, C. A. Pilato, M. C. Moore-Ede and E. D. Weitzman. 1982. "Mathematical Model of the Human Circadian System with Two Interacting 0scillators." Am. Journal Physiol. 11:R3-R17.

Krueger, G. P. and J. N. Fagg. 1981. Aeromedical Factors in Aviator Fatigue Crew Work/Rest Schedules and Extended Flight Operations: An Annotated Bibliography. USAARL-81-1, Army Aeromedical Research Lab., Fort Rucker, Alabama.

Krueger, G. P. and Y. F. Jones. 197B. "U. S. Army Aviation Fatigue-Related Accidents, 1971-1977." In Operational Helicopter Aviation. AGARD Conf. Proceedings No. 255. Defense Technical Information Center, Cameron Station, Alexandria, Virginia. 
Krueger, G. P., R. N. Armstrong and R. R. Cisco. 1980. "Aviator Performance in Week-Long Extended Flight Operations in a Helicoper Simulator." In Session A: Aircrew Safety and Survivability, R. Auffret, ed. AGARD Conference Proceedings No. 286. Available from the Defense Technica] Information Center, Cameron Station, Alexandria, Virginia.

LaDou, J. 1982. "Health Effects of Shiftwork." Western Journal of Medicine. $137(6): 525-530$.

Lavie, P. 1980. "The Search for Cycles in Mental Performance from Lombard to Kleitman." Chronobiologia. 7:247-256.

Lavie, P. 1982. "Ultradian Rhythms in Human Sleep and Wakefulness." In Biological Rhythms, Sleep and Performance, ed. W. B. Webb, pp. 239-272. John Wiley \& Sons, New York, New York.

Lavie, P., D. Gopher, R. Ogel and J. Zommer. 1981. "Ultradian Rhythms in Perceptual Motor Tasks." In The Twenty-Four Hour Workday: Proceedings of a Symposium on Variations in Work-Sleep Schedules, L. C. Johnson, D. I. Tepas, W. P. Colquhoun and M. J. Colligan, eds., pp. 181-196. National Institute for Occupational Safety and Health (NIDSH) Publication 81-127. U.S. Department of Health and Human Services, Cincinatti, Ohio.

LeClercq, G. R. and G. R. Krieger. 1983. Shiftwork and the Petrochemical Industry: Defining Concerns--Formulating Solutions. Testimony before the Subcommittee on Investigations and Oversight of the Committee on Science and Technology, U.S. House of Representatives, March 23, 1983, Washington, D.C.

Lees, M. A., L. W. Stone, H. D. Jones, K. A. Kimball, and D. B. Anderson. 1979. The Measurement of Man-Helicoper Performance as a Function of Extended Flight Requirements and Aviator Fatique. USAARL-79-12, Army Aeromedical Research Lab, Fort Rucker, ATabama.

Lewis, S. A., G. A. Christie, J. R. Daly et ai. 1972. "Preliminary Results of the Vigilance Tests from 'Project Pegasus'." In Aspects of Human Efficiency: Diurnal Rhythm and Loss of Sleep. The English Universities Press Limited. Distributed in the United States by Crane, Russak \& Co., New York, New York.

Lobban, M. C.. 1975. "Physiological Circadian Rhythms in Shift-Workers in the High Arctic (Abstract)." In Experimental Studies in Shift Work, W. P. Colquhoun, S. Folkard, P. Knauth and J. Rutenfranz, eds., pp. 166-167. Westdeutscher Verlag, Opladen, West Germany.

Lodeesen, M. March 1963. "Tired Jet Pjlots." Flying. p. 33.

Lovett, J. C. 1981. "Presentation on 'Variations in Work-Sleep Schedules: From the View of the Industrial Worker'." In The Twenty-Four Hour Workday: Proceedings of a Symposium on Variations in Work-Sleep Schedules, L. C. Johnson, D. I. Tepas, W. P. Colquhoun and M. J. Colligan, eds., pp. 393-397. National Institute for Occupational Safety and Health (NIOSH) Publication 81127. U.S. Department of Health and Human Services, Cincinatti, Ohio. 
Lyman, E. G. and H. W. Orlady. 1981. Fatique and Associated Performance Decrements in Air Transport Operations. NASA CR 166167, ASRS Office for Ames Research Center, Moffett Field, California.

Mackie, R. R., ed. 1977. Vigilance: Theory, Operational Performance, and Physiological Correlates. Published in coordination with NATO Scientific Affairs Division, Plenum Press, New York, New York.

Mackje, R. and J. Miller. 1978. Effects of Hours of Service, Regularity of Schedules and Cargo Loading on Truck and Bus Driver Fatique. Human Factors Research Inc. National Technical Information Service, Springfield, Virginia.

Mackie, R. R. and J. F. O'Hanlon. 1977. "A Study of the Combined Effects of Extended Driving and Heat Stress on Driver Arousal and Performance." In: Vigilance: Theory, Operational Performance, and Physiological Correlates. R. R. Mackie, ed., Plenum Press, New York, New York.

Mackworth, N. H. 1950. Research on Measurement of Human Performance. Medical Research Council Special Report, Series 268, H. M. Stationery Office, London, England.

Malaviya, P. and K. Ganesh. 1977. "Individual Differences in Productivity Across Type of Work Shift." Journal of Applied Psychology. 62(4):527-528.

Marris, R. L. 1980. "The Economics of Shift Working." In Studies of Shiftwork, W. P. Colquhoun and J. Rutenfranz, eds., pp. 417-426. Taylor \& Francis Ltd., London, England.

Martinek, H., S. Pilette and B. Biggs. 1978. The Effects of Work/Rest, Target Activity, Background Noise, and String Size on Operator Interpretation of Unattended Ground Sensor. HRB-Singer Inc, State College, Pennsylvania.

Masters, R. L. 1981. "Shift Work Research Needs in Aviation: An Operational Perspective." In The Twenty-Four Hour Workday: Proceedings of a Symposium on Variations in Work-Sleep Schedules. National Institute for Occupational Health (NIOSH) Publication No.81-127. U.S. Department of Health and Human Services. Public Health Service, Centers for Disease Control, Cincinatti, Ohio.

Maurice, M. 1975. Shift Work. Internt. Labour Office, Geneva, Switzerland.

McCornack, R. L. 1961. "Inspector Accuracy: A Study of the Literature." Sandia Corp. Technical Manual, SCTM-53-61 (14), Available from National Technical Information Service, Springfield, Virginia.

McFarland, R. A. 1971. "Understanding Fatigue in Modern Line." Ergonomics. $14: 1-10$.

McF arland, R. A. and A. L. Moseley. 1954. Human Factors in Highway Transport Safety. Harvard University School of Public Health, Highway Transportation Research Project, Boston, Massachusetts. 
McIntosh, B. E., J. L. Milton, and E. L. Cole. 1952. Pilot Performance During Extended Periods of Instrument Flight, USAF TR 6725 , RDO No. 694 34, Wright-Patterson Air Force Base, Dhio.

McKenzie, R. E. and L. L. Elliot. 1965. "Effects of Secobarbitol and d-Amphetamine on Performance During a Simulated Air Mission." Aerospace Medicine. (36):774-779.

"Medical Aspects of Aircraft Pilot Fatigue with Special Reference to Commercial Jet Pilot." Aerospace Medicine. 37(4 Section II): iv, 1-44.

Meers, A. 1975. "Performance on Different Turns of Duty Within a ThreeShift System and Its Relation to Body Temperature - Two Field Studies." In Experimental Studies in Shift Work, W. P. Colquhoun, S. Folkard, P. Knauth and J. Rutenfranz, eds., PD. 188-205. Westdeutscher Verlag, Opladen, West Germany.

Meers, A., A. Maasen, and P. Verhaegen. 1978. "Subjective Health After Six Months and After Four Years of Shift Work." Ergonomics. 21:857-859.

Melber, B. D., B. Berk, J. 01 sen and B. Tunestom. 1982. An International Comparison of Manpower and Staffing Regulations and Practice in Commercial Nuclear Power Plants. NUREG/CR-2953, PNL-4469. Prepared for the NucTear Regulatory Commission by Battelle, Human Affairs Research Centers, Seattie, Washington.

Melton, C. E., J. M. McKenzie, R. C. Smith, B. D. Polis and E. A. Higgins. 1973. Physiological, 8jochemical, and Psychological Responses in Air Traffic Control Personne l: Comparison of the 5-Day and 2-2-1 Shift Rotation Patterns. FAA-AM-73-22, Federal Aviation Administration, Office of Aviation Medicine, Washington, D.C.,

Melton, C. E., R. C. Smith, J. M. McKenzie, J. T. Saldivar and S. M. Hoffmann. 1975. Stress in Air Traffic Controllers: Comparison of Two Air Route Traffic Control Centers on Different Shift Rotation Patterns. Avajlable from National Technical Information Service, Springfield, Viriginia.

Metersky, M. L. 1967. A Study of Simulated ASW Crew Performance in Relation to Selected Fatique Factors." TR No. NADC-SY-6709. Available from the Defense Technical Information Center, Cameron Station, Alexandria, Virginia.

Miller, J. C. and R. R. Mackie. 1980. Vigilance Research and Nuclear Security Critical Review and Potential Applications to Security Guard Performance). Tectinical Report 2722, Human Factors Research, Inc., Santa Barbara, California.

Mills, J. N. and A. Fort. 1975. "Relative Effects of Sleep Disturbance and Persistent Endogenous Rhythm After Experimental Phase Shift." In Experimental Studies in Shift Work, W. P. Colquhoun, S. Folkard, P. Knauth and J. Rutenfranz, eds., pp.11-19. Westdeutscher Verlag, Opląden, West Germany. 
Mills, J. N., D. S. Minors, and J. M. Waterhouse. 1977. "The Physiological Rhythms of Subjects Living on a Day of Abnormal Length." J. Physiol. (London). 232:803-826.

Milis, J. N., D. S. Minors and J. M. Waterhouse. 1978. "Adaptation to Abrupt Time Shifts of the Oscillator(s) Controlling Human Circadian Rhythms." J. Physiol. 285:455-470.

Minors, D. S. and J. M. Waterhouse. 1981. "Anchor Sleep as a Synchronizer of Rhythms on Abnormal Routines." In The Twenty-Four Hour Workday: Proceedings of a Symposium on Variations in work-Sleep Schedules, L. C. Johnson, 0.1 . Tepas, W. P. Colquhoun and M. J. Colligan, eds., pp. 493-516. National Institute for Occupational Health (NIOSH) Publication No. 81-127. U.S. Department of Health and Human Services, Public Health Service, Centers for Disease Control, Cincinatti, Ohio.

Minors, D. S. and J. M. Waterhouse. 1983. "Circadian Rhythm Amplitude - Is It Related to Rhythm Adjustment and/or Worker Motivation?" Erqonomics. $26(3): 229-242$.

Mobley, W. H., R. W. Griffeth, H. H. Hand, and B. M. Meglino. 1979. "Review and Conceptual Analysis of the Employee Turnover Process." Psychologica? Bulletin. $86: 493-522$.

Mohler, S. R. 1966. "Fatigue in Aviation Activities." Aerospace Med. $37: 722-732$.

Mohler, S. R. 1976. "Physiological Index as an Aid in Developing Airline Pilot Scheduling Patterns." Aviation, Space, and Environ. Med. 47:238-247.

Mohler, S. R. and P. V. Siegel. 1964. Medical Facts for Pilots. Federal Aviation Agency, Ok lahoma City, Oklahoma.

Monk, T. H. 1980. "Traffic Accident Increases as a Possible Indicant of Desynchronosis." Chronobiologia. 7:527-529.

Monk, T. H. 1982a. "Research Methods of Chronobiology." In Biological Rhythms, Sleep, and Performance, ed. W. B. Webb, pp. 27-58. John Wiley \& Sons, New York, New York.

Monk, T. H. 1982b. "The Arousal Mode 1 of Time of Day Effects in Human Performance Efficiency." Chronobiologia. 9:49-54.

Monk, T. H., P. Knauth, S. Folkard, and J. Rutenfranz. 1978. "Memory Based Performance Measures in Studies of Shiftwork." Ergonomics. 21:819-826.

Moore, J. M. and R. D. Whitmore. Sept. 1982. A SAC B-52 Aircrew Scheduling Using Model ICAM's IDEF Methodology. Available from National Technical Information Service, Springfield, Virginia. 
Moore-Ede, M. C. 1982. Testimony before the Subcommittee on Investigations and Oversight of the Committee on Science and Technology, U.S. House of Representatives, Washington, D. C.

Moore-Ede, M. C. and C. A. Fuller. 1980. "Evaluation of Aircraft Accident Reports." Forum Int. Soc. Air Safety Invest. 13:13-15.

Moore-Ede, M. C., E. M. Sulzman, and C. A. Fuller. 1982. The Clocks That Time US. Harvard University Press, Cambridge, Massachusetts.

Moray, N. 1979. Mental Workload: Its Theory and Measurement. Published in coordination with NATO Scientific Affairs Division. Plenum Press, New York, New York.

Moray, N. 1982a. "A Model for Predicting Errors in the Nuclear Industry." In Proceedings of the Human Factors Association Annual Meeting. Seattle, Washington.

Moray, N. 1982b. "Subjective Mental Workload." Human Factors. 24(1):25-40.

Morgan, B. B. 1974. "Effects of Continuous Work and Sleep Loss in the Reduction and Recovery of Work Efficiency." American Industrial Hygiene Association Journal. 35:13-20.

Morgan, B. B., and G. D. Coates. 1974. Sustained Performance and Recovery During Cont inuous Operations. Interim Fechnica] Report ITR-74-2, Department of the Army. Available from the National Technical Information Service, Springfield, Virginia.

Morgan, B. B., B. R. Brown and E. A. Alluisi. 1974. "Effects on Sustained Performance of 48 -Hours of Continuous Work and Sleep Loss." Human Factors. $16: 406-414$.

Morgan, B. B., G. D. Coates, B. R. Brown and E. A. Alluisi, 1973. Effects of Cont inuous Work and Sleep Loss on Recovery of Sustained Performance. Report of Human Engineering Laboratory, Aberdeen Proving Ground, Maryl and.

Morgan, B. B., P. S. Winne and J. Dugan. 1980. "The Range and Consistency of Individual Differences in Continuous Work." Human Factors. 22(3):331340 .

Mott, P. E., F. C. Mann, Q. McLoughlin and D. P. Warwick. 1965. Shift Work: The Social, Psychological, and Physical Consequences. University of Michigan Press, Ann Arbor, Michigan.

Mullaney, D. J., D. F. Kripke and P. Fleck. 1981. Sleep Loss Effects on Continuous Sustained Performance. Navy Technical Report, AD \#A098682, Available from the Defense Technical Information Center, Washington, D.C. 
Nachreiner, F. 1980. "Role Perceptions, Job Satisfaction, and Attitudes Towards Shiftwork of Workers in Different Shift Systems as Related to Situational and Personal Factors." In Studies of Shiftwork, W. P. Colquhoun and J. Rutenfranz, eds., pp. 150-162. Taylor \& Francis Ltd., London, England.

Naitoh, P. 1981. "Circadian Cycles and Restorative Power of Naps." In The Twenty-Four Hour Workday: Proceedings of a Symposium on Variations in WorkSleep Schedules, L. C. Johnson, D. I. Tepas, W. P. Colquhoun and M. J. Colligan, eds., pp. 693-720. National Institute for Occupational Safety and Health (NIOSH) Publication 81-127. U.S. Department of Health and Human Services, Cincinatti, Ohio.

Nelson, T. M., T. H. Nilsson and M. Johnson. 1984. "Interaction of Temperature, Illuminance and Apparent Time on Sedantary Work Fatigue." Ergonomics $27(1): 89-101$.

Newman, J. E. 1977. "Development of a Measure of Perceived Work Environment (PWE)." Academy of Management Journal. 20:520-534.

Nicholson, A. N. 1970a. Duty Hours and Sleep Patterns in Transport Aircrew Operating Long Haul Routes. Report No. FPRC-1302, Flying Personnel Research Comittee, London, England.

Nicholson, A. N. 1970b. "Influence of Duty Hours on Sleep Patterns in Aircrew Operating in the Long Haul Transport Role: A Study of Single Crew Operations and Double Crew Cont inuous Flying Operations." In Rest and Activity Cycles for the Maintenance of Efficiency of Personnel Concerned with Military Flight Operations. NATO/AGARD CP-74-70, Available from the Defense Technical Information Center, Cameron Station, Alexandria, Virginia.

Nicholson, A. N. 1972. "Duty Hours and Sleep Patterns in Aircrew Operating World-Wide Routes." Aerospace Medicine. 43:138-141.

Nicholson, A. N. 1974. "Simulation and Study of High Workload Operations." AGARD Conference Proceedings No. 146. Available from the Defense Technical Information Center, Cameron Station, Alexandria, Virginia.

Nicholson, A. N. 1978. "Irregular Work and Rest." In Aviation Medicine Vol 1: Physiology and Human Factors, ed. G. Dhenin, Tri-Med Books Limited, London, pp. 494-503.

Nicholson, A. N. 1979. Sleep, Wakefulness and Circadian Rhythm. AGARD Lecture Series No. 105. Available from the Defense Technicat Information Center, Cameron Station, Alexandria, Virginia.

Nicholson, N., P. Jackson et al. 1978. "Shiftwork and Absence: An Analysis of Temporal Trends." Journal of Occupational Psychology. 51(2):127-137. 
Nicholson, A. N. and B. M. Stone. 1981. "Hypnotics and Shift Work." In The Twenty-Four Hour Workday: Proceedings of a Symposium on Variations in WorkS leep Schedules, L. C. Johnson, D. I. Tepas, W. P. Colquhoun and M. J. Colligan, eds., pp. 467-492. National Institute for Occupational Safety and Health (NIOSH) Publication 81-127. U.S. Department of Health and Human Services, Cincinatti, Ohio.

Nicholson, T. 1973. "Work, Rest and Safety in the Air." New Scientist. $5: 404-458$.

Nielsen, S. N. March 23, 1983. Testimony before the Subcommittee on Investigations and Oversight of the Committee on Science and Technology, U.S. House of Representatives, Washington, D.C.

Nord, W. R and R. Costigan. 1973, "Worker Adjustment to the Four-Day Week: A Longitudinal Survey." Journal of Applied Psychology. 58(1):60-66.

North Atlantic Treaty Organization. 1976. "Performance Decrement During Prolonged Night Driving." In Proceedings of the NATO Symposium on Vigilance II: Relationships Among Theory, Physiological Correlates, and Operational Performance, August 3-6, 1976, in St. Vincent, Italy.

North At lantic Treaty Organization/Advisory Group for Aerospace Research and Development (NATO/AGARD). 1979. Sleep, Wakefulness and Circadian Rhythm. AGARD Lecture Series No. 105. Avai Table from the Defense Technical Information Center, Cameron Station, Alexandria, Virginia.

Northrup, H. R., J. T. Wilson and K. M. Rose. 1979. "The Twelve-Hour Shift in the Petroleum and Chemical Industries." Industrial and Labor Relations Review. 32(3):312-326.

Oak Ridge National Laboratory. Monthly. Licensee Event Report (LER) Compilation. NUREG/CR-2000, Prepared for the Nuclear Regulatory Commission, Washington, D.C.

D'Hanlon, J. F. and G. R. Kelley. 1977. "Comparison of Performance and Physiological Changes Between Drivers Who Perform Well and Poorly During Prolonged Vehicular Operation." In Vigilance, pp. 87-110, R. R. Mackie, ed., Plenum Press, New York, New York.

0leron, G., P. Fraisse, N. Zuili and M. Siffre. 1972. "The Effect of Variations in the Sleep-Wakefulness Cycle During a 'Time-Isolation' Experiment on Reaction Time and Spontaneous Tempo." In Aspects of Human Efficiency: Diurnal Rhythm and Loss of Sleep. The English Üniversities Press Limited. Distributed in the United States by Crane, Russak \& Co., New York, New York.

$0^{\prime} \mathrm{Ne} i \mathrm{l}, \mathrm{P}, \mathrm{S}$, and H. A. Goldstein. 1983. Testimony before the Subcommittee on Investigations and Dversight of the Committee on Science and Technology, U.S. House of Representatives, March 23, 1983, Washington, D.C. 
Orth-Gomer, K. and R. O1ivegard Landen. 1982. "Intervention on Coronary Risk Factors by Changing Working Conditions of Swedish Policemen." In Psychophysiological Risk Factors of Cardiovascular Diseases. University of Stockholm, Sweden.

Ostberg, 0. 1980. "Interindividual Differences in Circadian Fatigue Patterns of Shiftworkers." In Studies of Shiftwork, W. P. Colquhoun and J. Rutenfranz, eds., pp. 131-142. Taylor \& Francis Ltd., London, England.

Ostberg, 0. and G. Svensson. 1975. "'Functional Age' and Physical Work Capacity During Day and Night." In Experimental Studies in Shift Work, W. P. Colquhoun, S. Folkard, P. Knauth and J. Rutenfranz, eds., pp. 254-264. Westdeutscher, Verlag, Opladen, West Germany.

Otway, H. J. and R. Misenta. 1980. "Some Human Performance Paradoxes of Nuclear Operations." Futures. 12:340-357.

Parker, R. et al. 1981. "Endocrine Rhythms Across Reversal Sleep-Wake Cycles." In The Twenty-Four Hour Workday: Proceedings of a Symposium on Variations in Work-STeep Schedules, L. C. Johnson, D. I. Tepas, W. P. Colquhoun and M. J. Colligan, eds., pp. 151-180. National Institute for Occupational Safety and Health (NIOSH) Publication 81-127. U.S. Department of Health and Human Services, Cincinatti, Ohio.

Parsons, H. 1972. Man - Machine System Experiments. John Hopk ins Press, Balt imore, Maryland.

Patkai, P. 1971a. "Interindividual Differences in Diurnal Variations in Alertness, Performance, and Adrenaline Excretion." Acta Physiologica Scandinavica. $81: 35-46$.

Patkai, P. 1971b. "The Diurnal Rhythm of Adrenaline Secretion in Subjects with Different Working Habits." Acta Physiologica Scandinavica. 81:30-34.

Patkai, P., K. Pettersson and T. Akerstedt. 1975. "The Diurnal Pattern of Some Physiological and Psychological Functions in Permanent Night Workers and in Men Working on a Two-Shift (Day and Night) System." In Experimental Studies in Shift Work, W. P. Colquhoun, S. Folkard, P. Knauth and J. Rutenfranz, eds., Pp. 131-141. Westdeutscher Verlag, Opladen, West Germany.

Peacock, 8., R. Glube, M. Miller and P. Clune. 1983. "Police Officers" Responses to 8 and 12 Hour Shift Schedules." Ergonomics. 26(5):479-494.

Pear Iman, C. A. 1982. "Sleep Structure Variation and Performance." In Biological Rhythms, Sleep, and Performance, ed. W. B. Wilse, pp. 143-174. John Wiley \& Sons, New York, New York.

Pearson, R. G. and G. E. Byars. 1956. The Development and Validation of a Checklist for Measuring Subjective Fatigue. Air University, School of Aviation Medicine, Randolph Air Force Base, Texas. 
Pere11i, L. D. 1980. Fatique Stressors in Simulated Long-Duration Flight: Effects on Performance, Information Processing, Subject Fatique, and Physiological Cost. Final Report for the period March 1977-January 1980. SAM-TR-80-49. USAF School of Aerospace Medicine, Aerospace Medical Division, Brooks Air Force Base, Texas.

Perry, I. C. 1974. Helicopter: Aircrew Fatigue. AGARD Advisory Report No. 69. Available from the National Technical Information Service, Springfield, Virginia.

Pickere1, E. W. and T. A. McDonald. 1964. "Quantification of Human Performance in Large Complex Systems." Human Factors. 6:647-662.

Platz, 0., J. Rasmussen and P. Z. Skamborg. 1978. Response Times of Operators in a Control Room. Riso National Laboratories, DK400, Roskilde, Denmark.

Pocock, S. J., R. Sergean and P. J. Taylor. 1980. "Absence of Cont inuous Three-Shift Workers: A Comparison of Traditional and Rapidly Rotating Systems." In Studies of Shiftwork, W. P. Colquhoun and J. Rutenfranz, eds., pp. 391-398. Taylor \& Francis Ltd., London, England.

Pollack, F. L. 1983. Testimony before the Subcomittee on Investigations and Oversight of the Combittee on Science and Technology, U.S. House of Representatives, March 23, 1983, Washington, D.C.

Poilmann, L. 1975. "Continuous Measurements of Heart and Respiratory Rate During a Long-Term Experiment with an Inverted Activity Cycle." In Experimental Studies in Shift Work, W. P. Colquhoun, S. Folkard, P. Knauth, and J. Rutenfranz, eds., pp. 94-102, Westdeutscher Verlag, Opladen, West Germany.

Poulton, E. C. 1970. Environment and Human Efficiency. Published by Charles C. Thomas, Springfield, Itiinois.

Presser, H. B. and V. S. Cain. 1983. "Shift Work Among Dual Income Families." Science. 219:876-879.

Preston, F. S. 1968. "Twelve Year Survey of Airline Pilots." Aerospace Medicine. $39: 312-314$.

Preston, F. S. 1973. "Further Sleep Problems in Airline Pilots on World-Wide Schedules." Aerospace Medicine. 44:775-782.

Preston, F. S. 1978. "Aircrew Schedules." Chapter 4 in Aviation Medicine: Health and Clinical Aspects, G. Ohenin, ed. pp. 37-50. Tri-Med Books, London, England.

Preston, F. S., S. C. Bateman, F. W. Meichen, R. Wilkinson and R. Short. 1976. "Effects of Time Zone Changes on Performance and Physiology of Airline Personnel." Aviation Space Environment Medicine. 47:763-769. 
Preston, F. S., H. P. Ruffel-Smith, and V. M. Sutton-Mattocks. 1973. "Sleep Loss in Air Cabin Crew." Aerospace Medicine. 44:931-935.

Price, H. E., P. Wallace, M. Bauman and M. Smith. 1980. Review of Staffing Requirements for Near-Term Operating License Facilities. NUREG/CR-1764. Prepared by Bio Technology, Inc., Falls Church, Virginia, for the Nuclear Regulatory Commission, Washington, D.C..

Pullmann, L. 1975. "Continuous Measurements of Heart and Respiratory Rate During a Long-Term Experiment with an Inverted Activity Cycle." In Experimental Studies in Shift Work, W. P. Colquhoun, S. Folkard, P. Knauth and J. Rutenfranz, eds., pp. 94-102. Westdeutscher Verlag, Opladen, West Germany.

Rafferty, J. F. 1983. "Watching the Biological Clock." Harvard Magazine. March/April:26-29.

Ralf, E. W., J. E. Uhlaner and H. E. Brogden. 1961. Field Study of Vigilance Under Highway Driying Conditions. Technical Research Note No. 118, U.S. Army Personnel Research Office. Available from Armed Services Technical Information Agency, Arlington, Virginia.

Rasmussen, J. and W. B. Rowe. 1981. Human Detection and Diagnosis of System Failures. Plenum Press, New York, New York.

Ray, J., 0. Martin and E. A. Alluisi. 1961. Guman Performance As a Function of the Work/Rest Cycle. National Research Council Bulletin, Council Publication 882 , Washington, D.C.

Reighard, H. L. 1983. Testimony before the Subcomittee on Investigations and Oversight of the Committee on Science and Technology, U.S. House of Representatives, March 23, 1983, Washington, D.C.

Reinberg, A. 1979. "Chronobiological Field Studies of 0il Refinery Shift Workers." Supplement 1 of Chronobiologia. 6:1-119.

Reinberg, A., P. Andlauer and N. Vieux. 1981. "Circadian Temperature Rhythm Amplitude and Long Term Tolerance of Shiftworking." In The Twenty-Four Hour Workday: Proceedings of a Symposium on Variations in Work-Sleep Schedules, L. C. Johnson, D. I. Tepas, W. P. Colquhoun and M. J. Colligan, eds., pp. 87104. National Institute for Occupational Safety and Health (NIOSH) Publication 87-127. U.S. Department of Health and Human Services, Cincinatti, Ohio.

Reinberg, A., A. J. Chaumont and A. Laporte. 1975. "Circadian Temporal Structure of 20 Shift-Workers (8-Hour Shift-Weekly Rotation): An Autometric Field Study." In Experimental Studies in Shift Work, W. P. Colquhoun, S. Folkard, P. Knauth and J. Rutenfranz, eds., Pp. 142-165. Westdeutscher Verlag, Opladen, West Germany.

Reinberg, A., N. Vieux and P. Andlauer. 1981. Night and Shift Work: Biological and Social Aspects. Pergamon Press, Elmsford, New York. 
Reinberg, A., N. Vieux, J. Ghata, A. J. Chaumont and A. Laporte. 1980. "Circadian Rhythm Amplitude and Individual Ability to Adjust to Shift Work." In Studies of Shiftwork, W. P. Colquhoun and J. Rutenfranz, eds., pp. 185188. Taylor \& Francis Ltd., London, England.

Rentos, P. G. and R. Shepard. 1976. Shift Work and Health - A Symposium. National Institute for Occupational Safety and Health (NIOSH) Publication No. 76-203. U.S. Dept. of Health, Education and Welfare, Cincinnati, Ohio.

Revkim, A. 1983. "Taking the Stress Out of Shift Work." Police Magazine. $6(3): 62-64$.

Richey, P. L. 1983. Testimony before the Subcomittee on Investigations and Oversight of the Committee on Science and Technology, U.S. House of Representatives, March 23, 1983, Washington, O.C.

Riemersma, J. B. J., A. F. Sanders, C. Wildervanck and A. W. Gaillard. 1976. "Performance Decrement During Prolonged Night Driving." In Proceedings of the NATO Symposium on Vigilance II: Relationships Among Theory, Physiological Correlates, and Operational Performance. Held in St. Vincent, Italy, August 3-6. Available from the Defense Technical Information Center, Camer on Station, Alexandria, Virginia.

Robison, D. 1978. "DuPont's 12-Hour Shift Improves QWL and Employee SelfEsteem at Six Cont inuous-Process Plants." World of Work Report. 3(2).

Rokicki, S. M. 1982. Fatique, Workload and Personality Indices of Air Traffic Controller Stress During an Aircraft Surge Recovery Exercise. U.S. Air Force School of Aerospace Medicine, Brooks Air Force Base, Texas.

Rokicki, S. M., W. F. Storm, M. L. Durant and R. J. Fulton. 1981. Undergraduate - Pilot - Training Duty Schedules and Aircrew Fatique. Final Report for Period April 1980-February 1981. SAM-TR-81-14. USAF School of Aerospace Medicine, Aerospace Medical Division, Brooks Air Force Base, Texas.

Ruffell-Smith, H. P. 1978. A Simulator Study of the Interaction of Pilot Work Load with Errors, Vigilance, and Decisions. TM-78482, Ames Research Center, Moffett Field, California.

Rutenfranz, J., J. Aschoff and H. Mann. 1972. "The Effects of a Cumulative Sleep Deficit, Duration of Preceding Sleep Period and Body Temperature on Muitiple Choice Reaction Time." In Aspects of Human Efficiency: Diurnal Rhythm and Loss of Sleep. The English Universities Press Limited. Distributed in the United States by Crane, Russak \& Co., New York, New York.

Rutenfranz, J., J. Aschoff and H. Mann. 1980. "The Effects of a Cumulative Sleep Deficit, Duration of Preceding Sleep Period and Body-Temperature on Multiple Choice Reaction Time." In Studies of Shiftwork, W. P. Colquhoun and J. Rutenfranz, eds. Taylor \& Francis Ltd., London, England. 
Rutenfranz, J., F. Klimmer and P. Knauth. 1975. "Desynchronization of Different Physiological Functions During Three Weeks of Experimental Nightshift with Limited and Unlimited Sleep." In Experimental Studies in Shift Work, W. P. Colquhoun, S. Folkard, P. Knauth and J. Rutenfranz, eds., pp. 74-77. Westdeutscher Verlag, Opladen, West Germany.

Rutenfranz, J., P. Knauth and D. Angersbach. 1981. "Shift Work Research Issues." In The Twenty-Four Hour Workday: Proceedings of a Symposium on Variations in Work-Sleep Schedules, L. C. Johnson, D. I. Tepas, W. P. Colquhoun and M. J. Colligan, eds., pp. 221-260. National Institute for Occupational Safety and Health (NIOSH) Publication 81-127. U.S. Department of Health and Human Services, Cincinatti, Ohio.

Rutenfranz, J., P. Knauth and W. P. Colquhoun. 1976. "Hours of Work and Shift Work." Ergonomics. 19:331-340.

Saldivar, J. T., S. M. Hoffmann and C. E. Melton. 1977. Sleep in Air Traffic Controllers. FAA-AM-77-5, Prepared for the U.S. Department of Transportation, Federal Aviation Administration, Office of Aviation Medicine, Washinton, $0 . C$.

Schaefer, K. E., B. R. Clegg, C. R. Corey, J. H. Dougherty and B. B. Weybrew. 1967. "Effect of Isolation in a Constant Environment on Periodicity of Physiological Functions and Performance Levels." Aerospace Medicine. 38:1002-1018.

Schaefer, K. E., C. M. Kerr, D. Buss and E. Haus. 1979. "Effect of 18-H Watch Schedules on Circadian Cycles of Physiological Functions During Submarine Patrols: Circadian Cycles in Submarine Patrols." Undersea Biomedical Research. (Submarine Supplement) pp. \$81-\$90.

Scheving, L. E and F. Halberg. 1980. Chronobiology: Principles and Applications to Shifts in Schedules. Sijthoff and Noordhoff, Alphen an den Rijn, The Netherlands.

Scheving, L. E., F. Halberg and J. E. Pauly. 1974. Chronobiology. G. Thieme Publishers, Stuttgart, Germany.

Schneider, M. F., J. D. Brooke, and N. Moray. 1982. Human Error Rates for 12-Hour vs. 8-Hour Shifts in Heavy Water Plant Operation. The Human Factors Group Report to the 12-Hour Shift Task Group of Ontario Hydro, Ontario, Canada.

Schreuder, 0. B. 1966. "Medical Aspects of Aircraft Pilot Fatigue." Aerospace Medicine. $37(4 / 11): 1-44$.

Schroeder, D. J. and D. R. Goulden. 1983. A Bibliography of Shift Work Research. FAA-AM-83-17, Available from the National Technical Information Service, Springfield, Virginia. 
Seaver, D. A. and W. G. Stillwe 11. 1983. Procedures for Using Expert Judgment to Estimate Human-Error Probabilities in Nuclear Power Plant Operations. NUREG/CR-2743, Nuclear Regulat ory Commission, Washington, D.C.

Sergean, R. 1972. "A Note on Current Trends in the Arrangement of Working Hours in the U. K." In Aspects of Human Efficiency: Diurnal Rhythm and LosS of Sleep. The English Universities Press Limited. Distributed in the United States by Crane, Russak \& Company, New York, New York.

Sergean, R. and J. Brierly. 1968. "Absence and Attendance Under Non-Continuous Three-Shift Systems of Work." Nature. 219(5153):536.

Sergean, R., D. Howel1, P. J. Taylor and S. J. Pocock. 1980. "'Compensation for Inconvenience': An Analys is of Shift Payments in Collective Agreenents in the U. K." In Studies of Shiftwork, W. P. Colquhoun and J. Rutenfranz, eds., pp. 439-448. Taylor \& Francis Ltd., London, England.

Shannon, R. H. and R. Ferguson. 1970. Problems of Fatigue in Patrol Aircrewmen During Extended Flight Operations. Patrol ASW Development Group Report 33. Available from the Defense Technical Information Center, Cameron Station, Alexandria, Virginia.

Shannon, R. H. and N. E. Lane. 1971. A Survey of Major P-3 Accidents With Special Emphasis on Fatigue. Patrol ASW Oevelopment Group Report No. 40. Available from the Defense Technical Information Center, Cameron Station, A lexandria, Virginia.

Shaw, P. 1978. "10-Hour Day in the 4-Day Week." Nurse Supervisor. $9(10): 47-56$.

Sheridan, T. B. 1981. "Understanding Human Error and Aiding Human Diagnostic Behavior in Nuclear Power Plants." In Human Detection and Diagnos is of System Failures, J. Rasmussen and W. B. Rowe, eds., Plenum, New York, New York.

Siegel, A. I., W. D. Bartter, J. J. Wolf, H. E. Knee and P. M. Haas. 1983. Front-End Analysis for the Nuclear Power Plant Maintenance Personnel Reliabilitty Model. NUREG/CR-2669, Nuclear Regulatory Commission, Washington, D.C.

Siege1, P. V., J. Gerathewohl and S. R. Mohler. 1969. "Time-Zone Effects." Science. $164: 1249-1255$.

Siegel, A. I., M. G. Pfeiffer, F. F. Kopstein and L. G. Wilson. 1979. Human Performance in Cont inuous Operations: Volume I. Human Performance GuideTines. Prepared by Applied Psychological Services, Inc. for U.S. Army Research Institute for the Behavioral and Social Sciences. Research Product 80-4a. Available from Defense Technical Information Center, Washington, D.C. 
Silver, R. May 31, 1984. "Canadian Nuclear Operators Suffer More Stress than Air Controllers." Nucleonics Week. pp. 2-3.

Simpson, L. P. and D. R. Goulden. 1976. Aviation Medicine Translations: Annotated Bibliography of Recently TransTated Material, $X$. Report No. FAAAM-81-4. Federal Aviation Administration, Washington, D.C.

Sinaiko, H. W. 1961. Selected Papers on Human Factors in the Design and Use of Control Systems. Dover Publications, New York, New York.

Singleton, W. T. 1971. The Human Operator in Complex Systems. Taylor \& Francis, Ltd., London, England. U.S. Distributor: International Publications Service, New York, New York.

Smith, H. P. R. 1975. A Simulator Study of the Interaction of Pilot Work load With Errors, Vigilance, and Decisions. NASA-TM-78482, National Aeronautic Space Administration, Washington, D.C.

Smith, M. J., M. J. Colligan, I. J. Frockt and D. L. Tasto. 1979. "Occupational Injury Rates Among Nurses as a Function of Shift Schedule." Journal of Safety Research. 11(4):181-187.

Smith, M. J., M. J. Colligan and D. L. Tasto. 1982. "Health and Safety Consequences of Shift Work in the Food Processing Industry." Ergonomics. $25(2): 133-144$.

Smith, P. C., L. M. Kendall, and C. L. Hulin. 1969. The Measurement of Satisfaction in Work and Retirement. Rand McNally, Chicago, IITinois.

Smith, R. C. 1973. "Comparison of the Job Attitudes of Personnel in Three Air Traffic Control Specialties." Aerospace Medicine. 44(8):918-927.

Smith, R. C. 1980. Stress, Anxiety, and the Air Traffic Control Specialist: Some Conclusions from a Decade of Research. Report No. FAA-AM-80-14. Federal Aviation Administration, Office of Aviation Medicine, Washington, D.C.

Smith, R. C. and G. L. Hutto. 1977. Job Attitudes of Airway Facilities Personnel. Report No. 77-21-82. Federal Aviation Administration, Civil Aeromedical Institute, Oklahoma City, Oklahoma.

Smith, R. C. and C. E. Melton. 1973. Susceptibility to Anxiety and Shift Difficulty as Determinants of State Anxiety of Air Traffic Controllers. Report No. FAA-AM-73-15. Prepared for Department of Transportation, Federal Aviation Administration, Office of Aviation Medicine, Washington, D.C.

Smith, R. P. 1981. "Boredom: A Review." Human Factors. 23(3):329-340.

Spencer, C. 1970. "Employee Attitudes to Shift Work." Personnel Practice Bulletin. 26(1):25-33.

SRI International. 1978. The Health Consequences of Shift Work. Prepared for the National Institute for Occupational Safety and Health (NIOSH), U. S. Department of Health and Human Services, Cincinatti, Onio. 
Stanford Research Institute. March 1977. Shift Work Practices in the United States. PB-274 707. Prepared for the National Institute for Occupational Safety and Health (NIOSH), U. S. Department of Health and Human Services, Cincinatti, Ohio.

Stenze1, W. W. and R. M. Buren. 1983. "Police Work Scheduling: An Important and Manageable Function." Police Chief. (June):54-56.

Steward, G. V. and J. M. Larsen. 1971. "A Four-Day, Three-Day Per Week Application to a Continuous-Production Operation." Management and Personnel Quarterly. 10:13-20.

Stolgitis, W. C. 1969. The Effect of Sleep Loss and Demanding Work/Rest Cycles: An Analysis of the Traditional Navy Watch System and a Proposed Alternative. Thes is from the U. S. Naval Postgraduate School. Availabie from the Technical Information Service, Springfield, Virginia.

Stone, R. B. 1983. Testimony before the Subcommittee on Investigations and Oversight of the Committee on Science and Technology, U.S. House of Representatives, March 23, 1983, Washington, D.C.

Storm, W. F. Undated. "Aircrew Fatigue During Extended Transport, Tactical, and Combat Post Operations." AGARD Lecture Series No. 105, Sleep, Wakefuiness, and Circadian Rhythm. Available from the Defense Technical Information Center, Cameron Station, Alexandria, Virginia.

Storm, W. F. 1980a. E-48 Crew Fatigue Associated with 3-Hour IOT\&E Mission. SAM-TR-80-40, School of Aerospace Medicine, Brooks Air Force Base, Texas.

Storm, W. F. 1980b. Mission Crew Fatigue During Rivet Joint II Demonstration/ Evaluation. SAM-TR-B0-37, School of Aerospace Medicine, Brooks Air Force Base, Texas.

Storm, W. F., P. J. Dowd, G. W. Noga, and L. A. Schuknecht. 1981. Fat igue in Double-Crew Aerial - Refue led Transport Missions. SAM-TR-81-23, School of Aerospace Medicine, Brooks Air Force Base, Texas.

Storm, W. F. and S. F. Gray. 1978. Minuteman Missile Crew Fatigue and 24-Hour A lerts. SAM-TR-78-19, School of Aerospace Medicine, Brooks Air Force Base, Texas.

Storm, W. F. and J. T. Merrifield. 1980. Fatigue and Workload in Four-Man C-5A Cockpit Crews (Volant Galaxy). SAM-TR-80-23, School of Aerospace Medicine, Brooks Air Force Base, Jexas.

Stolgitis, W. C. 1969. The Effect of Sleep Loss and Demanding Work/Rest Cycles: An Analysis of the Traditional Navy Watch System and a Proposed Alternative. Master Thesis from the U.S. Naval Postgraduate School. Available from the Clearinghouse for Federal Scientific and Technical Information, Springfield, Virginia. 
Stone, R. B. 1983. Testimony before the Subcommittee on Investigaions and Oversight of the Committee on Science and Technology, U. S. House of Representatives, March 23, 1983, Washington, 0.C.

Swain, A. O. and B. J. Bell. 1980. "Effects of Length of Work Period on Visual Detection and Decision-Making with Implications for Nuclear Power Plant Personne1." Nuclear Safety.

Swain, A. D. and B. J. Be11. 1983. Probabilistic Risk Assessment Training Program: Human Reliability Analysis - Course Notes. Notes for a course given August 22-26, 1983, Office of Nuclear Regulatory Research, Nuclear Regulatory Commission, Washington, D.C.

Swain, A. D. and H. E. Guttman. 1980. Handbook on Human Reliability Analysis With Emphasis on Nuclear Power Plant Applications. NURE $\bar{G} / \mathrm{C} R-1278$. Prepared by Sandia Laboratories for the Nuclear Regulatory Commission, Washington, D.C.

Swensson, A. 1969. "On Night and Shift Work: Studia Laboris et Salutis." Proceedings of an International Symposium, 0 s 10, January 31 to February 1, 1969. National Institute of Occupational Health, Stockholm, Sweden.

Tasto, 0. L., M. J. Colligan, et al. 1978. Health Consequences of Shift Work. Report No. PB-80-176563, SRI International, Menlo Park, California.

Tasto, D. L. and M. J. Colligan. 1977. Shift Work Practices in the United States. Report No. DHEW/PUB/N1OSH77/148. National Inst itute for Occupational Safety and Health (NIOSH), U. S. Department of Health and Human Services, Cincinatti, Ohio.

Taub, J. M. and R. J. Berger. 1974. "Effects of Acute Shifts in Circadian Rhythms of Sleep and Wakefulness on Performance and Mood." In Chronobiology, L. E. Scheving, F. Halberg and J. E. Pauly, eds., pp. $\overline{571-575}$. G. Thieme Publishers, Stuttgart, Germany.

Taylor, P. J. 1969. "The Problems of Shift Work." In On Night and Shift Work, ed. A. Swensson, pp. 15-30. National Institute of Occupational HeaTth, Stockholm, Sweden.

Taylor, P. J. 1980. "Shift and Day Work: A Comparison of Sickness Absence, Lateness, and Other Absence Behaviour at an 0il Refinery from 1962 to 1965." In Studies of Shiftwork, W. P. Colquhoun and J. Rutenfranz, eds., pp. 325334. Taylor \& Francis Ltd., London, England.

Taylor, P. J. May 1984. "Solutions to the Shiftwork Fatigue Problem." Nuclear News. pp. 45-49.

Taylor, P. J. and S. J. Pocock. 1980. "Mortality of Shift and Day Workers 1956-68." In Studies of Shiftwork, W. P. Colquhoun and J. Rutenfranz, eds., pp. 317-324. Taylor \& Franc is Ltd., London, England. 
Tejmar, J. 1980. "Shift Work Round the Clock in Supervision and Control: Schedules of Rewarded and Unrewarded Time." In Studies of Shiftwork, W. P. Colquhoun and J. Rutenfranz, eds., pp. 406-414. Taylor \& Francis Ltd., London, England.

Tepas, D. I. 1982. "Work/Sleep Time Schedules and Performance." In Biological Rhythms, Sleep, and Performance, ed. W. B. Webb, pp. 175-204. John Wiley \& Sons, New York, New York.

Tepas, D. I., J. Walsh and D. Armstrong. 1981. "Comprehensive Study of the Sleep of Shift Workers." In The Twenty-Four Hour Workday: Proceedings of a Symposium on Variations in Work-Sleep Schedules, L. C. Johnson, D. I. Tepas, W. P. Colquhoun and M. J. ColTigan, eds., pp. 419-434. National Institute for Occupational Safety and Health (NIOSH) Publication 81-127. U.S. Department of Health and Human Services, Cincinatti, Ohio.

Thackray, R. I. 1980. Boredom and Monotony as a Consequence of Automation: A Consideration of Evidence Relating Boredom and Monotony to Stress. FAA$\overline{A M}-80-\bar{l}$. Avajiable from the National Technical Information Service, Springfield, Virginia.

Thackray, R. I., J. P. Bailey and R. M. Touchstone. 1975. Physiological, Subjective, and Performance Correlates of Reported Boredom and Monotony While Performing Simulated Radar Control Task. FAA-AM-77-18. Avajlable from the National Technical Information Service, Springfield, Virginia.

Thackray, R. I., J. P. Bailey and R. M. Touchstone. 1977. The Effect of Increased Monitoring Load on Vigilance Performance Using a Simulated Radar Disptay. FAA-AM-77-18. AvaitabTe from the National Technicat Information Service, Springfield, Virginia.

Thackray, R. I., K. N. Jones and R. M. Touchstone. 1972. Self-Estimates of Distractibjlity as Related to Performance Decrement on a Task Requiring Sustained Attention. FAA-AM-72-25. Available from the National Technical Information Service, Springfield, Virginia.

Thackray, R. I., K. N. Jones and R. M. Touchstone. 1973. Personality and Physiological Correlates of Performance Decrement on a Monotonous Task Requiring Sustained Attention. FAA-AM-73-14. Avajlable from the Nationa 1 Technical Information Service, Springfield, Virgina.

Thackray, R. I. and R. M. Touchstone. 1981. Age-Related Differences in Complex Monitoring Performance. FAA-AM-81-12. Available from the Nationa 1 Techical Information Service, Springfield, Virginia.

Thackray, R. I. and R. M. Touchstone. 1982a. Performance of Air Traffic Control Specialists (ATCS's) On a Laboratory Radar Monitoring Task: An Exploratory Study of Complacency and a Compar ison of ATCS and Non-ATCS Performance. FAA-AM-82-1. Available from the National Technical Information Service, Springfield, Virginia. 
Thackray, R. I. and R. M. Touchstone. 1982b. Performance of 40-to 50-Year 01d Subjects on a Radar Monitoring Task: The Effects of Wearing B ifocal GTasses and Interpolated Rest Periods on Target Detection Time. FAA-AM-8216. Available from the National Technical Information Service, Springfield, Virginia.

Thierry, H. 1980. "Compensation for Shiftwork: A Model and Some Results." In Studies of Shiftwork, W. P. Colquhoun and J. Rutenfranz, eds., pp. 449462. Taylor \& Francis Ltd., London, England.

Thierry, H. 1981. "Compensation for Shiftwork: A Model and Some Results." In The Twenty-Four Hour Workday: Proceedings of a Symposium on Variations in Work-Sleep Schedules, L. C. Johnson, D. I. Tepas, W. P. Colquhoun and M. J. Colligan, eds., pp. 375-392. National Institute for Dccupational Safety and Health (NIDSH) Publication 81-127. U.S. Department of Health and Human Services, Cincinatti, Ohio.

Thierry, H., G. Hoolwerf and P. J. D. Drenth. 1975. "Attitudes of Permanent Day and Shift Workers Towards Shiftwork - A Field Study." In Experimental Studies in Shift Work, W. P. Colquhoun, S. Folkard, P. Knauth and J. Rutenfranz, eds., pp. 213-231. Westdeutscher Verlag, Opladen, Germany.

Thiis-Evensen, E. 1969. "Shift Work and Health." In On Night and Shift Work, ed. A. Swensson, pp. 81-107. National Institute of Occupationa? Health, Stockholm, Sweden.

Thompson, G. 1983. Testimony before the Subcommittee on Investigations and Dversight of the Committee on Science and Technology, U.S. House of Representatives, March 23, 1983, Washington, D.C.

Tilley, A. J., R. T. Wilkinson, P. S. G. Warren, B. Watson and M. Orud. 1982. "The Sleep and Performance of Shift Workers." Human Factors. 24(6):629641 .

Topmiller, D. A., J. S. Eckel and E. J. Kozinsky. 1982. Human Reliability Data Banks for Nuclear Power Plant Operations. Volume I: A Review of Existing Human Reliability Data Banks. NUREG/CR-2744/1 of 2, Nuclear Regulatory Commission, Washington, $\bar{D} . \mathrm{C}$.

Torsvall, L. and T. Akerstedt. 1978. Summary of a Longitudinal Study of Shift Work Effects on Well-Being. Report No. 92B. Laboratory for CTinical Stress Research, Karolinska Sjukhuset, Stockholm, Sweden.

Torsvall, L. and T. Akerstedt. 1980. "A Diurnal Type Scale - Construction, Consistency, and Validation in Shift Work." Scandinavian Journal of Work Environment, and Health. $6: 283-290$.

Tsaneva, N. and M. Daleva. 1975. "Field Study of the Diurnal Changes of the Adrenal System." In Experimental Studies in Shift Work, W. P. Colquhoun, S. Folkard, P. Knauth and J. Rutenfranz, eds., pp. 206-231. Westdeutscher Verlag, Opladen, Germany. 
Tune, G. S. 1980. "Sleep and Wakefulness in a Group of Shiftworkers." In Studies of Shiftwork, W. P. Colquhoun and J. Rutenfranz, eds., pp. 349354. TayTor \& Francis Ltd., London, England.

U.S. Department of Defense, Department of Navy. 1978. "Fatigue." Chapter 20 in U.S. Naval Flight Surgeon's Manual. U.S. Government Printing Office, Washington, D.C.

U.S. Department of Transportation. 1974. Medical Handbook for Pilots. Superintendent of Documents, U.S. Government Printing Office, Washington, D.C.

U.S. Department of Transportation. 1982. Air Operations Manual. Washington, D.C.

U.S. Federal Aeronautics Administration. 1964. "Ground Rest Periods and Duty Time Limitations for Flight Crews of Three or More." 14 CFR 42. Notice 6413; Docket No. 4028.

U.S. National Aeronautics and Space Administration. 1981. Pilot Fatigue and Circadian Desynchronosis: Report of a Workshop Held in San FrancisCo, Calif ornia, on Auqust 26-28, 1980. NASA Technical Memorandum 81275. Ames Research Center, Moffett Field, Cal ifornia.

U.S. National Transportation Safety Board. 1980. Aircraft Accident Report -Air New England, Inc. de davill and DHC-6 -300, N383EX, Hyannis Massachusetts, June 17, 1979. NTSB-AAR-80-1. Washington, D.C. Available from Nat iona 1 Technical Information Service, Springfield, Virginia.

U.S. Nuc lear Regulatory Commission, Washington, D.C:

NUREG-0090. 1982. Abnormal Occurrence Reports.

NUREG-0161. 1977. Instructions for Preparation of Data Entry Sheets for Licensee Event Report (LER) File.

NUREG-0572. 1979. Review of Licensee Event Reports (1976-1978).

NUREG-0585. 1979. TMI-2 Lessons Learned Task Force Final Report.

NUREG-0694. 1980. TMI-Related Requirements for New Operating Licenses.

NUREG-0731. 1980. Guidelines for Utility Management Structure and Technical Resources: Draft Report for Inter im Use and Comment.

NUREG-0737. 1980. Clarification of TMI Action P lan Requirements.

NUREG-0784. 1982. Long Range Research Plan, FY1984-FY1988.

NUREG-0800, 1981. Standard Review Plan. (Rev. 2) 
NUREG-0872RX. 1982. A Feasibility Study of Using Licensee Event Reports for a Statistical Assessment of the Effect of Overtime and Shift Work in Operator Error.

NUREG-0985. 1983. Human Factors Program PIan.

NUREG/CR-0901. 1979. Criteria for Safety-Related Nuclear Plant Operator Actions: A Preliminary Assessment of Availability Data.

NUREG/CR-0979. 1979. Licensee Performance Evaluation: Phase II.

NUREG/CR-1278. 1980. Handbook of Human Reliability Analys is With Emphasis on Nuclear Power Plant Application.

NUREG/CR-1764. 1980. Review of Staffing Reguirements for Near-Term Operating License Facilities.

NUREG/CR-1908. 1981. Criteria for Safety Related Nuclear Power P lant Operator Actions: Initial Pressurized Water Reactor (PWR) Simulator Exercises.

NUREG/CR-2000. Monthly. Licensee Event Report (LER) Compilation.

NUREG/CR-2534. 1983. Criteria for Safety-Related Nuclear Power Plant Operator Actions: Initial Boiling water Reactor (BWR) Simulator Exercises.

NUREG/CR-2669. 1983. Front, End Analysis for the Nuclear Power Plant Maintenance Personnel Reliability Model.

NUREG/CR-2743. 1983. Procedures for Using Expert Judgment to Estimate Human Error Probabilities in Nuclear Power Plant Operations.

NUREG/CR-2833. 1982. Critical Human Factor 1ssues in Nuclear Power Regulation and A Recommended Comprehensive Human Factors Long-Range P lan. Volumes I-III.

NUREG/CR-2986. 1983. The Use of Performance Shaping Factors and Quantified Expert Judgment in the Evaluation of Human Reliability: An Initial Appraisal.

NUREG/CR-3010. 1982. Post Event Human Decision Errors: Operator Action Tree/Reliability Correlation.

NUREG/CR-3092. 1983. Criteria for Safety-Related Nuclear Power P lant Operator Actions: Initial Simulator to Field Data Calibration.

NUREG/CR-3119. 1983. Nuc lear Power Safety Reporting System. Volumes I and II.

U.S. Nuclear Regulatory Commission. (Bimonthly News letter). Power Reactor Events. NUREG/BR-0051, U.S. Nuclear Regulatory Comission, Washington, D.C. 
U.S. Nuclear Regulatory Commission. 1980a. Nuclear Power Plant Staff Working Hours. IE Circular 80-02, U. S. Nuclear RegüTatory Comission, Washington, D.C.

U.S. Nuclear Regulatory Commission. 1980b. Systematic Assessment of Licensee Performance. SECY-80-83, U.S. Nuclear Regulatory Commission, Washington, D.C.

U.S. Nuclear Regulatory Comission. 1981a. Nuclear Power Plant Staff Working Hours. SECY-81-440, U. S. Nuclear Regulatory Comission, Washington, D.C.

U.S. Nuclear Regulatory Cormission. 1981a. Report on a Survey by Senior NRC Management to Obtain Viewpoints on the Safety Impact of Regulatory Activities from Representative Utilities Operating and Constructing Nuclear Power plants. U.S. Nuclear Regulatory Commission, Office of Inspection and Enforcement, Washington, D.C.

U.S. Nuclear Regulatory Commission. 1983. Regulatory Analysis Guidelines of the United States Regulatory Cormission. NUREG/BR-0058, U.S. Nuclear Regulatory Commission, Washington, D.C.

Vallet, M., J. M. Gagneux and V. Blanchet. 1981. "Noise and Sleep at Home: Stage Changes and Arousals." In Sleep 1980: Circadian Rhythms, Dreams, Noise, and Sleep, Neurophysiology, Therapy, pp. 220-224, W. P. Koella, ed., Publised by S. Karger, New York, New York. Available from the Defense Technical Information Center, Cameron Station, Alexandria, Virginia.

vanLoon, J. H. 1980. "Diurnal Body Temperature Curves in Shiftworkers." In Studies of Shiftwork, W. P. Colquhoun and J. Rutenfranz, eds., pp. 3541. Taylor \& Francis Ltd., London, England.

Verhaegen, P., A. Massen and A. Meers. 1981. "Health Problems in Shiftworkers." In The Twent $y$-Four Hour Workday: Proceedings of a Symposium on Varjations in Work-S Teep Schedules, L. C. Johnson, D. I. Tepas, W. P. Colquhoun and M. J. Colligan, eds., pp. 335-346. National Institute for Dccupational Health (NIOSH) Publication No. 81-127. U.S. Department of Health and Human Services, Centers for Disease Control, Cincinatti, Ohio.

Vernon, H. M. 1945. "Prevention of Accidents." British Journal of Industrial Medicine. (2):3.

Vervalin, C. A. 1972. "The Short Work Week Has Arrived." Hydrocarbon Processing. 51 (August).

Viteles, M. S. 1946. The Role of Fatique in Pilot Performance. National Research Counc il Committee on Selection and Training of Pilots, Civil Aeronautics Administration, Washington, D.C. 
Vokac, Z., P. Magnus, E. Jebens and N. Gundersen. 1981. "Apparent PhaseShifts of Circadian Rhythms (Masking Effects) During Rapid Shift Rotation." International Archives of Occupational and Environmental Health. 49:5365 .

Vokac, Z. and K. Rodah1. 1975. "A Field Study of Rotating and Continuous Night Shifts in a Steel Mill." In Experimental Studies in Shift Work, W. P. Colquhoun, S. Folkard, P. Knauth and J. Rutenfranz, eds., Pp. 168-173. Westdeutscher Verlag, Opladen, Germany.

Wadderburn, A. A. 1978. "Some Suggestions for Increasing the Usefulness of Psychological and Sociological Studies of Shiftwork." Ergonomics. $21(10): 827-833$.

Walker, J. 1978. The Human Aspects of Shiftwork. Renouf USA, Inc., Brookfield, Vermont.

Walker, J. 1980. "Frequent Alternation of Shifts on Continuous Work." In Studies of Shiftwork, W. P. Colquhoun and J. Rutenfranz, eds., pp. 379390. Taylor \& Francis Ltd., London, England.

Walsh, J., D. Tepas and P. Moss. 1981. "The EEG Sleep of Night and Rotating Shift Workers." In The Twenty-Four Hour Workday: Proceedings of a Symposium on Variations in Work-Sleep Schedules, L. C. Johnson, D. I. Tepas, W. P. Colquhoun and M. J. Colligan, eds., Pp. 451-466. National Institute for Occupational Safety and Health (NIOSH) Publication 81-127. U.S. Department of Health and Human Services, Cincinatti, Ohio.

Ward, R. E. 1983. Industrial Shift Work Scheduling: Current Practice. Testimony before the Subcommittee on Investigations and Oversight of the Committee on Science and Technology, U.S. House of Representatives, March 23, 1983, Washington, D.C.

Webb, W. B. 1972. "Patterns of Sleep Behavior." In Aspects in Human Efficiency: Diurnal Rhythm and Loss of Sleep. The English Universities Press Limited. Distributed in the United States by Crane, Russak \& Co., New York, New York.

Webb, W. B. 1981. "Work/Rest Schedules: Economic, Health, and Socjal Implications." In The Twenty-four Hour Workday: Proceedings of a Symposium on Variations in Work-Sleep Schedules, L. C. Johnson, D. I. Tepas, W. P. Colquhoun and M. J. Colligan, eds., pp. 1-12. National Institute for Occupational Safety and Health (NIOSH) Publication 81-127. U.S. Department of Health and Human Services, Cincinatti, Ohio.

Webb, W. B. 1982a. Bjological Rhythms, Sleep, and Performance. John Wiley \& Sons, New York, New York.

Webb, W. B. 1982b. "Sleep and Biological Rhythms." In Biological Rhythms, Sleep, and Performance, pp. 87-110. John Wiley \& Sons, New York, New York. 
Webb, W. B. 1982c. "Sleep, Biological Rhythms, Performance Research: An Introduction." In Biological Rhythms, Sleep, and Performance, pp. 1-26. John Wiley \& Sons, New York, New York.

Webb, W. B. and C. M. Levy. 1984. "Effects of Spaced and Repeated Total Sleep Deprivation." Ergonomics. 27(1):45-58.

Wedderburn, A. A. I. 1975. "EEG and Self-Recorded Sleep of Two Shiftworkers Over Four Weeks of Real and Synthetic Work." In Experimental Studjes in Shift Work, W. P. Colquhoun, S. Folkard, P. Knauth and J. Rutenfranz, eds., pp. 29-47. West deutscher Verlag, Opladen, Germany.

Wedderburn, A. A. I. 1980. "Social Factors in Satisfaction With Swiftly Rotating Shifts." In Studies of Shiftwork, W. P. Colquhoun and J.

Rutenfranz, eds., pp. 275-298. Tayior \& Francis Ltd., London, England.

Wedderburn, A. A. I. 1981. "How Important Are the Social Effects of Shiftwork?" In The Twenty-Four Hour Workday: Proceedings of a Symposium on Variations in Work-S leep Schedules, L. C. Johnson, D. I. Tepas, W. P. Colquhoun and M. J. Colligan, eds., pp. 321-334. National Institute for Occupational Safety and Health (NIOSH) Publication 81-127. U.S. Department of Health and Human Services, Cincinatti, Ohio.

Wehr, T. A. 1983. Testimony before the Subcommittee on Investigations and Oversight of the Conmittee on Science and Technology, U.S. House of Representatives, March 23, 1983, Washington, D.C.

Weitzman, E., C. Czeisler and M. Moore-Ede. 1981. "Sleep-Wake, Endocrine and Temperature Rhythms in Man During Temporal isolation." In The Twenty-Four Hour Workday: Proceedings of a Symposium on Variations in Work-Sleep Schedules, L. C. Johnson, D. I. Tepas, W. P. Colquhoun and M. J. Coliigan, eds., pp. 105-124. National Institute for 0ccupational Safety and Health (NIOSH) Publication 81-127. U.S. Department of Heaith and Human Services, Cincinatti, Ohio.

Weitzman, E. and D. Kripke. 1981. "Experimental 12-Hour Shift of the SleepWake Cycle in Man: Effects on Sleep and Physiologic Rhythms." In The Twentyfour Hour Workday: Proceedings of a Sympos ium on Variations in Work-STeep Schedules, L. C. Johnson, D. I. Tepas, W. P. Colquhoun and M. J. CoTligan, eds., pp. 125-150. National Institute for Occupational Safety and Heaith (NIOSH) Publication 81-127. U.S. Department of Health and Human Services, Cincinatti, Ohio.

Welford, A. T., R. A. Brown and J. E. Gabb. 1950. "Two Experiments on Fatique as Affecting Skilled Performance in Civilian Air Crew." British Journal of Psychology. 40:195-211.

Wever, R. A. 1979. The Circadian System of Man: Results of Experiments Under Temporal Isolation. Springer-Verlag, New York, New York. 
Wever, R. A. 1980. "Phase Shifts of Human Circadian Rhythms Due to Shifts of Artificial Zeitgebers." Chronobiologia. 7:303-327.

Wever, R. A. 1981. "On Varying Work-Sleep Schedules: The Biological Rhythm Perspective." In The Twenty-Four Hour Workday: Proceedings of a Symposium on Variations in Work-Sleep ScheduTes, L. C. Johnson, D. I. Tepas, W. P. Colquhoun and M. J. Colligan, eds., pp. 51-86. National Institute for Occupational Safety and Health (NIOSH) Publication 81-127. U.S. Department of Health and Human Services, Cincinatti, Ohio.

Wilkinson, R. T. 1958. The Effects of Sleep Loss on Performance. United Kingdom Medical Research Council, Cambridge, England.

Wilkinson, R. T. 1972. "Sleep Deprivation: Eight Questions." In Aspects of Human Efficiency: Diurnal Rhythm and Loss of Sleep. The English Universities Press Limited. Distributed in the United States by Crane, Russak \& Co., New York, New York.

Wilkinson, R. T. 1981. "Effects of Traffic Noise Upon Sleep in the Home: Subjective Report, EEG, and Performance the Next Day." In Sleep 1980: Circadian Rhythm, Dreams, Noise and Sleep, Neurophysiology Therapy. pp. 225-228. W. P. Koella, ed. Published by S. Karger, New York, New York. Available from the Defense Technical Information Center, Cameron Station, Alexandria, Virginia.

Wilkinson, R. T. 1982. "The Relationship Between Body Temperature and Performance Across Circadian Phase Shifts." In Rhythmic Aspects of Behavior, M. Brown and R. Graeber, eds. Published by Lawrence Erlbaum Associates, Hillsdale, New Jersey.

Wilkinson, R. T. and R. S. Edwards. 1969. Stable Hours and Varied Work as Aids to Efficiency. Report No. OES-512; TRCBR-27269. Roya T Nava1 Personnel Research Committee, London, England.

Wilkinson, R. T. and D. Houghton. 1982. "Field Test of Arousal: A Portable Reaction Timer With Data Storage." Human Factors. 24:487-493.

Wilkinson, R. T., P. D. Tyler and C. A. Varey. 1975. "Duty Hours of Young Hospital Doctors: Effects on the Quality of Work." Journal of Occupational Psychology. 48:219-229.

Williams, H. L. 1980. "Effects of Noise on Sleep: A Review." In Studies of Shiftwork, W. P. Colquhoun and J. Rutenfranz, eds., pp. 99-110. Taylor \& Francis Ltd., London, England.

Wilson, J. T. and K. M. Rose. 1978. The Twelve-Hour Shift in the Petroleum and Chemical Industries of the United States and Canada: A Study of Current Experience. Miscellaneous Series No. 26. Industrial Research Unit, The Wharton School, University of Pennsyivania, Philadelphia, Pennsylvania.

Witkin, R. May 20, 1983. "Safety of Lifting Air Traffic Limits Questioned." New York Times, page 3, column 1 . 
Wojtczak-Jaroszowa, J. 1977. Physiological and Psychological Aspects of Night and Shift Work. National Institute for Occupational Safety and Health, Cincinatti, Ohio. Available from the Superintendent of Documents, U.S. Government Printing Office, Washington, D.C.

Wojtczak-Jaroszowa, J. and A. Banoszkiewicz. 1974. "Physical Work Capacity During the Day and Night." Ergonomics. 17:193-198.

Wolcott, H. H., Ch. A. Hanson, W. D. Forster and T. Kay. 1979. "Correlation of Choice Reaction Time Performance with Biorhythmic Criticality and Cycle Phase." Aviation Space Environment Medicine. 59:34-39.

Wolinsky, J. 1982. "Beat the Clock: Efforts to Limit Damage from Night, Shift Work are Slowed by Economy." Monitor. pp. 28.

Wood, W. C. 1978. "Implementation of a Divisional Aviation Program to Decrease Flight Crew Fatigue." In Operational Hel icopter Medicine, S. C. Knapp, ed., AGARD Conference Proceedings No. 255. Available from the Defense Technical Information Center, Cameron Station, Alexandria, Virginia.

Woodward, D. P. and P. D. Nelson. 1974. A User Oriented Review of the Literature on the Effects of Sleep Loss, Workrest Schedules and Recovery on Performance. ADA009-778, Office of Naval Research, Arlington, Virginia.

Wynn, S. C. July 1979. The Impact of the Twelve-Hour Shift on Petrochemical Process Operators. Alberta Workers Health, Safety and Compensation, Occupational Health and Safety Division. Alberta, Canada.

Yoshitake, H. 1971. "Relations Between the Symptoms and the Feeling of Fatigue." Ergonomics. 14:175-185.

Zagoruiko, N. G. and Y. Tambovtsev. 1982. "Aspects of Human Performance in an Intensive Speech Task." International Journal of Man-Machine Studies. $16: 173-181$.

Zalusky, J.L. 1983. Testimony before the Subcommittee on Investigations and Oversight of the Committee on Science and Technology, U.S. House of Representatives, March 23, 1983, Washington, D.C.

Zamore, K., 1978. Shift Work and Well-Being. Studies on Blue Collar and White Collar Shift Workers. Laboratory Clinical Stress Research, Karolinska Institute, Stockholm, Sweden.

Zedeck, S., S. E. Jackson and E. Summers. 1983. "Shift Work Schedules and Their Relationship to Health, Adaptation, Satisfaction, and Turnover Intention." Academy of Management Journal. 26(2):297-310. 


\section{DISTRIBUTION}

No. of

Copies

OFFSITE

$L$

30

D. Morisseau

Air Rights Building $\# 3$

Mail Stop 5003A

4550 Montgomery Avenue

Bethesda, MD 20814

2 U.S. Nuclear Regulatory Commission

Public Document Room

Division of Technical

Information and Document Control

Washington, DC 20555

R. Henderson

242 Dorothy Avenue

Ventura, CA 93003

R. Moore

Comdt (G-XOM) -1

U.S. Coast Guard

Washington, DC 20590

R. Alkov

Naval Safety Center

Naval Air Station

Code 143

Norfolk, VA 23511

Dr. T. Monk

Institute of Chronobiology

New York Hospital - Cornell

Medical Center

Westchester Division

21 Bloomingdale Road

White Plains, NY 10605

Dr. C. Melton

2710 Walnut Road

Norman, OK 73069
No. of

Copies

Dr. G. Krieger

Boulder Medical Center, P.C. 2750 Broadway

Boulder, CO 80302

Dr. R. Curtis Graeber

200 Trysail Court

Foster City, CA 94404

Dr. W. Storm

Crew Technology Division

USAF SAM/UN

Brooks Air Force Base, TX 78235

F. Schneider

Mantech

Suite 52

25 Wood Street

Toronto, Ontario M4Y 2P9 Canada

2 Dr. M. J. Colligan

National Institute for

Occupational Health and Safety

4676 Columbia Parkway

Cincinnati, $\mathrm{OH} \quad 45226$

ONSITE

2 Battelle-Seattle

W. Rankin

3 Westinghouse Hanford Company.

D. Swain

80

Pacific Northwest Laboratory

A. J. Boegel (25)

R. M. Fleischman

V. E. Lee (15)

P. M. Lewis (30)

R. J. Sorenson

R. D. Widrig

Publishing Coordination (2)

Technical Information (5) 


$$
1
$$

